\title{
Uganda: Report on the Observance of Standards and Codes-Data Module, Response by the Authorities, and Detailed Assessment Using the Data Quality Assessment Framework
}

This Report on the Observance of Standards and Codes on Data Module for Uganda was prepared by a staff team of the International Monetary Fund as background documentation for the periodic consultation with the member country. It is based on the information available at the time it was completed on July 12, 2006. The views expressed in this document are those of the staff team and do not necessarily reflect the views of the government of Uganda or the Executive Board of the IMF.

The Response by the Authorities to this report, and the Detailed Assessments Using the Data Quality Assessment Framework (DQAF) are also included.

The policy of publication of staff reports and other documents by the IMF allows for the deletion of market-sensitive information.

To assist the IMF in evaluating the publication policy, reader comments are invited and may be sent by e-mail to publicationpolicy@imf.org.

Copies of this report are available to the public from

International Monetary Fund $\bullet$ Publication Services

700 19th Street, N.W. • Washington, D.C. 20431

Telephone: (202) 6237430 • Telefax: (202) 6237201

E-mail: publications@imf.org • Internet: http://www.imf.org

Price: $\$ 15.00$ a copy

\section{International Monetary Fund \\ Washington, D.C.}



INTERNATIONAL MONETARY FUND

UGANDA

\section{Report on the Observance of Standards and Codes (ROSC)—Data Module}

Prepared by the Statistics Department

Approved by Robert W. Edwards and Abdoulaye Bio-Tchané

July 12, 2006

The Report on the Observance of Standards and Codes (ROSC) data module provides an assessment of Uganda's macroeconomic statistics against the recommendations of the General Data Dissemination System (GDDS) complemented by an assessment of data quality based on the IMF's Data Quality Assessment Framework (DQAF July 2003). The DQAF lays out internationally accepted practices in statistics, ranging from good governance in data producing agencies to practices specific to datasets.

The datasets covered in this report are national accounts, consumer price index, government finance and balance of payments statistics. The agencies that compile the datasets assessed in this report are Uganda Bureau of Statistics (UBOS), Ministry of Finance, Planning and Economic Development (MFPED), and the Bank of Uganda (BOU).

The datasets to which this report pertains can be accessed in print and on the Internet:

$\begin{array}{ll}\text { UBOS: } & \text { http://www.ubos.org } \\ \text { MFPED: } & \text { http://www.finance.go.ug } \\ \text { BOU: } & \text { http://www.bou.go.ug }\end{array}$

This report is based on information provided prior to and during a staff mission from February 9-22, 2005 and publicly available information. The mission team was headed by Adriaan M. Bloem, and included Russel Freeman, Natalia Ivanik (all Statistics Department), Betty Gruber (Expert), and Lidia Tokuda (Statistics Department-Administrative Assistant).

Uganda is a participant in the GDDS and is also a member of AFRITAC East. 


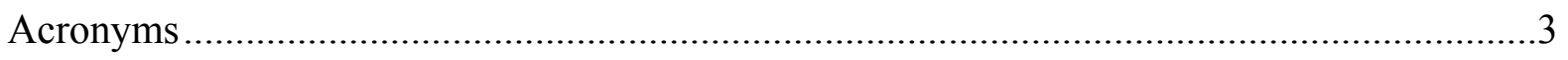

I. Overall Assessment.......................................................................................

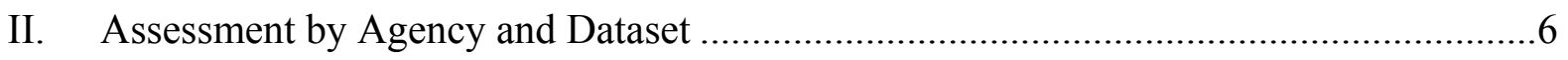

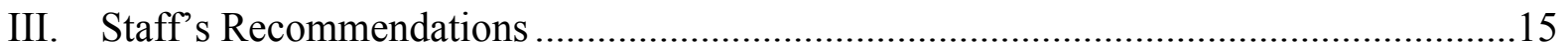

Tables

1. DQAF July 2003 - Summary Results...................................................................

2a. Assessment of Data Quality-Dimensions 0 and 1-Uganda Bureau of Statistics .........8

2b. Assessment of Data Quality - Dimensions 0 and 1-Ministry of Finance, Planning

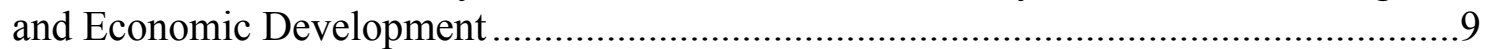

2c. Assessment of Data Quality_Dimensions 0 and 1-Bank of Uganda.........................10

3a. Assessment of Data Quality-Dimensions 2 to 5-National Accounts........................11

3b. Assessment of Data Quality_Dimensions 2 to 5-Consumer Price Index ...................12

3c. Assessment of Data Quality-Dimensions 2 to 5-Government Finance Statistics .....13

3d. Assessment of Data Quality_Dimensions 2 to 5-Balance of Payments Statistics ..... 14

Appendix Table

4. Practices Compared to the GDDS Coverage Periodicity, and Timeliness of Data 
ACRONYMS

1968 SNA

1993 SNA

BPM5

BOP

BOU

COICOP

CPI

DQAF July 2003

DSBB

GDDS

GFS

GFSM 1986

GFSM 2001

IFMS

IMF

ITRS

MFPED

NA

ROSC

SUT

UBOS

UNHS
System of National Accounts 1968

System of National Accounts 1993

Balance of Payments Statistics Manual, fifth edition

Balance of payments

Bank of Uganda

Classification of Individual Consumption by Purpose

Consumer Price Index

Data Quality Assessment Framework, July 2003 version

Dissemination Standards Bulletin Board

General Data Dissemination System

Government finance statistic

A Manual on Government Finance Statistics, 1986

Government Financial Statistics Manual 2001

Integrated Financial Management System

International Monetary Fund

International Transactions Reporting System

Ministry of Finance, Planning and Economic Development

National accounts

Report on the Observance of Standards and Codes

Supply and use table

Uganda Bureau of Statistics

Uganda National Household Survey 


\section{Overall ASSESSMent}

1. This Report on the Observance of Standards and Codes (ROSC) data module contains the following main observations covering four macroeconomic datasets: national accounts, the consumer price index (CPI), government finance statistics (GFS), and balance of payments (BOP). Within the available budget, the Ugandan authorities produce macroeconomic statistics with a strong emphasis on quality. They attach much importance to coordination across statistics, aiming at removing possible differences. The Uganda Bureau of Statistics Act, 1998 (Statistics Act) provides the legal basis for official statistics including national accounts and price statistics. The Statistics Act does mention BOP, but does not explicitly mention GFS. However, it does give the Uganda Bureau of Statistics the possibility to mandate other agencies to compile statistics. Because of this, it is seen as the legal basis for the agencies producing these statistics as well. In some key areas within the same datasets assessed, Uganda is not following most recent international standards, but plans are in place to improve this. In real sector, external sector statistics, and government finance statistics, usefulness of statistics suffers from limited coverage or lacking source data. In particular, this affects the national accounts that do not adequately cover agriculture, and the CPI that does not cover rural areas. GFS are limited to budgetary central government and local government. For the real and external sector, this is largely an issue of inadequate resources, which is also the cause for delays in publication, most notably for BOP statistics and GFS in the Bank of Uganda's publications. Notwithstanding delays in publications as noted, statistical programs are user oriented, which promotes the serviceability of the statistics. Data dissemination increasingly uses agencies' websites, which are informative but could usefully be further developed.

2. Section II provides a summary assessment by agency and dataset based on a four-part scale. This is followed by staff recommendations in Section III. Uganda started posting its metadata on the Dissemination Standards Bulletin Board (DSBB) on May 22, 2000.

Appendix I provides an overview of Uganda's dissemination practices compared to the GDDS. The authorities' response to this report and a volume of detailed assessments are presented in separate documents.

3. In applying the IMF's Data Quality Assessment Framework (DQAF July 2003), the remainder of this section presents the mission's main conclusions. The presentation is done at the level of the DQAF's quality dimensions, by agency for the first two dimensions and across datasets for the remaining four.

\section{Prerequisites of quality and assurances of integrity:}

- The Uganda Bureau of Statistics (UBOS), as empowered by the Statistics Act, has primary responsibility for official statistics. UBOS stresses coordination with other data producers and users, which it ensures through a Coordination Unit that has set up coordinating committees. Resources are not sufficient to meet the planned developments, including much needed expansion of source data. UBOS is not certain of its resources because it has no clearly identified position in the government budget. 
Demand is all-important in deciding the data collection program, and management strongly promotes quality awareness. The Statistics Act provides for the independence of the UBOS Executive Director. Measures are in place to promote transparency, although UBOS does not advise the public of prerelease of some of its data within government. A Code of Conduct (Uganda Government Standing Orders 1992) exists for civil servants that staff are acquainted with.

- $\quad$ No specific legal documents directly mention the responsibility of the Ministry of Finance, Planning and Economic Development (MFPED) to compile and disseminate GFS. However, Section 21 of the Statistics Act states that UBOS can mandate authority to an institution to compile and publish specific statistical data. UBOS relies on the MFPED to compile and disseminate GFS data. Data are protected under the Oath of Secrecy (Uganda Government Standing Orders 1992). The Public Finance and Accountability Act, 2003 assigns the responsibility to collect, compile, and disseminate data on Uganda's public finances to the MFPED. Data sharing and coordination with various data collecting agencies is satisfactory. Available resources meet present needs of most fiscal data programs. Changes in data collections follow demand, and the MFPED fosters quality awareness.

- $\quad$ UBOS has also mandated compiling and publishing BOP statistics to another institution, namely, the Bank of Uganda (BOU). The Bank of Uganda Statute, 1993 assures confidentiality of reporters' data, although the BOU also uses these data for supervision. Resources are not entirely adequate to meet needs and may be the cause for delays in publication. The BOU has limited ability to collect information from nonfinancial institutions. The BOU has an advisory committee following its data relevance, and management stresses the need for accurate statistics. The BOU rigorously upholds integrity of its statistics, and statistical considerations are the base for the choice of source data and design of data collection. The BOU promotes transparency of its statistical procedures and staff's awareness of ethical guidelines. The BOU has been very receptive to technical assistance advice from the IMF and has made good progress in implementing the recommendations.

5. Methodological soundness is uneven within each of the four assessed datasets. The national accounts do not follow up-to-date international standards and have a limited scope, but use international classifications and a generally correct base for recording. The CPI conforms broadly to international standards but also has a limited scope. The index covers six urban areas but excludes rural areas. The GFS follow A Manual on Government Finance Statistics, 1986 (GFSM 1986), and migration to the Government Finance Statistics Manual 2001 (GFSM 2001) has started. The statistics do not cover all the financial activity of government. The BOP statistics follow international standards although some statistics depart from definitions, scope, and classifications.

6. Accuracy and reliability differ across datasets. The CPI and the GFS have a sound underpinning with data, while the national accounts and the BOP statistics suffer from gaps. Most importantly, for the national accounts the coverage of agriculture is wanting. 
7. Serviceability is generally adequate. Periodicity meets requirements, and the national accounts and the CPI are also timely. GFS and BOP statistics, however, suffer from delay in publication. All three agencies actively promote consistency, although in GFS an adjustment line is needed to match overall deficit/surplus. Publications include a note signaling revisions, except for the national accounts. Usefulness of the data is an important consideration for all three agencies.

8. Accessibility of data is adequate across datasets but not of metadata. In addition to hard copy publications, data are available through the agencies' websites. Detailed data are available on demand. Metadata are available only through the IMF's DSBB, and are not all up-to-date.

\section{Assessment BY AgenCy ANd Dataset}

9. Assessment of the quality of four macroeconomic datasets - national accounts, consumer price index, government finance, and balance of payments statistics - was conducted using the DQAF July 2003. In this section, the results are presented at the level of the DQAF elements and using a four-point rating scale (Table 1). Assessments of the prerequisites of data quality and the assurances of integrity (Dimensions " 0 " and " 1 " of the DQAF) are presented in Tables 2a-c. For each dataset, the assessment of methodological soundness, accuracy and reliability, serviceability, and accessibility (Dimensions "2" to " 5 " of the DQAF) are shown in Tables 3a-d. 


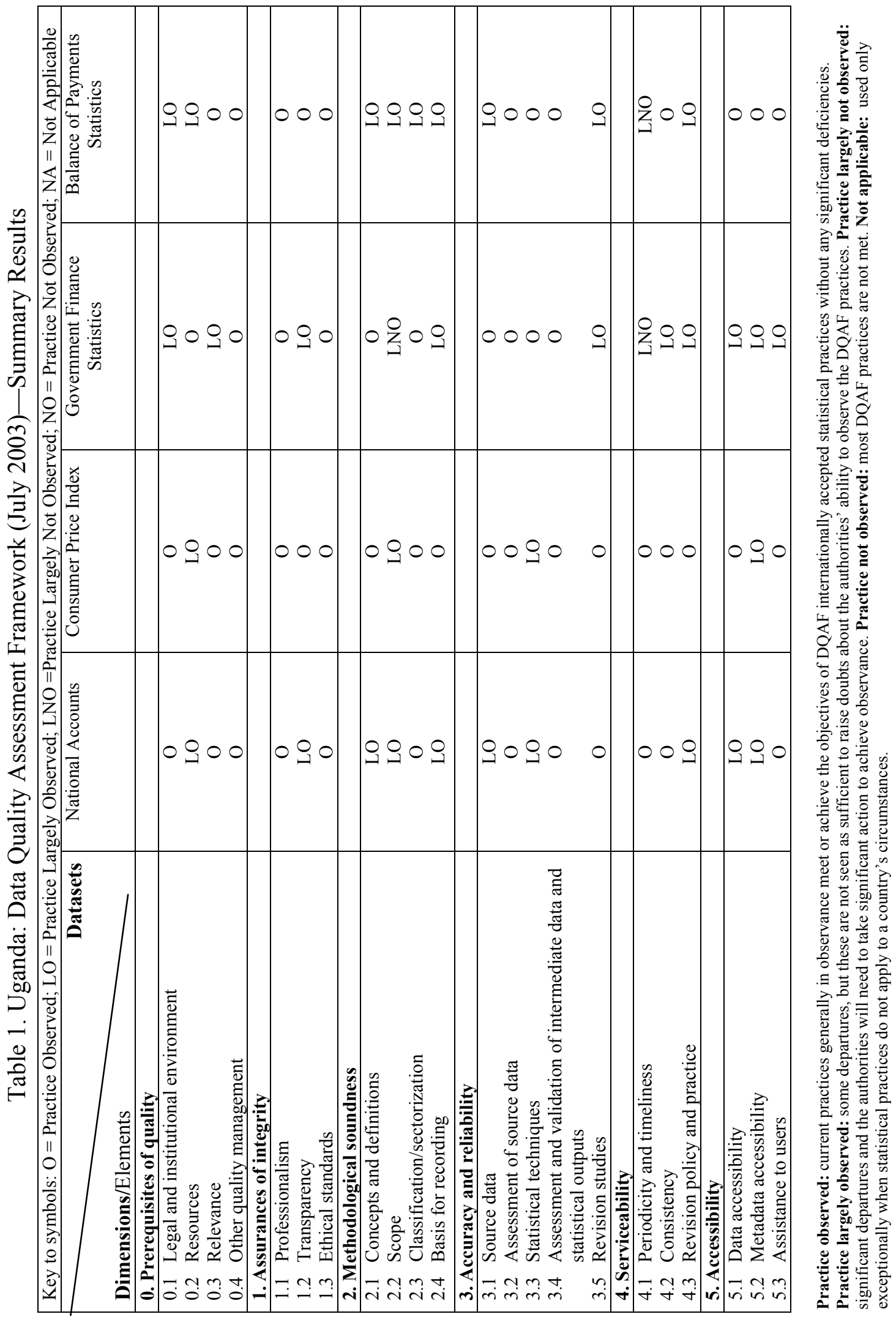




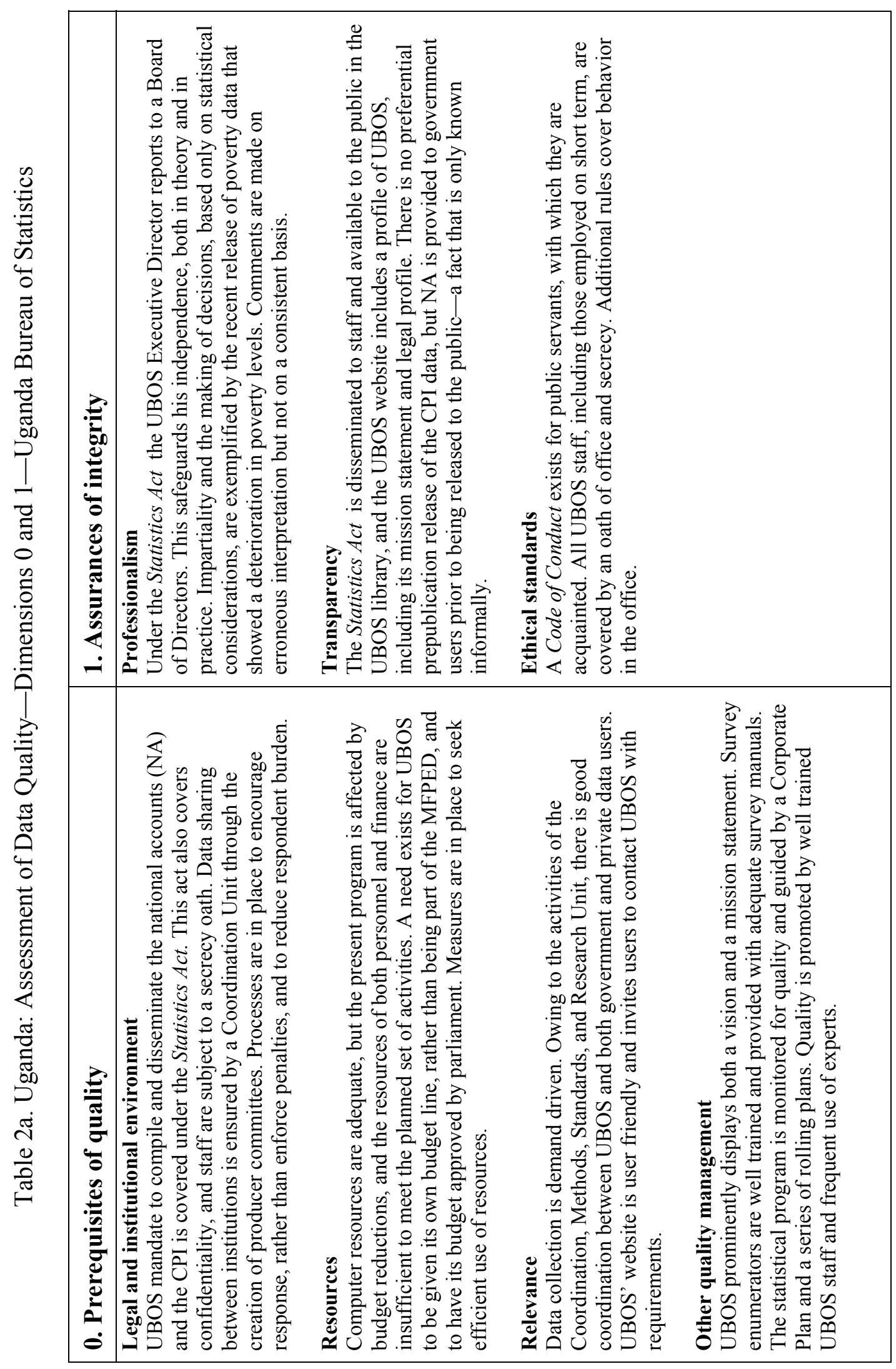




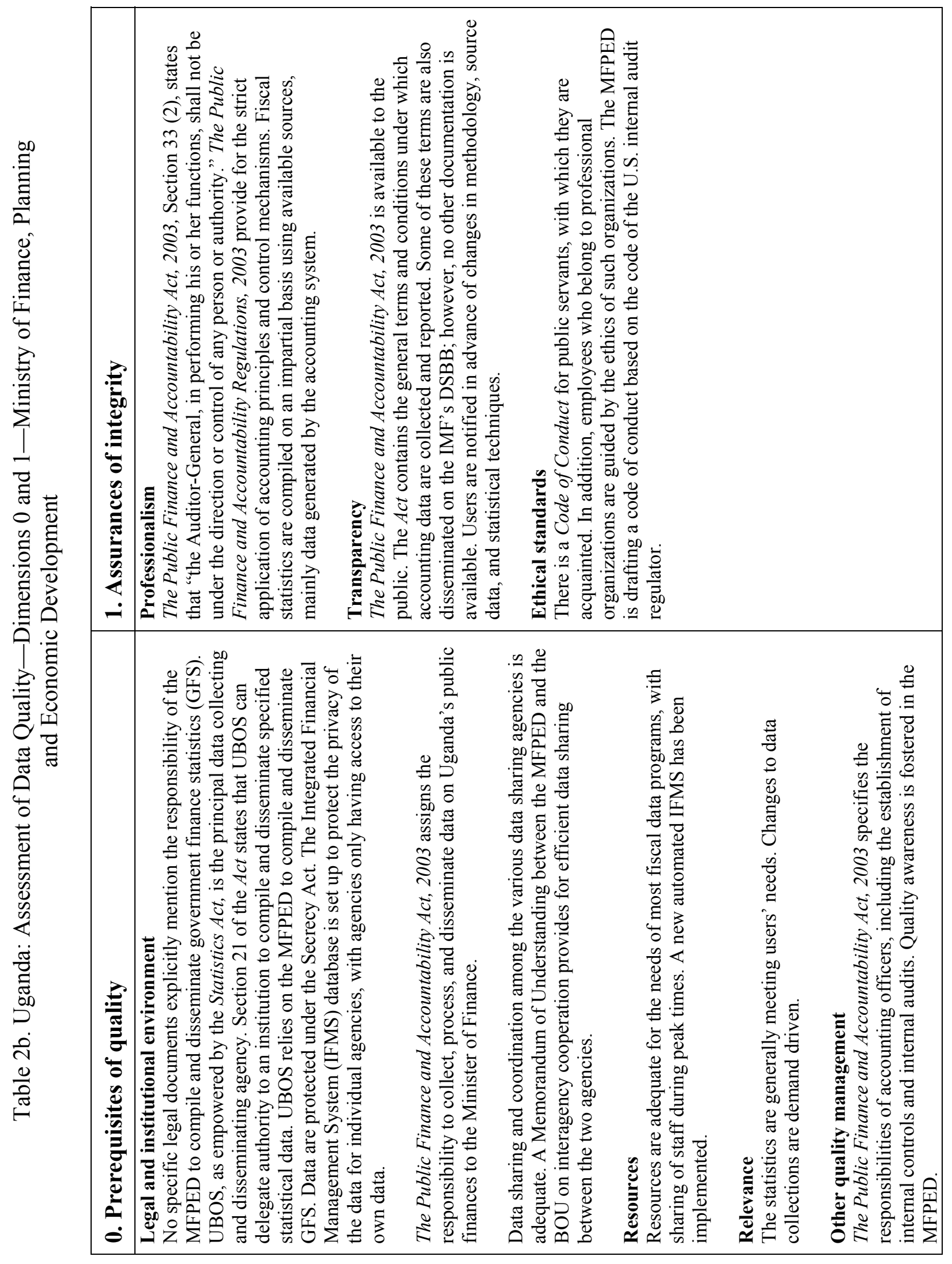




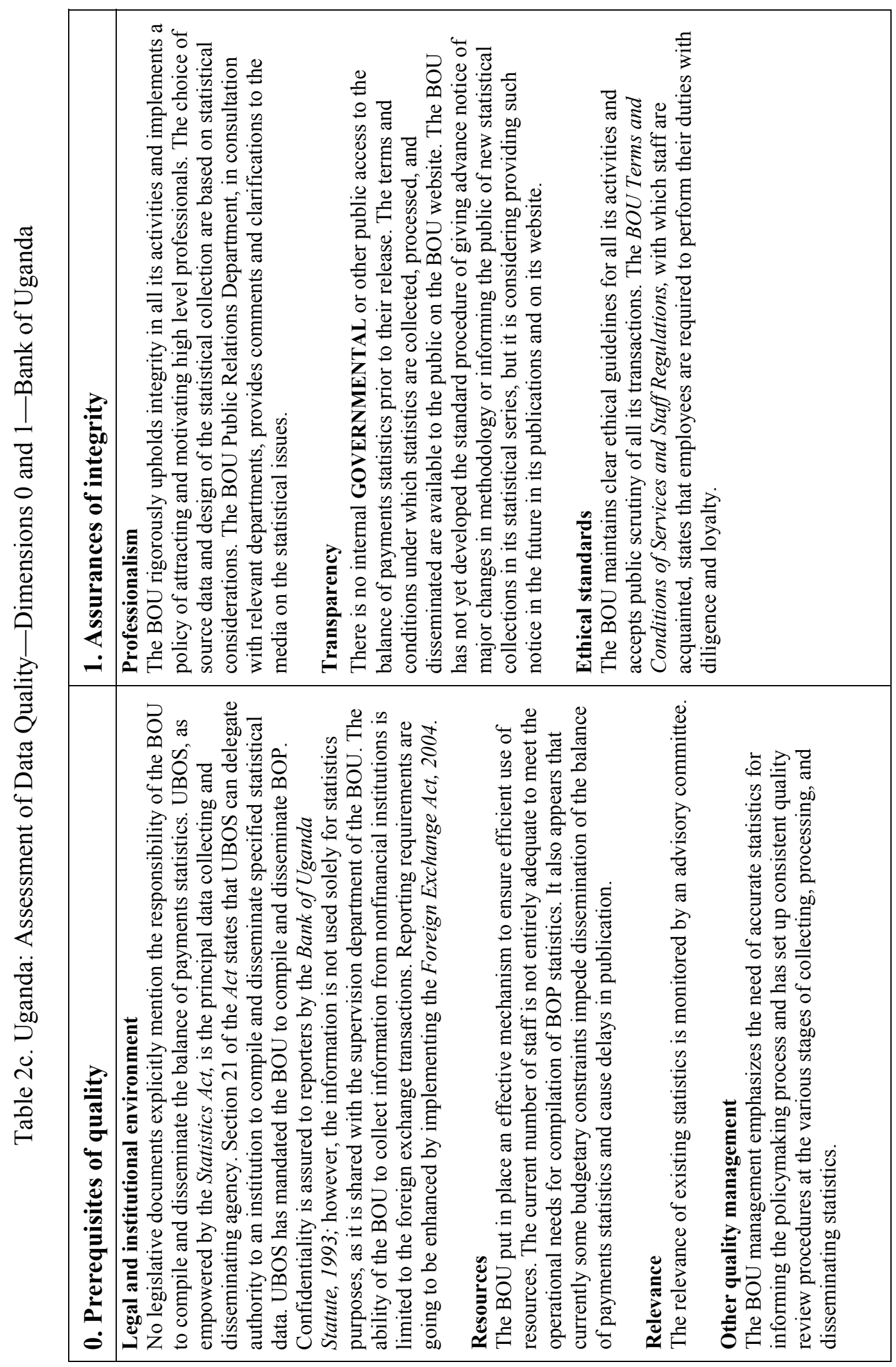




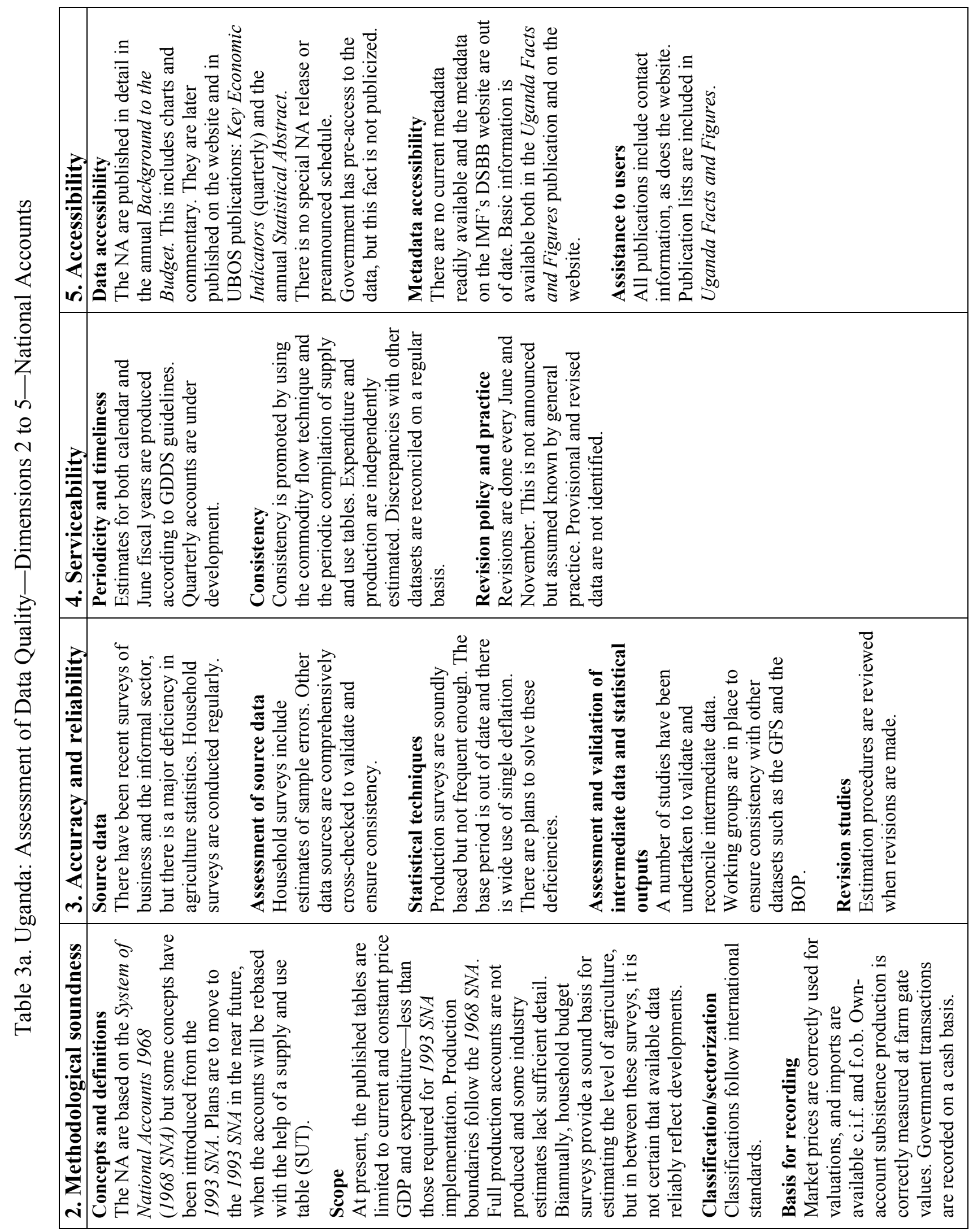




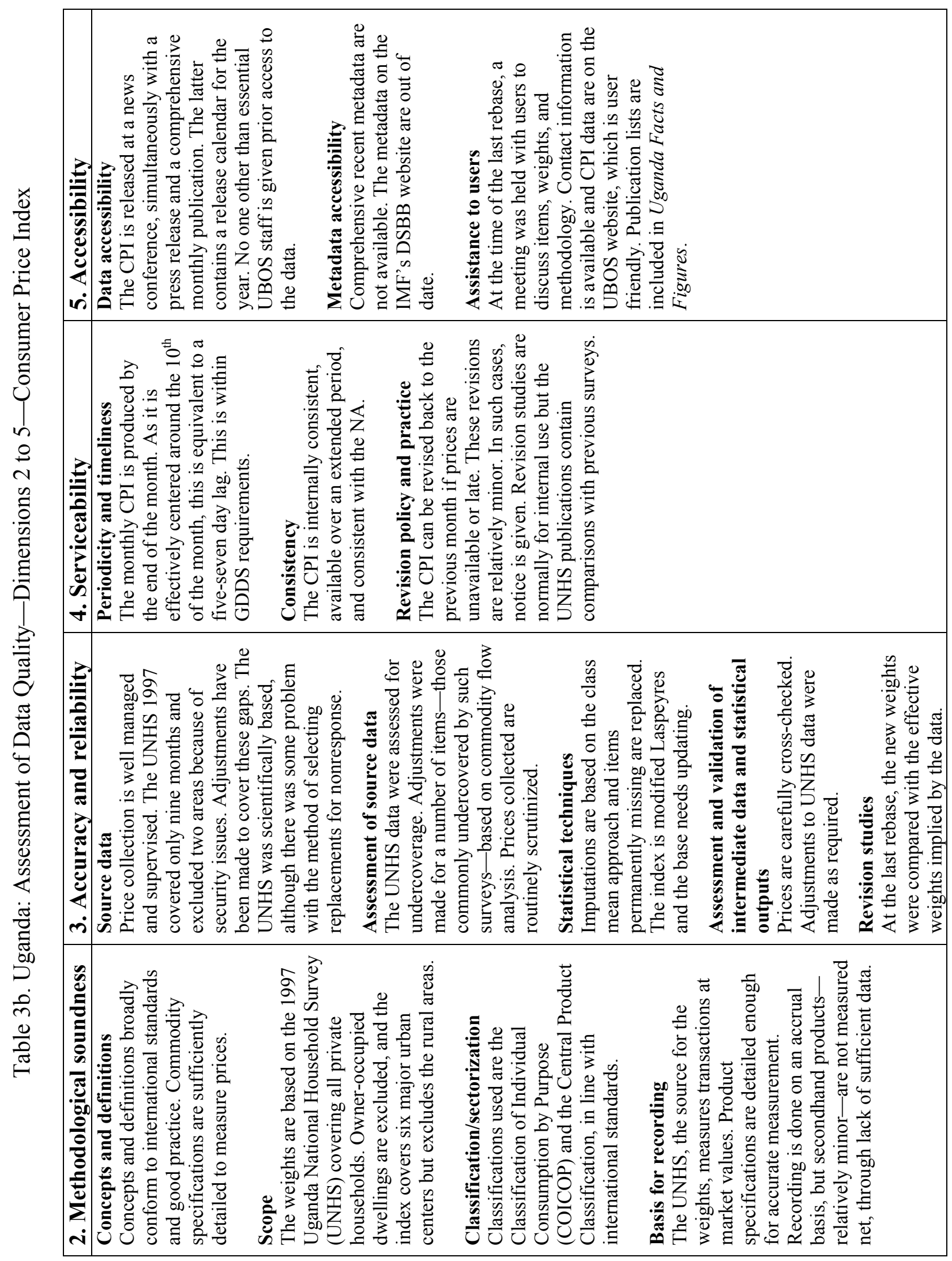




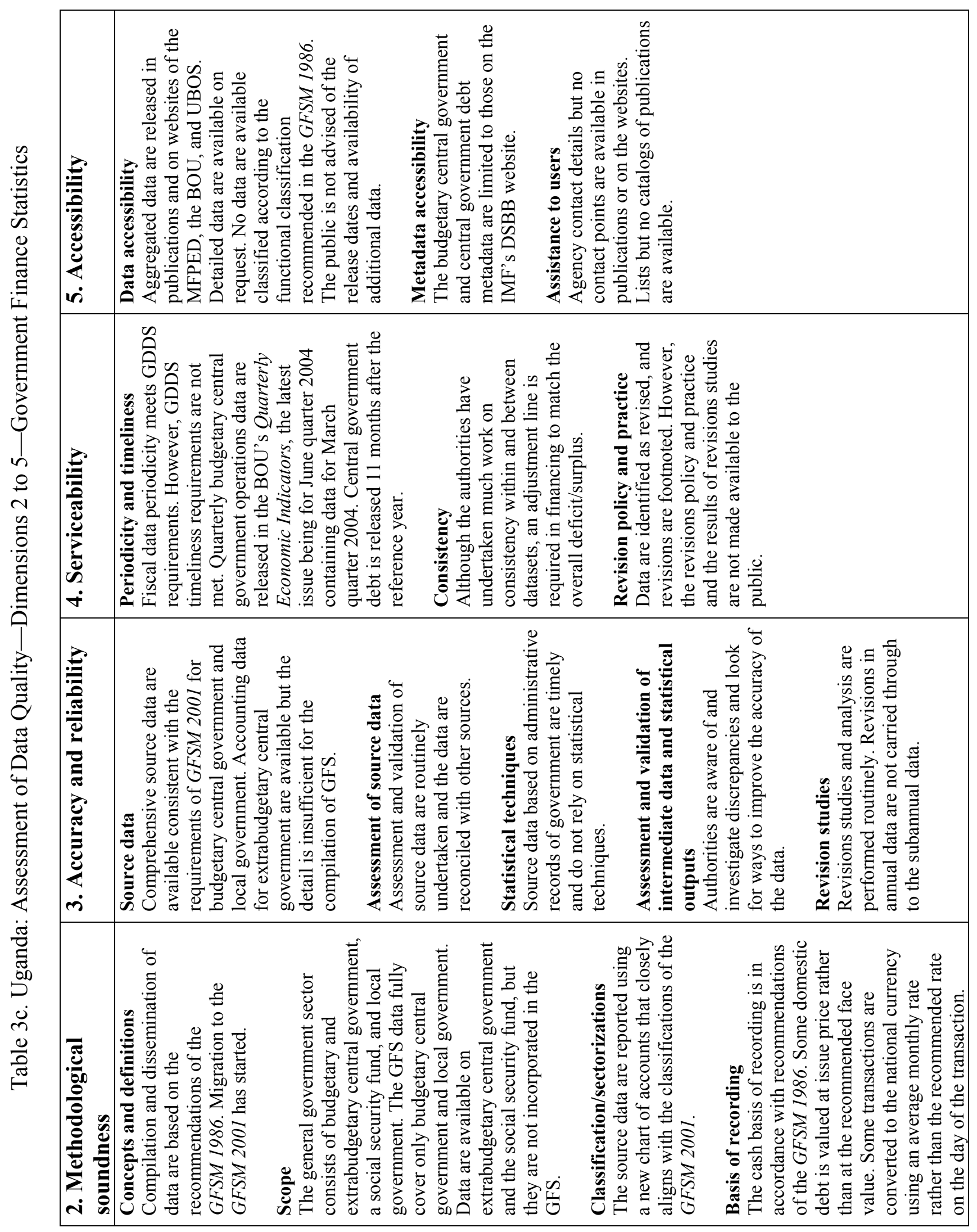




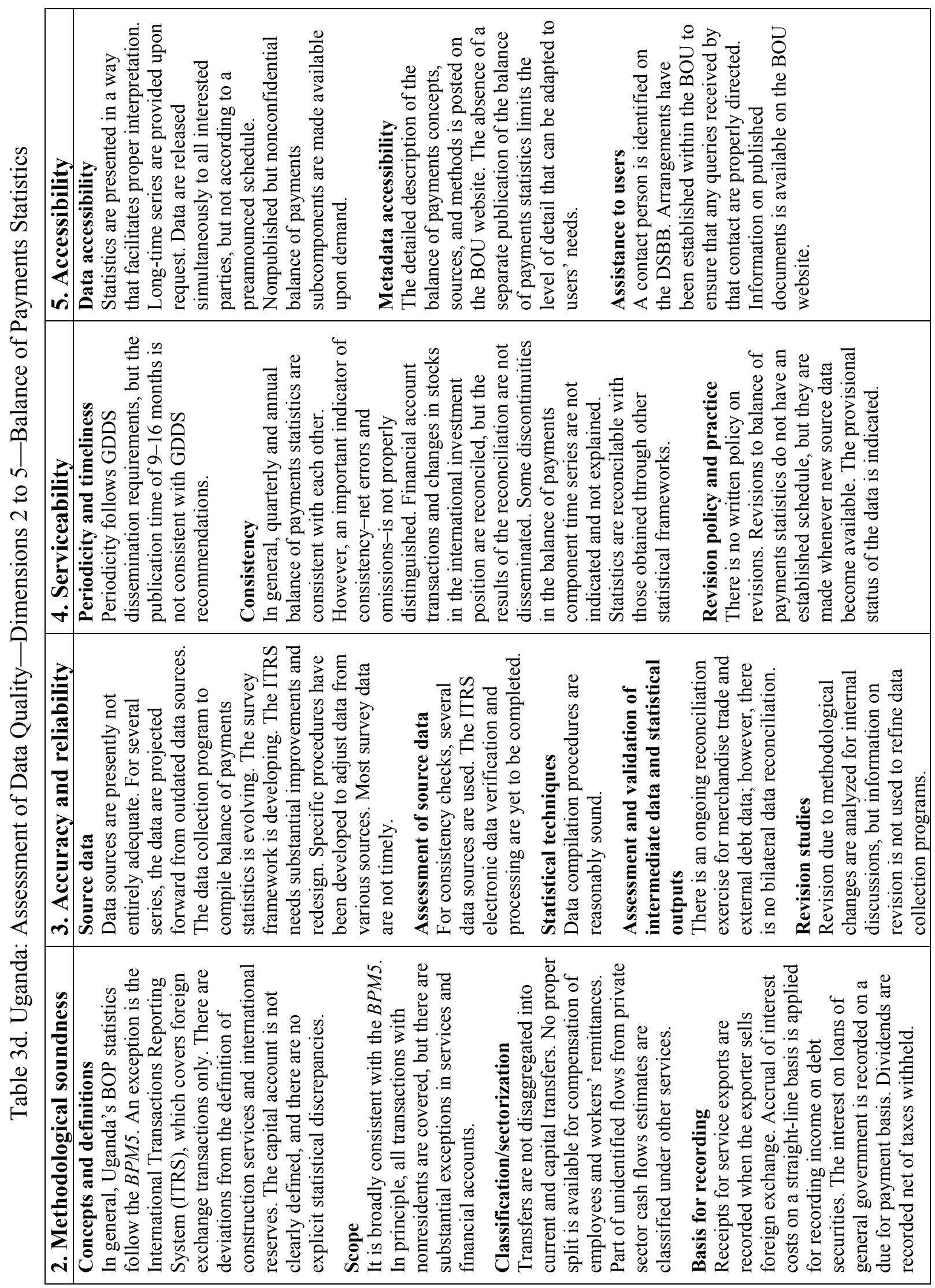




\section{STAFF's RECOMMENDATIONS}

10. Based on the review of Uganda's statistical practices on four datasets, discussions with the three data producing agencies, and survey responses from data users (see Appendix III of the Detailed Assessments volume), the mission has the following recommendations. They are designed to increase further Uganda's adherence to internationally accepted statistical practices and would, in the mission's view, enhance the analytical usefulness of Uganda's statistics.

\section{Cross-cutting recommendations}

- $\quad$ Strengthen the mandate for the BOU and the MFPED for collecting, compiling, and publishing their respective datasets; provide for a sound legal basis for data sharing among data-producing agencies; and for strengthened reporting requirements.

- Undertake a review of data dissemination practices, addressing, in particular, provision of current and comprehensive descriptions of sources and methods.

- $\quad$ Develop sound revision policies and practices, and make them known to the public.

\section{National Accounts}

- $\quad$ Give UBOS its own budget line, and have its budget subject to parliamentary approval.

- Give UBOS a budget sufficient to effectively implement the activities outlined in its five-year plan.

- $\quad$ Undertake an agriculture census supplemented by annual sample surveys.

- $\quad$ Undertake economy-wide business survey at least every five years, supplemented by annual sample surveys.

- $\quad$ Develop separate estimates for the finance industry.

- $\quad$ Release national accounts in news release format with accompanying text on economic performance and reason for revisions.

\section{Consumer Price Index}

- $\quad$ Expand and update the coverage of the index to cover the rural areas.

- $\quad$ Update the reference and weights base as soon as possible to 2003-2004. 


\section{Government Finance Statistics}

- $\quad$ Compile and disseminate GFS data for extrabudgetary central government and the National Social Security Fund.

- Disseminate budgetary central government operations and local government data in the GFSM 2001 format.

- $\quad$ Consolidate and disseminate GFS data for central government and general government.

- $\quad$ Improve the accessibility of data by (1) releasing data on a more timely basis; (2) providing contact points, and (3) advising availability of additional series.

- $\quad$ Migrate to the GFSM 2001.

\section{Balance of Payments Statistics}

- $\quad$ Ensure adequate resources with a view to improving balance of payments data.

- $\quad$ Complete the planned conversion of balance of payments statistics into BPM5, resolving existing problems with definitions, scope, and classifications.

- Improve the accuracy and timeliness of source data by strengthening the ITRS, and providing for better integration of the ITRS in the balance of payments compilation process.

- $\quad$ Refine the surveys frameworks, including those for the private capital flows survey to reduce respondent burden, while maintaining the information required.

- $\quad$ Improve trade data by incorporating the results of the Survey of Informal Cross Border Trade and greater use of partner country data sources for verification purposes.

- $\quad$ Improve dissemination media and format by launching a separate BOP statistics publication with a greater level of detail.

- Develop new source data and estimation techniques to ensure coverage in the BOP statistics of the following components: (1) export of freight and import of passenger transportation; (2) compensation of employees; (3) direct investment abroad; (4) the portfolio investment, assets; and (5) financial derivatives. 
Table 4. Uganda: Practices Compared to the GDDS Coverage Periodicity, and Timeliness of Data

\begin{tabular}{|c|c|c|c|c|c|}
\hline \multirow{2}{*}{ GDDS Data Category } & \multirow{2}{*}{$\begin{array}{l}\text { Coverage } \\
\text { (meets } \\
\text { GDDS) }\end{array}$} & \multicolumn{2}{|c|}{ Periodicity } & \multicolumn{2}{|c|}{ Timeliness } \\
\hline & & GDDS & Uganda & GDDS & Uganda \\
\hline \multicolumn{6}{|c|}{ COMPREHENSIVE FRAMEWORK } \\
\hline $\begin{aligned} \text { Fiscal sector: } & \text { Central govt. operations } \\
& \text { General govt. operations } \\
& \text { Central govt. debt }\end{aligned}$ & & $\begin{array}{l}\mathrm{A} \\
A \\
\mathrm{~A}\end{array}$ & & $\begin{array}{l}6-9 \text { months } \\
6-9 \text { months } \\
6-9 \text { months }\end{array}$ & \\
\hline Financial sector: Depository Corporations Survey & & $\mathrm{M}$ & & $2-3$ months & \\
\hline \multicolumn{6}{|c|}{ DATA CATEGORIES AND INDICATORS } \\
\hline \multicolumn{6}{|l|}{ Real Sector } \\
\hline $\begin{array}{l}\text { National accounts aggregates: } \\
\text { GDP (nominal and real) } \\
\text { Gross national income, capital formation, saving }\end{array}$ & Yes & $\mathrm{A}(Q)$ & A & $\begin{array}{l}6-9 \text { months } \\
6-9 \text { months }\end{array}$ & 5 months \\
\hline $\begin{array}{l}\text { Production index/indices } \\
\text { Manufacturing or industrial production index/indices } \\
\text { Primary commodity, agricultural, or other indices, as relevant } \\
\end{array}$ & Yes & $\begin{array}{c}\mathrm{M} \\
\text { As relevant } \\
\end{array}$ & M & $\begin{array}{l}6-12 \text { weeks } \\
6-12 \text { weeks }\end{array}$ & 6 months + \\
\hline $\begin{array}{l}\text { Labor market indicators: } \\
\text { Employment } \\
\text { Unemployment } \\
\text { Wages/earnings (all sectors) } \\
\end{array}$ & & $\begin{array}{l}\text { A } \\
\text { A } \\
\text { A }\end{array}$ & & $\begin{array}{l}6-9 \text { months } \\
6-9 \text { months } \\
6-9 \text { months }\end{array}$ & \\
\hline \multicolumn{6}{|l|}{ Fiscal Sector } \\
\hline $\begin{array}{l}\text { Central government aggregates: } \\
\text { Central govt. budgetary aggregates: revenue, expenditure, balance, } \\
\text { and financing with breakdowns (debt holder, instrument, currency) } \\
\text { Interest payments }\end{array}$ & $\begin{array}{l}\text { Yes } \\
\text { Yes }\end{array}$ & $\begin{array}{l}\mathrm{Q} \\
Q\end{array}$ & $\begin{array}{l}\text { Q } \\
\text { Q }\end{array}$ & $\begin{array}{l}1 \text { quarter } \\
1 \text { quarter }\end{array}$ & $\begin{array}{l}9-16 \text { months } \\
9-16 \text { months }\end{array}$ \\
\hline $\begin{array}{l}\text { Central government debt: } \\
\text { Central govt. debt: domestic and foreign debt, as relevant, with } \\
\text { appropriate breakdowns (debt holder, instrument, currency) }\end{array}$ & Yes & $\mathrm{A}(Q)$ & A & $1-2$ quarters & 11 months \\
\hline Government guaranteed debt & Yes & $A(Q)$ & A & 1-2 quarters & 11 months \\
\hline \multicolumn{6}{|l|}{ External Sector } \\
\hline Balance of payments aggregates & Yes & $\mathrm{A}(Q)$ & $\mathrm{Q}$ & 6 months & 16(9) months \\
\hline $\begin{array}{l}\text { Public and publicly guaranteed external debt outstanding, with } \\
\text { maturity breakdown }\end{array}$ & Yes & Q & Q & $1-2$ quarters & 9 months \\
\hline Public and publicly guaranteed debt service schedule & Yes & $6 \mathrm{M}$ & $\mathrm{Q}$ & $3-6$ months & 9 months \\
\hline Private external debt not publicly guaranteed & Yes & $A$ & $Q$ & $6-9$ months & 3 years \\
\hline $\begin{array}{l}\text { International reserves: } \\
\text { Gross official reserves denominated in U.S. dollars } \\
\text { Reserve-related liabilities }\end{array}$ & & M & M & $\begin{array}{l}1-4 \text { months } \\
1-4 \text { months }\end{array}$ & 1 month \\
\hline $\begin{array}{l}\text { Reserve-related liabilities } \\
\text { Merchandise trade: }\end{array}$ & $Y$ & & & $\operatorname{nins}$ & \\
\hline $\begin{array}{l}\text { Total exports and total imports } \\
\text { Major commodity breakdowns with longer time lapse }\end{array}$ & $\begin{array}{l}\text { Yes } \\
\text { Yes }\end{array}$ & $\begin{array}{l}\mathrm{M} \\
M\end{array}$ & $\begin{array}{l}\mathrm{M} \\
M\end{array}$ & $\begin{array}{l}8 \text { wks }-3 \text { mths } \\
8 \text { wks }-3 \text { mths }\end{array}$ & $\begin{array}{l}1 \text { month } \\
1 \text { month }\end{array}$ \\
\hline Exchange rates: spot rates & Yes & Daily & Daily & $1 /$ & 1 day \\
\hline
\end{tabular}

Italics indicate encouraged categories.

1/ Dissemination as part of a high-frequency (e.g. monthly) publication. 


\section{INTERNATIONAL MONETARY FUND}

UGANDA

\section{Report on the Observance of Standards and Codes (ROSC)_Data Module}

\section{Response by the Authorities}

July 12,2006

\section{Contents}

Page

I. Response to Cross Cutting Recommendations .............................................................. 2

II. Response by the Ministry of Finance, Planning and Economic Development ................... 2

III. Response by the Bank of Uganda ..................................................................... 4

IV. Response by the Uganda Bureau of Statistics ..................................................... 5

A. Consumer Price Index ............................................................................ 5

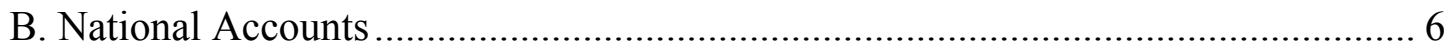




\section{Response to Cross Cutting Recommendations}

- $\quad$ The need to strengthen the mandate for central bank and the ministry of finance, planning and economic development for collecting, compiling and publishing their respective datasets, provide legal sound basis for the sharing among data producing agencies and for stronger reporting requirements;

- $\quad$ The need to review data dissemination practices, addressing in particular provision and comprehensive descriptions of sources and methods; and

- $\quad$ Develop sound revisions practices and make them known to the public.

The Uganda Bureau of Statistics (UBOS) as empowered by the Statistics Act is the principal data collecting and disseminating agency responsible for coordinating, monitoring and supervising the national statistical system. The Statistics Act however, allows UBOS to delegate authority to an institution to compile and disseminate specified statistical data.

UBOS relies on Ministry of Finance, Planning and Economic Development (MFPED) to compile and disseminate Government Finance Statistics (GFS) in light of the Public Finance and Accountability Act (PFAA) which assigns the responsibility to collect process and disseminate data on Uganda's public finances to the Minister of Finance. In addition, it is worth noting that MFPED generates and makes use of finance statistics data on a day to day basis. As such it is cost effective for UBOS to rely on MFPED in respect of these data.

While acknowledging that there is no express delegation of authority by UBOS to MFPED to compile and publish its datasets, the most urgent task is to address issues relating to data quality, assurances of data integrity, dissemination practices and sound revision practices. The Ministry intends to revive the joint committee between UBOS, MFPED and BoU to address the above issues. This committee will be responsible for endorsing the publication of data on government finance statistics. The committee's operation has in the past been constrained by the high staff changes in the finance statistics section of the Uganda Bureau of Statistics. This problem has now been resolved through recruitment to fill vacant posts in this area.

\section{Response by the Ministry of Finance, Planning And Economic Development}

\section{- $\quad$ Compile and disseminate Government Finance Statistics (GFS) data for extra budgetary central government and NSSF.}

At the moment MFPED compiles GFS on Budgetary Central Government and Local Governments. Plans are however under way to increase coverage to extra budgetary institutions in the 2006/07 financial year. The revival of the joint committee on GFS is expected to play a key role. 
- $\quad$ Disseminate budgetary central government and local government data in GFSM 2001 format.

\section{- $\quad$ Migrate to GFSM2001.}

The Ministry recognizes the significance of GFSM2001 in aligning GFS statements to private sector accounting and the associated high levels of transparency. We are also aware that GFSM2001 seeks to encourage accrual accounting to ensure consistency with other statistical systems such as the System of National Accounts, Monetary Statistics and Balance of Payments Statistics.

Uganda has made considerable progress in adopting the GFSM2001. A new chart of accounts that is consistent with GFSM2001 was introduced in FY2003/04. The chart of accounts which lays out codes for recording accounting transactions is now fully operational. In addition an Integrated Financial Management System (IFMIS) which operates using the new chart of accounts was introduced in FY2004/05 on a pilot basis for 6 Ministries and 4 local government units.

Complete coverage of all 18 ministries will be on line by $30^{\text {th }}$ June 2006 . In addition 6 local governments will be brought on board bringing the total to 10 out of over 120 units. At the moment it is possible to produce GFS in the GFSM2001 methodology in respect of revenues and expenditure by economic classification. The task of incorporating expenditures on the IFMIS in the GFS Classification of Functions of Government (COFOG) will be completed by $30^{\text {th }}$ June 2006. Full migration to GFSM 2001 will be gradual as the transition from cash accounting to accrual will likely be tackled after the complete roll out of IFMIS.

\section{- $\quad$ Consolidate and disseminate GFS data for central government and general government.}

GFS data is currently disseminated on annual basis in official publications such as background to the budget, budget speech, revenue and expenditure estimates books and the statistical abstract in GFSM1986. However, publication in GFSM2001 will be gradually introduced as part of these publications. As mentioned above this information does not capture extra-budgetary institutions.

\section{- Improve the availability of data by releasing data on a timelier basis; providing contact points and advising availability of additional series.}

The introduction of IFMIS should improve the timeliness of above the line data when all ministries, agencies and local governments are covered. However the availability of information on domestic bank financing is the key limiting factor to the timeliness of the complete set of finance statistics for budgetary central government. Since June 2005, the timeliness of the monetary survey has improved from a lag of two to one month. The MFPED web site will be improved to provide contact points and details on availability of additional series. 


\section{RESPONSE BY THE BANK OF UGANDA}

- $\quad$ Ensure adequate resources with a view to improving balance of payments data.

In terms of resource adequacy, the BOP section which had been reduced to three (3) staff (following the transfer of one staff to another section and the other staff taking study leave to pursue a masters program abroad) has been allocated two (2) additional staff after a departmental reorganization. Financial resources for the planned surveys in 2005/06 have also been provided.

- $\quad$ Complete the planned conversion of balance of payments statistics into BPM5, resolving existing problems with definitions, scope and classification.

Work intended to fulfill the planned conversion of balance of payments into BPM5 is ongoing. In particular, new surveys have been designed to collect data on - transportation and offshore investors in the corporate bond market. In addition, revisions to the commercial bank daily foreign exchange transactions reports have been proposed to compile additional data on financial derivatives (forwards and swaps). The return has been presented to the financial information sharing committee and awaits approval. A workshop with commercial bank staff compiling BOP data has been scheduled in February 2006 to address reporting weaknesses.

- Improve the accuracy and timeliness of source data by strengthening the ITRS and providing for better integration of the ITRS in the balance of payments compilation process.

The use of ITRS data has been revisited and data from this source for use in the BOP line items will be selected from the monthly foreign currency position return of commercial banks showing transactions between residents and non-residents. For better integration of this source in the BOP, data on deposits and withdrawals in the return will be used for compiling some components of the service account and private transfers. At the workshop for commercial banks' staff, submission of accurate returns will be emphasized.

- $\quad$ Refine the surveys frameworks, including those for the private capital flows survey to reduce respondent burden, while maintaining the information required.

The surveys framework for private capital flows has been refined and in 2005, data from this source together with the Uganda Investment Authority data on licensed investment projects was incorporated in the BOP data for 2003. In addition, the data for 2003 was used to derive estimates for 2004. However, private capital flow survey data has not been timely.

- $\quad$ Improve trade data by incorporating the results of the survey of informal cross border trade and greater use of partner country data sources for verification purposes.

The final results (report) of the Informal Cross Border Trade Survey have not been provided. The trade statistics will be revised when the report is finalized by UBOS and TEDD.

- Improve dissemination media and format by launching a separate BOP statistics publication with greater level of detail. 
Inclusion of additional details in the current dissemination formats has been implemented. The recent annual report contained detailed tables of both the BOP and the IIP.

- $\quad$ Develop new source data and estimation techniques to ensure coverage in the BOP statistics of the following: (1) export of freight and import of passenger transportation; (2) compensation of employees; (3) direct investment abroad; (4) the portfolio investment assets; and (5) financial derivatives.

New data sources have been designed for the compilation of freight and passenger transportation. (1) Freight transportation by mode is compiled using customs data on ports of entry and exit. Passenger transportation is to be compiled with effect from January 2006, using data compiled by the Immigration Department on ports of entry and exit, destination of exiting passengers and origin of arriving passengers and residency status augmented by a monthly survey of travel prices from the different airline carriers and bus transporters. (2) No work has been done on compensation of employees although the use of national household surveys by UBOS has been identified as a potential source of this data. (3) Direct investment assets are to be compiled in the private capital flows survey conducted by TEDD through targeting enterprises that have branches or related enterprises abroad. (4) Data from the Bank for International Settlement has been identified as a potential source for portfolio investment assets. (5) Revisions to the commercial bank daily forex transactions reports have been proposed to compile additional data on financial derivatives (forwards and swaps).

\section{RESPONSE BY THE UGANDA BUREAU OF STATISTICS}

\section{A. Consumer Price Index}

- $\quad$ Expand coverage for the Consumer Price Index to make it more representative.

The current index is computed from consumption data collected monthly from outlets in six urban centers - two in central region, two in the east, one in the west and one in the north. Apart from some bias against some regions, it is also biased against the rural areas. As a way of minimizing the above biases, advantage has already been taken of the ICP (which has been collecting data from both urban and rural centers). The collected data will be used in the expanded data collection programme when the new index is produced effective first quarter 2006/07. Due to limited financial resources adequate number of additional staff can not be recruited and the rural centers are purposively selected (instead of selection through a scientific sampling procedure) to minimize travel expenses.

\section{- $\quad$ Update the reference period using more recent UNHS data.}

The current CPI base of 1997/98 needs to be updated and already the process is underway. The latest UNHS for which results are available is 2002/03 but this is already three years old. The 2005/06 UNHS has just come to a close and the results are expected in the last months of 2006. Using the 2002/03 UNHS results, new weights and new items have been compiled. Collecting prices for the identified new items from all centres (original six urban centres and the newly incorporated rural centres) has started. The new index will therefore have weights based on UNHS 
$2002 / 03$ but prices of 2005/06. When the 2005/06 UNHS results became available, adjustments in weights will be made so that both weights and prices are on 2005/06 base.

The updated index will be based on seven urban centres and seven rural centres.

A 'High - Income' index based on prices collected from Kampala (Capital City) only will also be computed.

\section{- $\quad$ Other Considerations}

As a direct consequence of adopting the above steps, the cost of conducting the data collection exercises will shoot up and the timeliness of the index (dissemination on the last working day of the month) will most likely not be attainable. More vehicles, personnel and funds will be required. However, delays associated with data collection and data capture can be tackled by provision of hand-held computers to carry out the two activities simultaneously in the field. There is no budget provision for these computers.

\section{B. National Accounts}

\section{- $\quad$ Fully adopting the 1993 SNA.}

The adopting the 1993 SNA has been a gradual process. Achievements so far include the production of a Supply and Use Table (SUT) for year 2002 at the end of 2005. Production of rebased GDP estimates is already underway and the exercise is expected to be concluded during the first half of 2006/07 financial year. The sequence of accounts of the total economy is to be produced based on the SUT and a SAM is almost ready.

The main hindrance in the past has been the inadequate funds to conduct the various surveys to generate required data. Funds have also limited the recruitment of additional staff. With the independent budget line, UBOS will be able to prioritize and progress will be subject to the level of funding available.

- $\quad$ Undertake an agriculture census supplemented by annual sample surveys.

There were high hopes that funds will be provided in the 2005/06 financial year budget for UBOS to conduct the agriculture census, but no funds were provided and it is not clear whether funds will be provided in 2006/07. As an interim measure, an agricultural module was included in the 2005/06 UNHS. Fieldwork for the UNHS ended in April 2006 and a final report is expected in October 2006.

Since 2004, UBOS has been collecting some data on agricultural production through the Permanent Agricultural Statistical System (PASS), funded by NORAD. Five districts were covered in PASS 2004, ten in PASS 2005 and eight are planned to be covered in PASS 2006. No more funding is expected from the current funder and therefore the programme is not expected to continue after PASS 2006. 
An agricultural census is still required to generate data for proper estimation of the agricultural sector since the above two efforts are just stop-gap measures.

- $\quad$ Undertake economy-wide business survey at least every five years, supplemented by annual sample surveys.

The last economy-wide survey - "The Uganda Business Inquiry" (UBI) was for financial year $2000 / 01$. We were hoping that the next survey would be for 2005/06 but it was not conducted due to financial constraints. The $2006 / 07$ budget has no provision for conducting an economy-wide survey but an "Annual Business Inquiry" (ABI), is planned for 2006/07 financial year and is expected to cover up to 500 businesses countrywide.

- $\quad$ Develop separate estimates for the finance industry.

Separate estimates for the sector (Financial Intermediation and Insurance) were produced in the Supply and Use Table 2002. The rebasing of GDP to 2002 base year exercise which is currently on will therefore produce separate estimates for the sector for all years covered by the rebasing and thereafter separate estimates will always be produced.

- $\quad$ Release national accounts in news release format with accompanying text on economic performance and reason for revisions.

The current practice is to publish revised estimates in the next publication (Key Economic Indicators) coming after the main release in the Background to the Budget and Statistical Abstract publications. Brief explanations are always given about the changes from earlier estimates.

UBOS has no immediate plans to release the annual national accounts estimates and revisions in news release formats. However, when the quarterly GDP estimates start coming out (first drafts expected before end of 2006/07), we hope to use the news release format for disseminating the figures. 


\title{
INTERNATIONAL MONETARY FUND
}

\author{
UGANDA
}

\section{Detailed Assessments Using the Data Quality Assessment Framework (DQAF)}

Prepared by the Statistics Department

Approved by Robert W. Edwards and Abdoulaye Bio-Tchané

July 12, 2006

This document contains a detailed assessment by dataset of the elements and indicators that underlie the data quality dimensions discussed in Uganda's Report on the Observance of Standards and Codes (ROSC)-Data Module. It also includes as appendices the DQAF generic framework and the results of the users' survey. 


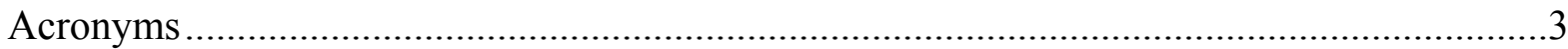

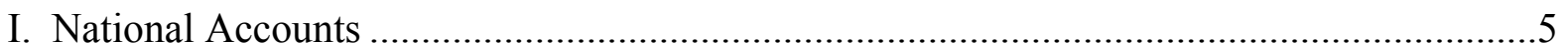

II. Price Statistics (Consumer Price Index) .................................................................24

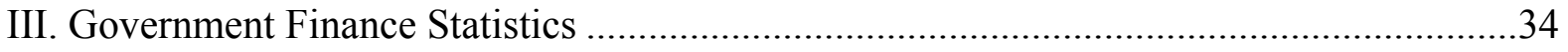

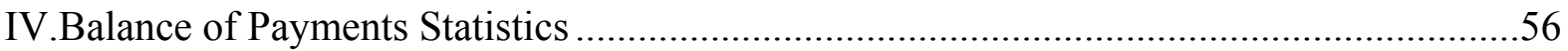

Tables

1. DQAF (July 2003): Summary of Results for National Accounts .................................22

2. DQAF (July 2003): Summary of Results for Price Statistics (Consumer Price Index)...33

3. DQAF (July 2003): Summary of Results for Government Finance Statistics ................54

4. DQAF (July 2003): Summary of Results for Balance of Payments Statistics................79

\section{Appendices}

I. Summary of the General Data Dissemination System (GDDS) .................................81

II. Data Quality Assessment Framework - Generic Framework.....................................83 
ACRONYMS

1968 SNA

1993 SNA

BPM5

BOP

BOPS

BOU

CAA

$\mathrm{CDO}$

COFOG

COICOP

COBE

CPI

DQAF July 2003

DSBB

EAC

FDI

FIS

FISC

FMOC

GDP

GDDS

GFS

GFSM 1986

GFSM 2001

HIPC

HBS

HS

ICP

IFMS

IIP

IMF

ISIC

ISWGNA

ITRS

ITSC

MAAIF

MFSM

MFPED

MTTI

NORAD

PCFS

$\mathrm{RD}$

ROSC
System of National Accounts 1968

System of National Accounts 1993

Balance of Payments Manual, fifth edition

Balance of Payments

Balance of Payments Section

Bank of Uganda

Civil Aviation Authority

Cotton Development Organization

Classification of the Functions of Government

Classification of Individual Consumption by Purpose

Census of Business Establishments

Consumer Price Index

Data Quality Assessment Framework, July 2003 version

Dissemination Standards Bulletin Board

East African Committee

Foreign direct investment

Financial Institution Statute, 1993

Financial Information Sharing Committee

Financial Market Operation Committee

Gross Domestic Production

General Data Dissemination System

Government Finance Statistics

A Manual on Government Finance Statistics, 1986

Government Financial Statistics Manual 2001

Heavily Indebted Poor Country Initiative

Household Budget Survey

Harmonized System of Commodity Description and Coding

International Comparison Project

Integrated Financial Management System

International Investment Position

International Monetary Fund

International Standard industrial Classification

Inter-secretariat Working Group on National Accounts

International Transactions Reporting System

International Trade Statistics Committee

Ministry of Agriculture, Animal Industry and Fisheries

Monetary and Financial Statistics Manual

Ministry of Finance, Planning, and Economic Development

Ministry of Trade, Tourism and Industry

Norwegian Agency for Development Co-operation

Private Capital Flow Survey

Bank of Uganda Research Department

Report on the Observance of Standards and Codes 


$\begin{array}{ll}\text { SBE } & \text { Single bill of entry } \\ \text { SITC } & \text { Standard International Trade Classification } \\ \text { STA } & \text { IMF Statistics Department } \\ \text { SUT } & \text { Supply and use table } \\ \text { TEDD } & \text { Trade and External Debt Department } \\ \text { TFTS } & \text { Task Force on Trade Statistics } \\ \text { UBI } & \text { Uganda Business Inquiry } \\ \text { UBOS } & \text { Uganda Bureau of Statistics } \\ \text { UCDA } & \text { Uganda Coffee Development Authorities } \\ \text { UIA } & \text { Uganda Investment Authorities } \\ \text { UNHS } & \text { Uganda National Household Survey } \\ \text { URA } & \text { Uganda Revenue Authority } \\ \text { USAID } & \text { United States Agency for Internal Development } \\ \text { UTA } & \text { Uganda Tea Authority } \\ \text { WGPCF } & \text { Working Group on Private Capital Flows }\end{array}$




\section{Detailed Assessment Using the Data Quality AsSessment Framework (DQAF)}

The following detailed information on indicators of statistical practices in the areas of the national accounts, prices, government finance, and balance of payments statistics was gathered from publicly available documents and information provided by the Ugandan officials. This information, organized along the lines of the generic DQAF (see Appendix II), was used to prepare the summary assessment of data quality elements, based on a four-part scale of observance, shown in Uganda's Report on the Observance of Standards and Codes (ROSC)_Data Module.

\section{National Accounts}

\section{Prerequisites of quality}

\section{$0.1 \quad$ Legal and institutional environment}

\subsubsection{The responsibility for collecting, processing, and disseminating the statistics is clearly specified}

The Uganda Bureau of Statistics (UBOS) is a semiautonomous body within the Ministry of Finance, Planning and Development (MFPED) operating under the Uganda Bureau of Statistics Act, 1998. ${ }^{1}$ Under the provisions of this act (Part 4) the Bureau is designated the principal data collecting and disseminating agency responsible for coordinating, monitoring, and supervising the National Statistical System. This covers all agencies in Uganda, whether government or not, responsible for gathering official statistical data directly through surveys or administrative action. UBOS is governed by a Board of Directors that formulates policy, monitors the implementation of the Bureau's plans and programs, and approves the annual budget and actions plans. In addition, it determines the Bureau's structure, staffing levels and terms of service, and establishes the rules and procedures for:

- $\quad$ staff appointments, career development, and discipline,

- $\quad$ the purchase of goods and services and the disposal of assets, and

- $\quad$ the proper management of the Bureau's finances and assets.

The Board comprises a chairperson, a representative of the ministry responsible for statistics, a representative from the Institute of Statistics at the university, and up to three members appointed from major producers and users. It is responsible for keeping the minister informed of the progress of the business of the Bureau at three-monthly intervals.

The Executive Director of UBOS, who is appointed by the minister on the recommendation of the Board, is responsible for implementing Board policies.

\footnotetext{
${ }^{1}$ Referred to in the rest of the text as the Statistics Act.
} 
The Statistics Act (Part V) authorizes UBOS to collect statistics for Uganda relating to a wide range of data relating to demographic, economic, financial, and social matters. The responsibility for the production and dissemination of national accounts is implicitly covered within the broad mandate to collect, compile, analyze, and publish Uganda's official statistics, and the Statistics Act (Fourth Schedule) clearly specifies both the industrial breakdown of economic activities and the component detail commonly required for national accounts. The same schedule also refers to data relating to personal consumption, wholesale and retail prices, and costs of living. Thus, the schedule also covers the responsibility to produce the consumer price index (CPI). UBOS's mandate is completed by the final item in the schedule, which refers to "other, as approved by the Board."

\subsubsection{Data sharing and coordination among data-producing agencies are adequate}

UBOS's Coordination, Methods, Standards, and Research Unit has the responsibility, among other things, for determining user's needs and ensuring data standards. This unit has set up producer committees - including representatives from government ministries such as the Ministry of Agriculture, Animal Industry and Fisheries (MAAIF), Ministry of Trade and Tourism and Industry (MTTI), the National Council of Science and Technology, and organizations in the districts - which meet to discuss the standards of data production. To ensure consistency, they have produced a Compendium of Statistical Concepts and Definitions Used in the Uganda Statistical System and Services. This document is kept up-todate and is provided to data producers. In addition, the line ministries are linked to UBOS Directorates, via specific contact persons in each organization.

A technical working group with representatives from UBOS, the Bank of Uganda (BOU), and the MFPED has recently been set up to coordinate government finance statistics. Further, an International Trade Statistics Committee is in place to reconcile external trade data, which in addition to representatives from the above three organizations, includes a member of the Uganda Revenue Authority (URA). While these bodies do not always meet as frequently as planned, the latter has had success in virtually eliminating the discrepancies between the balance of payments (BOP) statistics and the national accounts.

\subsubsection{Individual reporters' data are to be kept confidential and used for statistical purposes only}

The Statistics Act (Part V, section 19) stipulates that - except for purposes of prosecution under the act itself - no individual information may be disclosed or arranged in a form that allows possible identification of such information. There are, however, some exceptions, namely, when (1) the respondent has already published the same data; and (2) a document is published that allows identification of the respondent by virtue of the fact that they are the only undertaking or business in that particular sphere of activities. In the latter case, the particulars must not allow identification of production costs, capital employed, or profits arising from the business. 
The questionnaires used for data collection clearly specify the confidentiality of the data for UBOS and the purposes for which the data will be used.

Data can be released — with identifiers removed - specifically for research purposes providing a written undertaking is obtained that (i) the data will not be released to other persons; (ii) the findings are made available to the Bureau; and (iii) the Executive Director is satisfied that unit records cannot be identified as relating to any particular person or business.

All persons involved in processing data collected under the Statistics Act are required by Part IV, section 13 to sign a UBOS oath of secrecy. The Statistics Act (Part VII, section 29) also prescribes penalties of a fine or imprisonment for anyone using information gathered under the act for personal gain, or providing such information to other persons without lawful authority.

Offices are normally kept locked when staff are absent. Where required, office access is restricted to authorized staff. Standard practice is to destroy questionnaires after storing for seven years.

\subsubsection{Statistical reporting is ensured through legal mandate and/or measures to encourage response}

The Statistics Act (Part V, section 17) provides UBOS with the power to collect information from respondents to the "best of his or her belief" and in a timely manner. Noncompliance with this can result in a fine or imprisonment for the respondent, although in practice UBOS prefers to rely on gentle persuasion.

UBOS tries where possible to minimize the burden on respondents. For example, the data collection that is being developed for the producer price index is being coordinated with the surveys undertaken for the index of industrial production so that all data required from individual respondents are collected at one time. In addition, survey questionnaires contain contact details for requiring assistance with completing the form.

\section{$0.2 \quad$ Resources}

\subsubsection{Staff, facilities, computing resources, and financing are commensurate with statistical programs}

Since its establishment as a semiautonomous body in June 1998, the UBOS has had generally adequate resources, with government funds being supplemented by donors such as the World Bank, the Department for International Development (DFID), and the Norwegian Agency for Development Co-operation (NORAD). Over the past few months, however, UBOS has been subject to financial constraints both in the level of budgeted funds and in the timing of the receipt of these funds. These constraints have affected both its ability to pay its staff and to produce crucial indicators such as the CPI, in a timely manner. 
Overall, the present resources are not adequate to allow UBOS to carry out the expanding range of activities as outlined in its Five Year Plan. ${ }^{2}$

Staffing levels are below the level required for UBOS's planned operations. There is an immediate need for five more statisticians, one of whom is needed for national accounts, which is developing a quarterly series. The section currently has a head and three staff, one of whom is responsible for the annual series and one for developing quarterly accounts; the other is a new recruit. Apart from the last, these staff have all had international training in national accounts, but there are not enough of them to do the required work. There is also a problem with data on agriculture, which are a crucial input into the national accounts system. These data were until recent years collected by the MAAIF through their field staff, but changes in the structure of the Ministry have caused this data collection system to break down. The UBOS plan calls for this gap to be filled by an Agriculture Census and ongoing annual surveys. With assistance from NORAD, these plans are well advanced-a pilot survey for the census has been completed-but progress has now stalled because of a lack of funds. The implementation of this program will require both more staff and additional funds for field work.

Staffing for the CPI is adequate for the present, with a total of 21 staff: the head, three statisticians, eight statistical assistants, five data collectors, and four support staff. The Section Head has attended an IMF prices course and seven others have statistics degrees or diplomas. However, as part of the International Comparison Project (ICP), it is planned to expand the range of commodities for which prices are collected, and to collect prices from rural areas. For this exercise to lead to a permanent improvement in the quality of the CPI, additional funds and staff will be needed after the one-off ICP Project is completed.

Staff retention in UBOS is good as the work is challenging and the salaries are reasonable, although there has been a problem of losing IT staff to the banking sector.

Computer resources are acceptable and staff training has been provided with donor assistance. Data stored on the internal UBOS network are regularly backed up on tapes, and backing up other files is the responsibility of the individuals concerned.

UBOS will be moving into a new building adjacent to the MFPED in Kampala, built with donor funding, around the end of 2005.

A problem arises with the financing of UBOS. Under the Statistical Act (Part III, section 7) it is the function of the Board of Directors to approve the annual budget and action plan for UBOS. This budget is not then forwarded for approval and appropriation by the Parliament as allowed for in the Statistical Act (Part VI, section 22) but is funded from a subvention from the MFPED vote who then, in effect, has the final say in the size and timing of the

\footnotetext{
${ }^{2}$ As outlined in Corporate Plan, Strategies and Objectives 2002-2007, UBOS, July 2002.
} 
UBOS budget. Reductions in the budget at this point are affecting the ability of UBOS to meet its program.

\subsubsection{Measures to ensure efficient use of resources are implemented}

Staff are evaluated regularly to determine their need for training and their suitability for promotion.

UBOS has implemented a robust financial management system that produces reports for audit by the Auditor-General.

Survey and questionnaire designs are based on international standards, which are monitored by the Coordination, Standards, Methods and Research Unit and are also frequently developed with input from international experts.

\subsection{Relevance}

\subsubsection{The relevance and practical utility of existing statistics in meeting users' needs are monitored}

Data collection is demand driven. As mentioned in 0.1.2, the Coordination, Methods, Standards, and Research Unit has the responsibility, among other things, for determining users' needs, and has set up producer committees and communicated with other users. Changing data needs are monitored, as exemplified by the poverty monitoring program, which has evolved in recent years. The UBOS website invites users to write to the Executive Director stating their requirements.

\subsection{Other quality management}

\subsubsection{Processes are in place to focus on quality}

UBOS has developed what it refers to as its "vision" that UBOS must be a "Centre of Excellence" in statistical production in Africa, measured by results in corporate indicators. These corporate performance indicators relate to meeting targets of timeliness, quality, the dissemination of methodology information, and the usefulness of their products as measured by the number of quotations in the press and research papers written.

This vision is published in the Corporate Plan and is displayed in UBOS offices together with the UBOS Mission Statement: "We aim at continuously building and developing a coherent, reliable, efficient and demand-driven national statistical system to support management and development initiatives."

Enumerators are given training and survey manuals to ensure the quality of data collections. 


\subsubsection{Processes are in place to monitor the quality of the statistical program}

The Corporate Plan outlines strategic objectives together with the related performance/effectiveness indicators covering the period of the five-year plan. It is recognized that these are umbrella indicators and more specific indicators are built into the three-year rolling plans and budgets, which take account of actual performances and changing circumstances.

UBOS has wide access to international experts and frequently uses them on technical issues.

\subsubsection{Processes are in place to deal with quality considerations in planning the statistical program}

It is recognized that there are trade-offs between resources and accuracy. For example, in the Uganda Business Inquiry, 2002, only a limited range of final data was published for Agriculture, Mining and Quarrying, Construction and Transport, because the number of units covered in these areas did not allow full analysis.

\section{Assurances of integrity}

\subsection{Professionalism}

\subsubsection{Statistics are produced on an impartial basis}

The Statistical Act supports the independence of UBOS. The Executive Director-although appointed by the Minister - is recommended by the Board of Directors. The Board also instructs the Bureau to provide high quality central statistics information services. UBOS is confident that it produces data impartially and gave examples of recent data releases relating to poverty levels, which were not necessarily popular but were nevertheless published.

\subsubsection{Choices of sources and statistical techniques as well as decisions about dissemination are informed solely by statistical considerations}

Choice of data sources is determined solely by statistical considerations as evidenced by the comprehensive cross-checking of different data sources undertaken by the National Accounts Section to determine the "best-quality" estimates. In addition, recent poverty figures were widely disseminated - as noted above — despite showing an increase in Ugandan poverty levels. 


\subsubsection{The appropriate statistical entity is entitled to comment on erroneous interpretation and misuse of statistics}

UBOS has in the past challenged statements made regarding its activities, and distortions in the publication of its CPI news release, but does not respond to misuse of its statistics on a systematic basis.

\subsection{Transparency}

1.2.1 The terms and conditions under which statistics are collected, processed, and disseminated are available to the public

The Statistics Act is available in the UBOS library, and its website includes a profile of UBOS summarizing its vision and mission and legal foundations.

\subsubsection{Internal governmental access to statistics prior to their release is publicly identified}

The national accounts are available to government users well before they are available to the general public, and this fact is known by common practice, rather than being specifically publicized. There is no preferential release access to CPI data.

\subsubsection{Products of statistical agencies/units are clearly identified as such}

The products of UBOS are clearly identified in all publications, including the Background to the Budget, which is published by MFPED.

\subsubsection{Advance notice is given of major changes in methodology, source data, and statistical techniques}

Advance notice of revisions to national accounts methodology, source data and techniques is not generally provided to the general public, although it is known to key stakeholders in the production of statistics. The last rebase to 1997-98 was, however, referred to in the Corporate Plan. The CPI does indicate when a figure is to be revised the following month, and advance notice of a rebase was provided in the GDDS website, although the target date was not met.

\subsection{Ethical standards}

\subsubsection{Guidelines for staff behavior are in place and are well known to the staff}

All UBOS staff, even those employed short-term, take the Oath of Office and Secrecy as outlined in the third schedule to the Statistical Act. This covers both the need for secrecy and the prohibition on using confidential data for personal gain. The staff is also covered by the Code of Conduct (Uganda Government Standing Orders 1992), with which they are 
acquainted. UBOS has prepared additional rules covering issues such as the use of the Internet during office hours and the use of office vehicles.

\section{Methodological soundness}

\subsection{Concepts and definitions}

2.1.1 The overall structure in terms of concepts and definitions follows internationally accepted standards, guidelines, or good practices

The general framework for compiling the Ugandan national accounts is the System of National Accounts 1968 (1968 SNA), but includes certain elements of the System of National Accounts 1993 (1993 SNA). Examples of this are the valuation of output at basic values and imports of goods at free on board (f.o.b.) prices. UBOS is working toward further implementation of the 1993 SNA guidelines, and according to current plans a revised time series rebased to 2002, benchmarked on a supply and use table, will be published toward the end of 2005. This series will incorporate the 1993 SNA to the extent that data allow.

\subsection{Scope}

2.2.1 The scope is broadly consistent with internationally accepted standards, guidelines, or good practices

UBOS compiles accounts for both calendar and fiscal years. The range covers the following accounts:

- $\quad$ annual value added and gross domestic product (GDP) at current and constant prices;

- broken down into monetary and nonmonetary production by industry

including a formal/informal split for manufacturing

- $\quad$ annual expenditure on GDP at current and constant prices;

- $\quad$ including a breakdown of fixed capital formation into private/public construction and other (machinery and vehicles)

While a specific Rest of the World Account is not compiled, coordination with the BOU ensures that the BOP statistics are largely consistent with the national accounts.

In addition, a number of derived tables are produced covering percentage growth rates, percentage distributions, and implicit deflators. If the above tables were produced following 1993 SNA guidelines, they would fall short of the minimum set recommended by the Inter-secretariat Working Group on National Accounts (ISWGNA), as they do not include:

- $\quad$ annual value added components at current prices by activity; and

- $\quad$ sequence of accounts for the total economy (up to net lending). 
With respect to the other ISWGNA recommendations for 1993 SNA implementation, quarterly accounts are under development and a supply and use table for 2002 is being compiled. All deviations from the scope required by the $1993 \mathrm{SNA}$ are being reviewed as part of the implementation process.

The scope of the accounts includes Ugandan embassies in other countries, and the production boundary includes own-account production of agriculture goods for own consumption, so it is in line with the $1968 S N A$ requirements.

The requirements of a full production account are not met insofar as there are no published estimates of intermediate consumption or output, although the latter is usually implicit in the worksheets. No independent estimates are made for the output of the finance industry, which is implicitly included in the base-year data for the miscellaneous services industry and has been extrapolated forward.

\subsection{Classification/sectorization}

\subsubsection{Classification/sectorization systems used are broadly consistent with internationally accepted standards, guidelines, or good practices}

The following internationally recommended classification systems are used in the compilation of the national accounts:

- The International Standard Industrial Classification (ISIC rev 3) is used to classify the principal activities of enterprises. This has been supplemented by additional codes relevant to local conditions, covering the activities of Coffee Processing, Tea Processing, Manufacture of Jaggery (a sugar byproduct), and Cotton Ginning.

- $\quad$ The Standard International Trade Classification (SITC) is used to classify commodity trade.

- $\quad$ The Classification of Individual Consumption by Purpose (COICOP) — as used in the 1999-2000 and 2002-2003 household surveys - underlies the household final consumption estimates, which are prepared independently.

\subsection{Basis for recording}

\subsubsection{Market prices are used to value flows and stocks}

The valuation rules for valuing stocks and flows are in accordance with the 1993 SNA. Market output is valued at basic prices and intermediate consumption at purchaser prices, excluding deductible value added tax. In addition, imports and exports are measured on an f.o.b. basis, and an estimate of insurance and freight is available from BOP statistics. UBOS national accounts also correctly value own account subsistence production at farm gate prices, rather than at prices in the local market, which is only correct in the particular case of the two being equal. 


\subsubsection{Recording is done on an accrual basis}

Transactions are recorded on an accrual basis except for budgetary central government, which is measured on a cash basis.

\subsubsection{Grossing/netting procedures are broadly consistent with internationally accepted} standards, guidelines, or good practices

UBOS collects data on the establishment level and records them on a gross basis.

\section{Accuracy and reliability}

\subsection{Source data}

\subsubsection{Source data are obtained from comprehensive data collection programs that take into account country-specific conditions}

The source data for the national accounts are a mixture of surveys - predominantly those undertaken in UBOS — administrative records, and data providing indirect estimates of output.

There are some serious gaps in the coverage that need to be filled before the data collection program could be considered adequate for the compilation of national accounts. The most serious deficiency in terms of size at this time is in the area of agriculture statistics, which contributes some 40 percent of GDP. The present estimates for cash crops are reasonable, being based on data from the relevant development authorities, but the estimates for food crops are based on benchmark volumes derived from the 1997 and 1999-2000 household surveys extrapolated by the MAAIF data on acreages and yields. These latter data are not soundly based and urgently need to be replaced by a comprehensive data collection program.

Manufacturing estimates are based on the Census of Business Establishments (COBE) undertaken in 1989, extrapolated forward by data from the Index of Industrial Production. The forthcoming rebase will update these estimates using data from the Uganda Business Inquiry 2000-01 (UBI). The gap of more than ten years between such surveys is too long, and there is a need to establish a more regular program of economy-wide censuses supplemented by annual sample surveys. The Index of Industrial Production needs to be rebased, given expanded coverage, subjected to a methodology review, and provided with sufficient resources to be updated on a regular basis. A program of producer price indices is currently under development. These improvements are important given the planned development of quarterly accounts.

Construction estimates for the private sector are based on COBE data extrapolated by the Index of Industrial Production component for cement and roofing materials. Government construction estimates are based on development expenditure data and information on aid- 
funded project expenditure. These estimates could be improved by developing improved baseline data and indices of production and prices.

Miscellaneous Services covers a wide range of business, personal, and financial services and needs to be estimated in a less aggregated manner. In particular, separate estimates for the finance industry should be compiled using standard national accounting approaches.

Those surveys that have been undertaken, such as the UBI, have been soundly based on an updated business register. The sample and questionnaire design, field techniques, and data processing and checking have been of a high standard. Household surveys have been run regularly, every two or three years since 1989, and again these have all been run to international standards in all respects.

Ad hoc surveys are conducted occasionally - a case in point being the Informal Cross Border Trade Survey, which started in 2004 and is still continuing.

Price deflators/inflators where used are mainly derived from the CPI and are currently being improved with the development of producer price indices.

\subsubsection{Source data reasonably approximate the definitions, scope, classifications, valuation,} and time of recording required

Overall, the source data generally reasonably approximate the definitions, scope, classifications, valuation, and time of recording required for national accounts purposes. The primary deficiencies relate to agriculture, which is not adequately covered on an annual basis.

\subsubsection{Source data are timely}

The timeliness of source data is mixed. The household surveys produce results within six months of the end of the period, but financial resource difficulties lead to delays in the collection of data for the index of industrial production.

\subsection{Assessment of source data}

3.2.1 Source data - including censuses, sample surveys and administrative records-are routinely assessed, e.g., for coverage, sample error, response error, and nonsampling error; the results of the assessments are monitored and made available to guide statistical processes

The household sample surveys include estimates of sampling error. The results of other surveys, such as the 2002 UBI, are analyzed to determine the coverage, accuracy, and validity of the results. 


\subsection{Statistical techniques}

\subsubsection{Data compilation employs sound statistical techniques to deal with data sources}

The source surveys undertaken by UBOS are generally soundly based. A case in point is the 2000-01 Uganda Business Inquiry, which was a national survey covering about 4,000 establishments nationwide. This was preceded by a complete enumeration of all businesses in the country to update the business register to serve as a sampling frame. The sample design ensured that all large businesses were covered. Generally, the definition of "large" was employment greater than 20 persons, but this definition was varied from industry to industry. Systematic sampling was used to select the surveyed establishments. Data collection was carried out using a mix of postal and face-to-face interviewing. Initial editing was carried out in the field by the enumerator, and second stage editing was built into the computer program used for processing. Nonresponse was dealt with using data obtained from similar businesses, in the same industry and the same employment band.

Household surveys are regular and soundly based. Typically, they are scientifically designed using a stratified two-stage sample consisting of a nationally representative sample of households. The geographical area sampling frame is the most recently available Population and Housing Census. Each district is a stratum with further substratification as district town, other urban areas (i.e., trading centers), and rural areas. The 1997 survey, ${ }^{3}$ for example, covered 666 Enumeration Areas, and had a sample size of 6,655 households. The questionnaire was pilot tested and enumerators were well trained and supervised in the field. There is sometimes substitution of households, which may overstate actual response rates.

For other industries, such as agriculture, forestry and fishing, the national accounts estimates are based on expert opinion rather than sound survey.

\subsubsection{Other statistical procedures (e.g., data adjustments and transformations, and statistical analysis) employ sound statistical techniques}

The data adjustments that take place, for example, after the comparison and reconciliation of disparate data sources, are generally soundly based. However, the main deficiencies in the transformation of data relate to the excessive use of single indicator extrapolation and the reliance on outdated benchmark data. In many cases, the base data used in the accounts at this time date back to the 1989 Census of Business Establishments. Estimates of work in progress are included in the business surveys and implicit in the construction estimates, but are not estimated for agriculture. This lacuna will become more of an issue now that quarterly accounts are being developed. Agriculture has a further problem in that the reconciliations between production and consumption that have been traditionally undertaken tend to match one year's consumption with the same year's production. In practice,

\footnotetext{
${ }^{3}$ This survey is the main source of the CPI weights, and together with the 2000-01 survey provides the basis for the household final consumption estimate.
} 
consumption has to lag production by a few months. This issue will resurface as quarterly accounts are developed.

There are few comprehensive data to estimate stocks, but the expenditure side estimates are based on volume changes. Thus a valuation adjustment is not required. Taxes on products are extrapolated by volume measures, so base year tax rates are implicit. Similarly, trade margin volumes are estimated using base year margin rates. Expenditure estimates are independently made.

An input/output study was undertaken in 1992, and a supply and use table for 2002 is currently being prepared.

\subsection{Assessment and validation of intermediate data and statistical outputs}

\subsubsection{Intermediate results are validated against other information where applicable}

The data used as the main inputs to the national accounts are usually validated against other primary/secondary sources. The agriculture estimates have been consistently cross-checked and reconciled with equivalent estimates obtained from the household surveys. Data from both the 2002 UBI and the 2002-03 UNHS Informal Sector Module results were reconciled against existing national accounts estimates.

\subsubsection{Statistical discrepancies in intermediate data are assessed and investigated}

The studies referred to in 3.4.1 also drew conclusions on the reasons for any discrepancies and recommended solutions for the elimination of the differences.

\subsubsection{Statistical discrepancies and other potential indicators of problems in statistical outputs are investigated}

The national accounts process has always used commodity flow analysis for the major agriculture products, and the revision currently being undertaken will be based on a supply and use table. As household consumption is calculated independently, for periods when there

are no supply and use tables, a statistical discrepancy occurs between GDP by production and expenditure on GDP. This discrepancy is always shown explicitly.

\subsection{Revision studies}

\subsubsection{Studies and analyses of revisions are carried out routinely and used internally to} inform statistical processes (see also 4.3.3)

The estimation procedures for preliminary national accounts estimates are frequently reviewed and used in the light of final data. 


\section{Serviceability}

\subsection{Periodicity and timeliness}

\subsubsection{Periodicity follows dissemination standards}

The national accounts are compiled annually, which meets the recommendations of the GDDS. Given that estimates are produced for both a calendar year and the June fiscal year, the estimates are implicitly six monthly. Quarterly estimates are currently being developed.

\subsubsection{Timeliness follows dissemination standards}

UBOS consistently publishes the first set of national accounts five months after the end of the period, which is within the guidelines recommended by the GDDS. This first publication - disseminated by way of the Background to the Budget document published by the MFPED in early June - contains current fiscal year data one month prior to the end of that period. Thus, some of those estimates contain forecasted elements, so the first nonforecasted set of accounts are for the period ending the previous December, referred to above.

\subsection{Consistency}

\subsubsection{Statistics are consistent within the dataset}

Estimates of GDP by production and expenditure on GDP are produced independently, and regular reconciliation exercises are undertaken, using the commodity flow technique. This approach, together with periodic input/output studies and the supply and use tables in preparation, ensures the internal consistency of the accounts.

\subsubsection{Statistics are consistent or reconcilable over a reasonable period of time}

Consistent series of GDP by type of economic activity and expenditure on GDP are available back to the early 1980 s.

\subsubsection{Statistics are consistent or reconcilable with those obtained through other data sources and/or statistical frameworks}

The national accounts are consistent with both the BOP and merchandise trade statistics. Differences do occur from time to time, but a statistical committee (the ITSC) meets to reconcile these data. UBOS bases budgetary central government estimates on MFPED data, so these are consistent with GFS, but extrabudgetary central government and local government estimates have been done independently. The new Government Finance Statistics Technical Working Group will ensure that these estimates are consistent in the future. Agriculture production and consumption figures are also reconciled regularly. 


\subsection{Revision policy and practice}

\subsubsection{Revisions follow a regular and transparent schedule}

Revisions have been published regularly - every June and November-for many years, but this schedule is not published, and is known only by the established pattern. Advance notice is not normally provided on when the next rebase is due. UBOS Corporate Plan 2002-2007 did provide advance notice of the impending rebase to 1997-98, but this is not done consistently.

\subsubsection{Preliminary and/or revised data are clearly identified}

The data published in June are provisional, and the fiscal year data contain partial projections because they are compiled before the end of the period. However, neither the provisional nor the revised data are identified as such.

\subsubsection{Studies and analyses of revisions are made public (see also 3.5.1)}

Some revision analysis is done with the first set of accounts and this is sometimes incorporated into the text accompanying the analysis of the economy in the Background to the Budget document.

\section{Accessibility}

\subsection{Data accessibility}

5.1.1 Statistics are presented in a way that facilitates proper interpretation and meaningful comparisons (layout and clarity of text, tables, and charts)

The national accounts data are published clearly and in considerable detail — by type of activity and expenditure by type, in current and constant prices - as part of the Background to the Budget document produced by the MFPED. Commentary on the economy and some charts are included in this publication. Detailed tables are also published in the quarterly Key Economic Indicators and the annual Statistical Abstract. The latter also contains commentary on the reasons for growth in each industry. The latter two publications are produced by UBOS.

\subsubsection{Dissemination media and format are adequate}

Dissemination is done through publications and by posting the data on the UBOS website. There are no specific information releases designed to facilitate publication of national accounts information in the local newspapers. 


\subsubsection{Statistics are released on a preannounced schedule}

There is no precise preannounced schedule date for the release of the data, but the timing of the budget - when the first release is made - is known to interested parties by dint of its regularity.

\subsubsection{Statistics are made available to all users at the same time}

Government receives data for budget purposes prior to their release to the public. They do not disclose this to outside users, but it is assumed to be common public knowledge by way of long-standing practice.

\subsubsection{Statistics not routinely disseminated are made available upon request}

Data are published in considerable detail, but further information is available on request. In the source data publications, the public is specifically encouraged to utilize the underlying data sets for more detailed analysis.

\subsection{Metadata accessibility}

5.2.1 Documentation on concepts, scope, classifications, basis of recording, data sources, and statistical techniques is available, and differences from internationally accepted standards, guidelines, or good practices are annotated

Sources and methods relating to the current national accounts compilation are not readily available. The GDDS metadata on the IMF website date back to February 2004-July 2002 in one case.

\subsubsection{Levels of detail are adapted to the needs of the intended audience}

The published data in the main publications-Background to the Budget, Key Economic Indicators and the Statistical Abstract - include a full range of GDP and expenditure tables, and the Uganda Facts and Figures publication 2003 - the 2004 has not been published yethas some basic information and charts. The website also has a layman's guide to GDP in the frequently-asked questions section.

\subsection{Assistance to users}

\subsubsection{Contact points for each subject field are publicized}

All publications contain information regarding a general e-mail address for enquiries and refer readers to the UBOS website, which is user friendly. 
5.3.2 Catalogs of publications, documents, and other services, including information on any charges, are widely available

A list of publications is published as an appendix to the "Uganda Facts and Figures" booklet, and the website www.ubos.org clearly indicates a list of available UBOS publications and prices. 
$-22-$

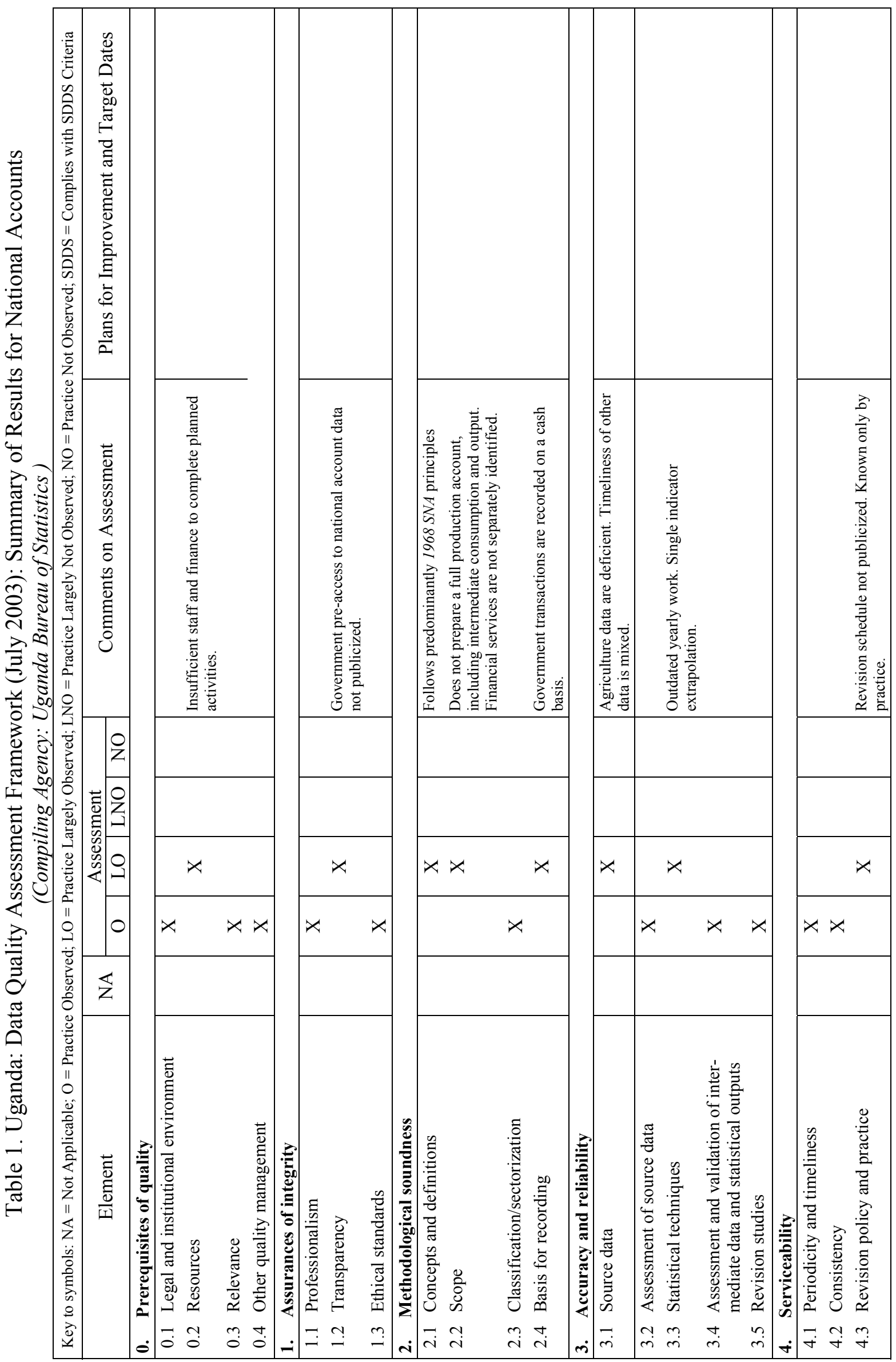




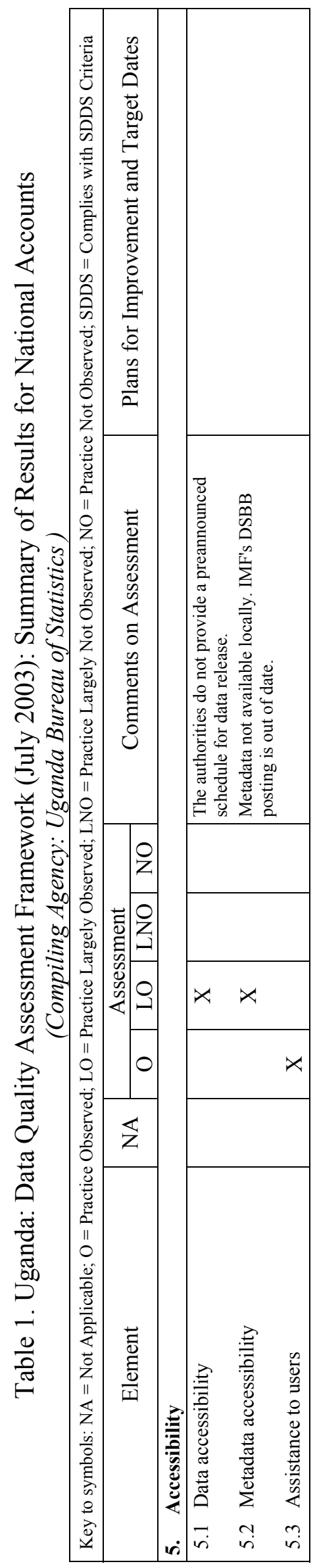




\section{Price Statistics (Consumer Price Index)}

\section{For assessments of the Prerequisites of quality (0.) and Assurances of integrity (1.)} dimensions, see the National Accounts section.

\section{Methodological soundness}

\subsection{Concepts and definitions}

\subsubsection{The overall structure in terms of concepts and definitions follows internationally accepted standards, guidelines, or good practices}

The concepts and definitions used in compiling of the CPI broadly conform with international recommendations and good practices. The definition of household consumption expenditures and the specification of products follow international recommendations.

The commodity specifications contain considerable detail, and other practices imply that high accuracy price data are collected. Further, the survey on which the weights are based followed international standards with respect to commodity detail and sampling techniques.

\section{$2.2 \quad$ Scope}

\subsubsection{The scope is broadly consistent with internationally accepted standards, guidelines, or good practices}

The weights are based on the 1997 Uganda National Household Survey (1997 UNHS), which covered all private households in Uganda-irrespective of size and income level—some 98.8 percent of all households. The exclusion of institutional units such as schools, hospitals, and army barracks is a common practice.

The index is designed, however, to cover only urban households. Price collections are undertaken in the six main urban centers, and the weights represent the expenditure in these centers. So, in effect about 14 percent of the total population is covered. In addition, owneroccupied dwellings are excluded as is travel expenditure abroad by Ugandan householdsthe latter item would be relatively small. Own-account production of agriculture products is included in the weights - correctly valued at farm-gate prices - and while other own-account production is not included, data collected in the household survey program suggest this is not significant.

Thus, there is a significant deficiency in scope with respect to the rural areas, although there are plans to collect rural prices as part of the International Comparison Project (ICP). 


\subsection{Classification/sectorization}

\subsubsection{Classification/sectorization systems used are broadly consistent with internationally accepted standards, guidelines, or good practices}

The Classification of Individual Consumption by Purpose (COICOP) is used to classify expenditure. Products are classified using the Central Product Classification (CPC) as recommended by the 1993 SNA.

\section{$2.4 \quad$ Basis for recording}

\subsubsection{Market prices are used to value flows and stocks}

The valuation of consumption expenditures in the UNHS, which provide the basis for deriving the weights, is in accordance with the 1993 SNA since all purchases are valued at purchasers' prices. In particular, the valuation of food produced for own consumption is correctly done at farm-gate prices, which is the true market value for such consumption where the producer is also the consumer.

Production specifications include price determining characteristics. For example, the instructions for the purchase of matooke (green bananas) in the marketplace clearly indicate the location in the particular market where the purchase should be made, and also note that purchases should not be made from lorries located immediately outside the market. Prices of purchased goods and price quotations used are based on actual transaction prices.

\subsubsection{Recording is done on an accrual basis}

Prices of goods and services are recorded in the period they are purchased, in accordance with the accrual principal.

\subsubsection{Grossing/netting procedures are broadly consistent with internationally accepted standards, guidelines, or good practices}

At this time no used cars are included, but other durable goods are included that could be new or secondhand. These goods are recorded gross because no data are available of secondhand sales. Secondhand clothing is an important item but interhousehold sales of a nonbusiness nature would be negligible. 


\section{Accuracy and reliability}

\subsection{Source data}

\subsubsection{Source data are obtained from comprehensive data collection programs that take into account country-specific conditions}

The two main data sources for CPI production are the household surveys - which have been undertaken regularly, sometimes annually, sometimes two-yearly, since 1989 - and the UBOS CPI price collection program. Both of these are continuously reviewed and crosschecked against other data to ensure accuracy. Together, they provide a sound basis for CPI production.

The 1997 UNHS — the basis for the current weights - covered only the period from March to November 1997, but the bias that might have resulted from using these data unadjusted was eliminated by identifying those commodities with higher seasonal consumption in the December-February period and estimating total consumption using the commodity flow technique. This was done through matching the supply from production and net imports with household consumption and other demands.

The UNHS was scientifically designed using a stratified two-stage sample, consisting of a nationally representative sample of households. The geographical area sampling frame was compiled from the 1991 Population and Housing Census. Each district was a stratum with further substratification as district, town, other urban areas (i.e., trading centers) and rural areas. The survey covered 666 Enumeration Areas and had a sample size of 6,655 households. The questionnaire was pilot tested, and enumerators were well trained and supervised in the field. There was some substitution of households, which may overstate actual response rates.

All private households were covered and institutions were excluded, which is in line with standard CPI practice. Two areas - Gulu, Kitgum - were excluded from the UNHS because of security issues. The data used for the CPI weights were adjusted for this deficiency, using population data and other ratios based on historical information.

The frequency of price collection is adequate. Prices of perishables - fruit and vegetablesand charcoal are collected twice a month, and most prices of other commodities are collected monthly. The exceptions are rent, which is collected quarterly; education charges, which are collected three times a year at the beginning of each term; and electricity charges, which are collected directly from the Uganda Electricity Distribution Company whenever the charges are revised. The selection of outlets is done using a purposive approach, and the selection of products was done using a cutoff of 0.05 percent of total expenditure. One or several product varieties were chosen to represent each item. 
For producing the CPI, some 2,600 price observations are collected each month, from 550 outlets, covering 121 items. Additional price data are collected to anticipate the needs of the ICP and to allow product substitutions and the addition of new items such electronics.

Price collections are undertaken in the six urban centers by staff located in each center. These price collections are supervised by more senior staff from Kampala for at least some of the pricing days each month, to ensure the collection of quality data. This is further ensured by a comprehensive product description that covers, among other things, exactly where in the market each observation of the item should be purchased, the mode of observation, purchased or otherwise, the routine for estimating the price, and any other miscellaneous observation pertinent to price measurement. Prices for rented dwellings are taken from a fixed sample of existing tenants or landlords in each center.

New products that potentially could be included in the index are identified from general knowledge, observation, and items identified in the household expenditure surveys.

\subsubsection{Source data reasonably approximate the definitions, scope, classifications, valuation, and time of recording required}

The source data are consistent with the definitions, scope-with the exceptions already noted - and classifications for CPI estimation. Where these have deviated, appropriate adjustments have been made. Only those prices that are known to change on an occasional basis are collected less frequently than monthly. An example is school fees, which only change at the beginning of a term.

\subsubsection{Source data are timely}

Household survey data are usually available within six months of the end of the period, which is adequate for CPI purposes. The price collection program is also timely, but the observations, in general, relate only to the first half of the month for which they are reported. So in fact the centerpoint of price observation is probably the $10^{\text {th }}$ of each month rather than the $15^{\text {th }}$. The CPI is always published on the last working day of the month to which it relates, but a truer measure of timeliness would probably be five-seven days after the end of the period.

\subsection{Assessment of source data}

3.2.1 Source data-including censuses, sample surveys and administrative records-are routinely assessed, e.g., for coverage, sample error, response error, and nonsampling error; the results of the assessments are monitored and made available to guide statistical processes

The household surveys, the source for the CPI weights, are all based on scientific samples, so sample errors are calculated. Nonsampling errors are kept in check through extensive enumerator training and supervision. Adjustments were made for those items typically 
understated in household surveys, plus some items of particular importance in Uganda, using the commodity flow technique. Items adjusted included alcoholic beverages, soda, tobacco, and sugar.

In addition, the prices collected are routinely subjected to considerable scrutiny.

\subsection{Statistical techniques}

\subsubsection{Data compilation employs sound statistical techniques to deal with data sources}

Compilation procedures are organized to minimize errors. Price averaging is done in the field and any outliers are confirmed or rejected at that point. The average prices computed are subject to further scrutiny for possible errors - by comparing them to prices for past months - back in Kampala. The computer entry of price data is double checked manually for accuracy.

Adjustments for nonresponse are soundly based. The procedures ensure that like is compared to like. For example, if price observations are made for a commodity in three markets one month, and the following month only two market observations are gathered, then a price is estimated for the missing market. This approach avoids spurious price changes.

Prices for temporarily missing products are imputed using the class mean approach, whereby the price change is estimated from the price change of other similar items in the same subgroup. Seasonal products are treated in the same manner. Products that are permanently unavailable are replaced and outlets are replaced if they close down. In practice, very little quality adjustment is required, although this will need to be reviewed after the next revision when it is planned to introduce cars into the index. One item that is often problematical due to quality differences, is secondhand clothing, an important item in this region. To avoid these problems, price changes are estimated by proxy using changes in the wholesale prices of imported bales of clothing.

In general, products that are new to the market and new outlets are introduced at the time the index is revised.

\subsubsection{Other statistical procedures (e.g., data adjustments and transformations, and statistical analysis) employ sound statistical techniques}

Other statistical procedures are sound. Elementary level indices are for the most part based on arithmetical averages of price observations, the exception being for rents that use a geometric mean. The CPI uses the modified Laspeyres formula, and the index weights have been price adjusted to align with the price reference period. The weight reference period is now nearly eight years old, and as it was based on price adjusted data it should be updated as soon as possible. 


\subsection{Assessment and validation of intermediate data and statistical outputs}

\subsubsection{Intermediate results are validated against other information where applicable}

Household survey data are cross-checked against other data, such as production and imports, and adjustments made to items such as alcohol and tobacco. The production and consumption of agricultural products are fully reconciled each time a household survey is completed, to ensure that CPI weights are correct.

\subsubsection{Statistical discrepancies in intermediate data are assessed and investigated}

Unusual movements in the index are investigated during the price validation process.

\subsubsection{Statistical discrepancies and other potential indicators of problems in statistical outputs are investigated}

CPI data are subject to a wide range of checks, both relating to the prices and the consistency of the weights.

\subsection{Revision studies}

3.5.1 Studies and analyses of revisions are carried out routinely and used internally to inform statistical processes (see also 4.3.3)

At the time of the last revision a study was undertaken to compare the new weights with the so-called "effective weights" of various index subgroups. For this, the weights in the old index were moved with price changes to determine their effective weight at the time of the most recent household survey. These effective weights were compared with the new weights obtained from the survey to see if there were any large differences that might point to possible data problems.

\section{Serviceability}

\subsection{Periodicity and timeliness}

\subsubsection{Periodicity follows dissemination standards}

The CPI is produced monthly in line with GDDS recommendations.

\subsubsection{Timeliness follows dissemination standards}

The CPI is produced at the end of the month to which its refers. However, as the prices are centered around the $10^{\text {th }}$ of the month rather than the middle, this is equivalent to a lag of around five-seven days, which is within GDDS recommendations. 


\subsection{Consistency}

\subsubsection{Statistics are consistent within the dataset}

The CPI is internally consistent. The National Index is the weighted sum of the regional indices.

\subsubsection{Statistics are consistent or reconcilable over a reasonable period of time}

The current index covering six urban centers dates back five years and can be readily linked to the previous one covering five urban centers, so in practice there is a long reconcilable series.

\subsubsection{Statistics are consistent or reconcilable with those obtained through other data sources and/or statistical frameworks}

The CPI weights are derived from the same source - the 1997 UNHS — using the same approach, as the national accounts household final consumption, so the two series are consistent.

\subsection{Revision policy and practice}

\subsubsection{Revisions follow a regular and transparent schedule}

The CPI is sometimes revised back one month, that is when prices are late, estimates that can be revised the following month. Normally the level of revisions is minor. However, the timing of the proposed rebasing of the index is not publicized in advance.

\subsubsection{Preliminary and/or revised data are clearly identified}

When data are expected to be revised, the news release states this fact and provides a reason. For instance, the January 2005 CPI is expected to be revised in February when data on rental charges are finalized.

\subsubsection{Studies and analyses of revisions are made public (see also 3.5.1)}

The additional revision studies done were undertaken for internal use only; however, the ongoing household surveys include comparisons with previous surveys as part of the analysis in the published reports. 


\section{Accessibility}

\subsection{Data accessibility}

\subsubsection{Statistics are presented in a way that facilitates proper interpretation and meaningful comparisons (layout and clarity of text, tables, and charts)}

The monthly CPI is released to the public by way of a press conference. The press release is published with a brief commentary on monthly price changes and charts showing trends over the year. The monthly publication is released at the same time and contains a wide range of tables with:

- month-on-month comparisons of headline inflation and underlying inflation-which excludes food crops - by urban center;

- $\quad$ monthly price changes by commodity group by urban center; and

- $\quad$ monthly and annual series by subgroup by center over a seven-eight year period.

In addition, the CPI series are accessible on the UBOS website www.ubos.org. This website, although still in the process of further development, is user friendly.

Seasonally adjusted data are not published.

\subsubsection{Dissemination media and format are adequate}

The news release is prepared in a form that could readily be published, and longer series are available for other users.

\subsubsection{Statistics are released on a preannounced schedule}

The monthly CPI publication contains a release calendar for the year and includes both the expected date and the actual time of release.

\subsubsection{Statistics are made available to all users at the same time}

Figures are released at 11:00 a.m. on the day of release and appear on the UBOS website, www.ubos.org, the same day. No prior access is given to anyone other than UBOS staff involved in the compilation, checking, and preparation of the release.

\subsubsection{Statistics not routinely disseminated are made available upon request}

Back series are available and have been provided in the past on request. 


\subsection{Metadata accessibility}

5.2.1 Documentation on concepts, scope, classifications, basis of recording, data sources, and statistical techniques is available, and differences from internationally accepted standards, guidelines, or good practices are annotated

Comprehensive metadata are not available. Previously, metadata were included in the CPI publication whenever revisions occurred, but the last time was in July 1993. The GDDS metadata on the IMF website dates back to July 2002 and are out of date. At the time of the rebase to the 1997-98 base, UBOS held a meeting with users such as the Bank of Uganda, MFPED, Makarere University, and the Economic Research Centre to discuss changes to items, weights, and methodology.

\subsubsection{Levels of detail are adapted to the needs of the intended audience}

Data are published in aggregate form and in detail, to assist all users. The website includes a simple description of the CPI in the frequently asked questions section to assist the uninitiated user.

\subsection{Assistance to users}

\subsubsection{Contact points for each subject field are publicized}

All publications contain information regarding a general e-mail address for enquiries and refer readers to the UBOS website, which is very user-friendly and includes a section on frequently asked questions.

5.3.2 Catalogs of publications, documents, and other services, including information on any charges, are widely available

A list of publications is published as an appendix to the "Uganda Facts and Figures" booklet, and the website www.ubos.org clearly indicates a list of available UBOS publications and prices. 
- 33 -

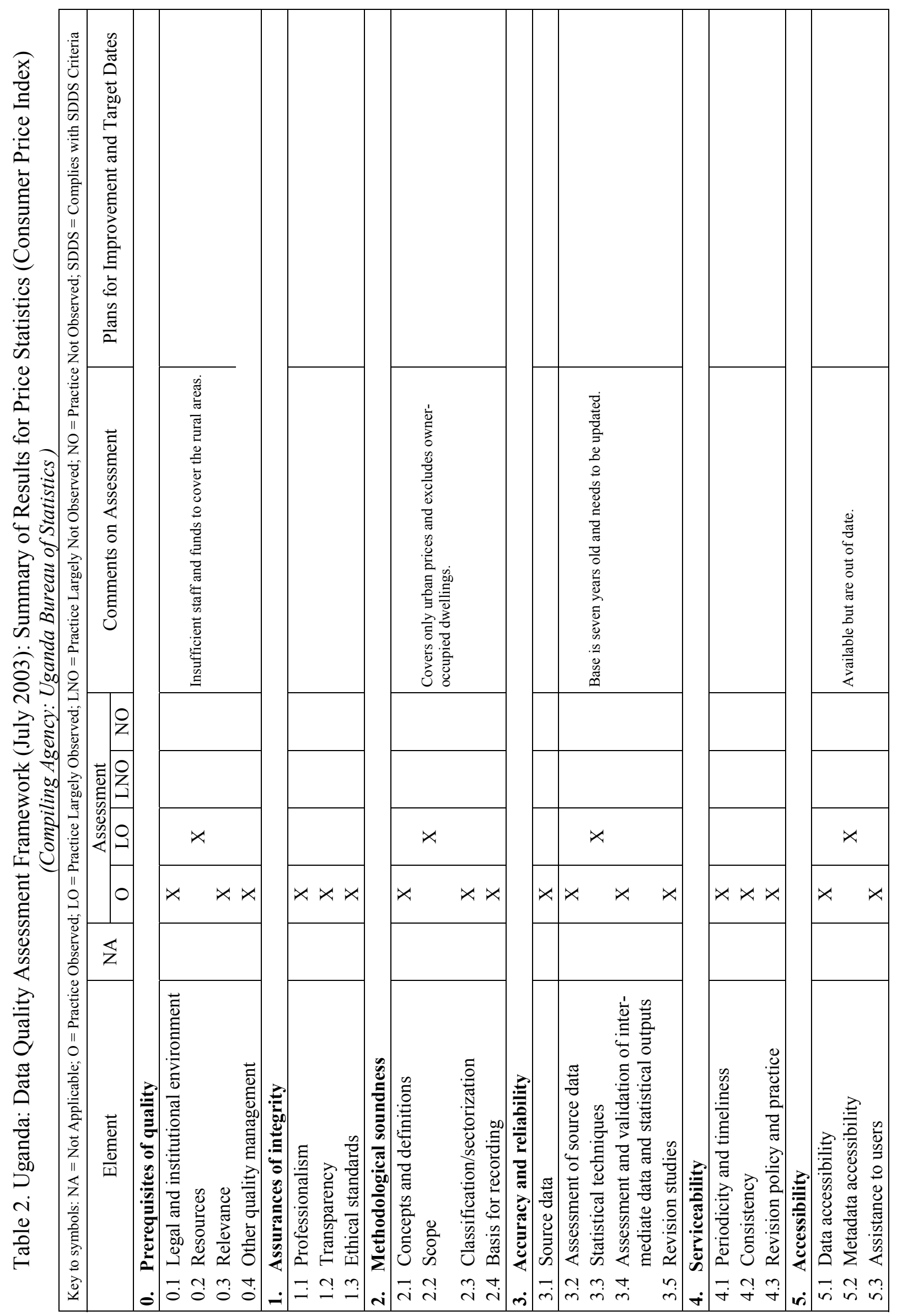




\section{GovernMENT FinANCE STATISTICS}

\section{Prerequisites of quality}

\subsection{Legal and institutional environment}

\subsubsection{The responsibility for collecting, processing, and disseminating the statistics is clearly specified}

The Uganda Bureau of Statistics (UBOS), as empowered by the Uganda Bureau of Statistics $A c t, 1998$, is the principal data collecting and disseminating agency responsible for coordinating, monitoring, and supervising the National Statistical System. Section 21 of the Statistics Act states UBOS can delegate authority to an institution to compile and disseminate specified statistical data. UBOS relies on the Ministry of Finance, Planning and Economic Development (MFPED) to compile and disseminate government finance statistics (GFS). No specific legal documents assign this responsibility.

The Public Finance and Accountability Act, 2003 assigns the responsibility to collect, process and disseminate data on Uganda's public finances to the Minister of Finance. The Act also stipulates that the Accountant-General prepare and submit to the Auditor-General and the Minister of Finance a full set of government accounts within a period of four months of the end of the reference year and the Auditor-General, within nine months after the end of the reference year, certify the accounts. The Act does not specifically mention GFS. The Ministerial Policy Statement for the MFPED for 2004-05 lists as one of the budget proposals for the financial year ending 2004-05 the data collection and analysis of the GFS. The Fiscal Section, Macroeconomic Policy Department of the MFPED, compiles and analyzes GFS using data collected under the Act.

\subsubsection{Data sharing and coordination among data-producing agencies are adequate}

The system of data sharing among the compiling agencies is generally adequate. The Statistics Act stipulates that UBOS should promote standardization in the collection, analysis, and publication of statistics to ensure uniformity in quality, coverage, and reliability of statistics information, and promote cooperation and rationalization among users and providers of statistics to avoid duplication of efforts and ensure optimal utilization of scarce resources.

A memorandum of understanding between the MFPED and the Bank of Uganda (BOU) on interagency cooperation provides for efficient data sharing between the two agencies. The coordination is enhanced through a number of interagency groups that promote consistency of methods and results, including:

- $\quad$ the Committee on External Debt that comprises the MFPED and the BOU and handles issues related to the external debt statistics, such as the reconciliation 
exercise, Heavily Indebted Poor Country Initiative (HIPC) receipt treatment, and technical arrears (meets every month);

- $\quad$ the Prayer Breakfast Group (the MFPED and the BOU) which during its weekly meetings handles balance of payments (BOP), national accounts, monetary, and fiscal issues;

- $\quad$ a monthly meeting on internal debt; and

- $\quad$ cash flow monthly meetings involving the Treasury Department, the Macroeconomic Policy Department, the BOU, the Uganda Revenue Authority, and the Ugandan Computer Services to review fiscal performance and reconcile data, where necessary.

\subsubsection{Individual reporters' data are to be kept confidential and used for statistical purposes only}

Data on government finances are protected under the Oath of Secrecy (Uganda Government Standing Orders 1992). The Integrated Financial Management System (IFMS) database is set up to protect the privacy of data for individual agencies, with agencies only having access to their own data.

\subsubsection{Statistical reporting is ensured through legal mandate and/or measures to encourage response}

A general legal mandate given to the Accountant-General ensures compliance with the requirement to provide information on government finances. The Public Finance and Accountability Act, 2003, (Section 7) provides the Accountant-General the right to request information from all government agencies as he may deem necessary to fulfill his duties and responsibilities. The Act requires each accounting officer to submit accounts for the financial year within three months of the end of each financial year to the Minister and the AuditorGeneral, with a copy to the Accountant-General. The Act also provides the AccountantGeneral with the authority to specify the format in which they should be presented.

\section{$0.2 \quad$ Resources}

0.2.1 Staff, facilities, computing resources, and financing are commensurate with statistical programs

Resources are adequate for the needs of most of the fiscal data programs, with sharing of staff during peak times. Resources are insufficient at this time to enable the annual compilation of GFS for extrabudgetary central government and the social security fund. Resources are also insufficient for compiling GFS aggregates and major components subannually for local government, extrabudgetary central government, and the social security fund at frequency requirements from A Manual on Government Finance Statistics 1986 (GFSM 1986). As the MFPED expands, resources, particularly accommodation, may come under pressure. 
The Accountant-General's Department has good quality staff, 44 of which are chartered accountants. Senior managers have tertiary qualifications and are very experienced. Staff members receive professional, orientation, and on-the-job training. The Government encourages the staff to undertake, and pays for, the continuous professional development courses provided by the Institute for Certified Public Accountants of Uganda.

Staff members of the Fiscal Section in the MFPED, who compile government fiscal data, are all qualified economists/statisticians with a number of them holding masters degrees in economics. The Government provides employees with opportunities to attend workshops, seminars, and training courses including IMF GFS courses. Employees are allowed to further their studies by entering higher training institutions while in employment.

All employees have access to their own personal computer with most internal communication being conducted by e-mail. At present, most of the source data are still in a hard copy format, and employees have to enter the data into the database and undertake compilation and analysis with the use of Excel. However, with the introduction of the IFMS, a wide area network and the automation of many processes will be established. Daily back ups are made of the database and stored off site. A disaster recovery plan has been developed and construction of an external site is to commence in approximately two months.

\subsubsection{Measures to ensure efficient use of resources are implemented}

Annual reviews of staff performance are conducted. Resources to produce accounting and GFS data are budgeted, measured, and reviewed annually. Monthly meetings are held to review activities. There is a specific allocation of resources for the compilation of GFS; however, it is subject to budget cuts in the case of underperformance of domestic revenues. The MFPED is considering the protection of resources for GFS against budget cuts.

\section{$0.3 \quad$ Relevance}

\subsubsection{The relevance and practical utility of existing statistics in meeting users' needs are monitored}

The main data users are the Macroeconomic Policy Department, Treasury Department, Inspectorate of the Accountant-General's Office, the BOU, UBOS, and the IMF. The data are used to monitor budget performance, fiscal analysis, liquidity management, and for external reporting. Subject to the needs of the major stakeholders, the Accountant-General's Department addresses new and emerging data requirements. The needs of users outside government, other than the IMF, are not monitored. 


\subsection{Other quality management}

\subsubsection{Processes are in place to focus on quality}

Processes are in place to ensure quality of the fiscal data. Meetings are held with all government accountants with an emphasis on quality. The MFPED, with the BOU and UBOS, has established committees to examine the quality of data and the interrelationships between datasets. Staff training emphasizes the importance of quality and how it can be achieved.

\subsubsection{Processes are in place to monitor the quality of the statistical program}

The collection and processing of government finance data is vested in the government accounting systems. The Public Finance and Accountability Act, 2003 specifies the appointment and duties of accounting officers for each agency. These officers are responsible for all revenue and expenditure of their specific budget lines, the reporting of them, and the establishment of effective internal control mechanisms and internal audit.

The Auditor-General has the responsibility to perform annual audits, examine financial reports, and report on the outcome. The annual audit reports are submitted to parliament.

\subsubsection{Processes are in place to deal with quality considerations in planning the statistical program}

There is no trade-off between timeliness and accuracy. Extra staff are brought in from the Debt Department and the Internal Audit Department during the peak period when the Accountant-General is preparing the final accounts. The Internal Audit staff focus on quality control. GFS data are compiled on a timely basis. However, there are delays in the dissemination of the data (see 4.1.2).

\section{Assurances of integrity}

\section{$1.1 \quad$ Professionalism}

\subsubsection{Statistics are produced on an impartial basis}

The Public Finance and Accountability Act, 2003 Section 33 (2) states that "the AuditorGeneral, in performing his or her functions, shall not be under the direction or control of any person or authority." The Public Finance and Accountability Regulations, 2003 provide for the strict application of accounting principles and control mechanisms. Fiscal statistics are compiled on an impartial basis using available sources, mainly data generated by the accounting system. 


\subsubsection{Choices of sources and statistical techniques as well as decisions about dissemination are informed solely by statistical considerations}

No statistical techniques are used in the compilation of fiscal data since all the data currently disseminated are obtained from actual accounting records prepared in accordance with The Public Finance and Accountability Act, 2003, The Public Finance and Accountability Regulations, 2003, and Treasury Accounting Instructions.

\subsubsection{The appropriate statistical entity is entitled to comment on erroneous interpretation and misuse of statistics}

The dissemination of government finance data in the publications of the MFPED, the BOU, and UBOS is accompanied by an analysis of the outcome of government finances that minimizes the possibility of misuse or erroneous interpretation. The officials in the MFPED responsible for the provision of government finance data to the other agencies also provide advice and explanations to these agencies for incorporation in the publication. Data misinterpretations or misuse of fiscal data are addressed through formal channels within the MFPED.

\subsection{Transparency}

\subsubsection{The terms and conditions under which statistics are collected, processed, and disseminated are available to the public}

The Public Finance and Accountability Act, 2003 is available to the public. The Act contains the general terms and conditions under which accounting data are collected and reported. Some of these terms are also disseminated on the IMF DSBB. However, no other documentation describing the process of collection, processing, and dissemination for GFS is available to the public either in hard copy or electronically.

\subsubsection{Internal governmental access to statistics prior to their release is publicly identified}

The MFPED, the BOU, and UBOS share data prior to release to undertake accuracy checks and data reconciliations to ensure accurate data are released. This process is not publicly identified.

\subsubsection{Products of statistical agencies/units are clearly identified as such}

Government finance data disseminated by the MFPED are shared with the BOU, UBOS, donors, the IMF, and the World Bank. The statistical tables released in the publications of the BOU and UBOS are accompanied by a footnote that discloses the source of the data. 
1.2.4 Advance notice is given of major changes in methodology, source data, and statistical techniques

Advance notice is given through the press or seminars of major changes in methodology, source data, and statistical techniques. The implementation of the IFMS, for example, has been advised through the press, seminars, and the MFPED website.

\subsection{Ethical standards}

\subsubsection{Guidelines for staff behavior are in place and are well known to the staff}

There is a Code of Conduct (Uganda Government Standing Orders 1992) for public servants, with which they are acquainted. In addition, staff who belong to professional organizations are guided by the ethics of such organizations. The MFPED is drafting a code of conduct based on the code of the U.S.A. internal audit regulator.

\section{Methodological soundness}

\subsection{Concepts and definitions}

\subsubsection{The overall structure in terms of concepts and definitions follows internationally accepted standards, guidelines, or good practices}

The concepts and definitions used in the compilation and dissemination of data for budgetary central government and local government are based on the recommendations of GFSM 1986. Migration from the GFSM 1986 to the Government Finance Statistics Manual 2001 (GFSM 2001) framework has started with some changes to methodology and the introduction of a new chart of accounts based on the classification of the GFSM 2001.

Detailed budgetary central government data are compiled for revenues and grants, expenditures and lending, and financing. Apart from the presentation of functional expenditures, the data are prepared broadly in accordance with GFSM 1986. The functional expenditure presentation reflects Uganda's own budgetary nomenclature and classifications and is not bridged to the functional classification recommended in the GFSM 1986. In some instances, Uganda has commenced migration of its methodology from GFSM 1986 to GFSM 2001:

- Interest payments and external loan repayments are recorded on a due-for-payment basis;

- $\quad$ Payments of arrears are recorded below the line;

- $\quad$ Sales of equity other than shares (privatization) are recorded below the line as a disposal of a financial asset; and 
- Grants in kind, and the equivalent disbursements thereof, are included in revenue (as grants) and current or capital expenditure, respectively.

Budgetary central government data also are prepared monthly on a cash flow statement basis for policy purposes. These data are compiled in a format recommended in GFSM 1986 but are presented in a modified format to suit the government's policy framework. A cash budgetary balance is derived as the difference between total domestic revenues and budget support and total locally funded expenditure, which encompasses recurrent and capital expenditures and net lending.

The MFPED compiles data on outstanding central government domestic debt stock monthly. Debt is classified by holder and by type of government debenture, or Treasury bills. Partial data, disseminated monthly by the BOU, include total central government outstanding nonbank domestic borrowing, and commercial bank and the BOU holdings of government securities. Data on the outstanding central government external debt are also provided.

The MFPED has undertaken a major exercise to compile GFS data for local government for the period 1997-98 to 2001-02. Using final accounts and additional information from all local governments (districts, municipalities, and town councils), the MFPED compiled consolidated data for local government, eliminating transfers between these units. Local governments completed spreadsheets providing additional detail to the final accounts to enable the MFPED to compile GFS. The MFPED intends to compile local government data annually. The exercise was partially undertaken in 2003-04 for the reference year 2002-03 but not completed due to budget constraints. The MFPED plans to finalize compilation of data for 2002-03 and embark on compiling data for 2003-04 in 2004-05. In the future, local government data will be compiled with a one-year lag. Local government data were reported to the IMF for the Government Finance Statistics Yearbook 2004 in accordance with GFSM 2001.

The Government of Uganda has introduced an IFMS, which is an automated information system designed to support the improvement of public sector budgeting, financial management and accounting. It will do this by providing timelier, transparent and accurate financial information that meets international standards. A new chart of accounts was implemented for use by all budgetary central government and local government units from July 1, 2004. The chart of accounts is closely aligned with the definitions and classifications of GFSM 2001. Currently, the new system is being pilot tested by a number of ministries and local governments. Reporting will continue on a cash basis with a move to accrual basis planned in the longer term.

In recent years, two IMF-GFS technical assistance missions have worked closely with the authorities on the new chart of accounts and the building of bridge tables to the GFS classifications. The MFPED commenced reporting to the IMF on the basis of GFSM 2001 for the Government Finance Statistics Yearbook 2004. The data were compiled on the GFSM 1986 basis and then converted to the GFSM 2001 basis using a bridge table. Reporting to the IMF for operational purposes is still on a GFSM 1986 basis. Dissemination 
of data by the MFPED on budgetary central government operations will continue on the basis of GFSM 1986 for the time being. As source data from July 1, 2004 are classified according to the new chart of accounts, GFS will be compiled on the GFSM 2001 basis and then converted to the GFSM 1986 basis using a bridge table.

\section{$2.2 \quad$ Scope}

\subsubsection{The scope is broadly consistent with internationally accepted standards, guidelines, or good practices}

The general government sector in Uganda consists of budgetary central government, extrabudgetary central government, the National Social Security Fund, and local government. GFS currently are compiled for budgetary central government and local government.

Data are available on most cash transactions of budgetary central government plus amounts for grants received in kind. Transactions (deposits and disbursements) associated with project aid accounts with commercial banks currently are not included in the fiscal operations data. There has been a change in government policy and from January 1, 2005 these funds must be deposited into project accounts at the BOU. A transition period of 18 months has been granted, by which time all project aid accounts must be transferred from commercial banks to the BOU. Transactions in the accounts with the BOU are regularly reported by the BOU to the MFPED.

The scope of the budgetary central government operations data as presented is broadly in accordance with the recommendations of GFSM 1986. However, a national functional expenditure classification is used instead of the Classification of the Functions of Government (COFOG) recommended in GFSM 1986.

Cash-based data for local government are available for the periods 1997-98 to 2001-02 in accordance with both GFSM 1986 and GFSM 2001.

In the longer term, the authorities plan to compile GFS data for extrabudgetary central government and the social security fund and to consolidate data for the central government and general government.

Data are provided on central government gross debt classified by residency (foreign/domestic) of the counterparty to the liabilities. Local governments are not authorized to incur debt. However, short-term borrowings that can be backed by their local revenues or unconditional grants may be allowed after clearance by the Ministry of Local Government.

Full coverage of budgetary central government and local government is achieved when GFS data are first compiled for a reference period. 


\subsection{Classification/sectorization}

\subsubsection{Classification/sectorization systems used are broadly consistent with internationally accepted standards, guidelines, or good practices}

Source data for revenue, expenditure, and financing transactions are classified in the new chart of accounts in accordance with the classifications of GFSM 2001. The chart of accounts provides for the detailed classification of transactions.

Data are presented in the format of GFSM 2001 for reporting to the IMF for the Government Finance Statistics Yearbook. However, the data are presented in a format broadly in accordance with GFSM 1986 in reporting to the IMF for operational purposes and in the MFPED publication Background to the Budget. These data are then used by the BOU and UBOS as source material for presentation of fiscal accounts in their publications. The fiscal accounts are compiled generally according to GFSM 1986. As noted previously in Section 2.2.1, a national functional expenditure classification is used for data currently disseminated. However, a bridge table has been prepared to enable classification and presentation of data in the future, according to COFOG.

The institutional structure of general government is in accordance with GFSM 1986. GFS data are provided separately for budgetary central government and local government.

\subsection{Basis for recording}

\subsubsection{Market prices are used to value flows and stocks}

Tax revenue is recorded on a collections basis, that is, when collections are receipted, while nontax revenue is recorded on a cash basis. Expenditure is recorded on a check-printed basis for central government expenditure and on a release basis for transfers to local governments and other institutions that receive block grants. Financing is recorded at the time the transfer of funds is recorded by the BOU. Domestic debt is recorded on a mixture of cost value (issue price) and face value by the banking system.

For amounts denominated in foreign currency:

- deposits are credited using the BOU "on spot" rate for that day;

- donor inflows, recorded in U.S. dollars, and debt servicing are converted to Ugandan shillings using the average monthly interbank rate; and

- debt liabilities, recorded in U.S. dollars, are converted to the national currency using the end of period rate. 
GFSM 1986 recommends that the transaction amounts denominated in foreign currency are converted to the national currency using the midpoint between the buying and selling market rates on the date of recording.

\subsubsection{Recording is done on an accrual basis}

Transactions are generally recorded on a cash basis for central government in accordance with GFSM 1986. Domestic interest payments are recorded on a due-for-payment basis. Local government activity is recorded on a cash basis by district councils and on an accruals basis by municipal and town councils.

\subsubsection{Grossing/netting procedures are broadly consistent with internationally accepted standards, guidelines, or good practices}

All transactions are shown on a gross basis, except for financing transactions and corrective transactions, such as refunds of taxes, which are shown net. These procedures are in accordance with GFSM 1986.

Net lending is recorded as prescribed in GFSM 1986, with repayments deducted from lending.

\section{Accuracy and reliability}

\subsection{Source data}

3.1.1 Source data are obtained from comprehensive data collection programs that take into account country-specific conditions

Data collection programs used to compile source data are comprehensive for revenue, expenditure, and financing of budgetary central government.

The Uganda Revenue Authority (URA) compiles data on tax and nontax revenue. Revenue data are provided to the Tax Policy Department, Directorate of Economic Affairs (MFPED), who pass the data to the Macroeconomic Policy Department (MFPED). The Trade and External Debt Department (BOU) advises the Macroeconomic Policy Department and the Accountant-General on timeliness of budget support disbursements.

Expenditure data for budgetary central government units are captured at three levels: releases (money transferred to agencies), checks printed, and checks cashed. Data compiled by the Ugandan Computer Services (MFPED) on checks printed are provided aggregated to the Fiscal Section of the Macroeconomic Policy Department. Releases data are used for transactions where no checks are issued. 
From January 1, 2005 project aid funds are required to be deposited with the BOU (see 2.2.1). Transactions in accounts with the BOU are captured by the MFPED systems. Data on the remaining project aid funds with the commercial banks are not collected.

Financing data are sourced from the monetary survey, the general ledger of the BOU, and the central depositary system for securities.

BOU compiles debt data. The Treasury will be responsible for the compilation of debt data in the future.

Data for local governments are sourced from the final audited accounts of each local government and supplementary information provided by the local governments.

Financial information is provided quarterly to the MFPED by extrabudgetary central government units and the National Social Security Fund. Audited financial accounts are submitted also to the MFPED.

The IFMS is currently being pilot tested by a number of ministries and local governments. From July 1, 2005, the IFMS will go live and will capture data electronically for all budgetary central government units and be pilot tested with 10 local government units. The new chart of accounts is closely aligned with the classifications of the GFSM 2001. IMFGFS technical assistance missions in recent years have worked with the authorities to develop bridge tables between the draft new chart of accounts and the GFS classifications.

A comprehensive register of individual general government units is maintained and updated annually by the Department of Public Service. However, the budget automatically captures any new units, and it is possible the list of units covered by the budget is more up-to-date than the list of the Department of Public Service.

\subsubsection{Source data reasonably approximate the definitions, scope, classifications, valuation, and time of recording required}

The source data for budgetary central government and local government are reported in accordance with the new chart of accounts, which was developed on the basis of the classifications of the GFSM 2001. The codes and definitions closely align with the GFS classifications and definitions. The new chart of accounts does not align with the GFSM 2001 functional classification of expenditure. However, a bridge table has been prepared for use with data reported under the IFMS.

A cash basis of recording is used in the present system and will be used initially in the IFMS. The authorities plan to move to an accruals basis in the future.

Extrabudgetary central government units and the National Social Security Fund report quarterly and annually to the MFPED. However, these units have their own charts of accounts, which are not consistent with the GFSM 1986 or GFSM 2001 classifications. 


\subsubsection{Source data are timely}

The source data on budgetary central government operations are timely. Monthly cash flow data are available in the second week following the reference month. The timeliness is expected to improve once all units are reporting on the IFMS. Revenue data are available on the fifteenth day after the reference period. Financing data are available one month after the reference period.

Annual transactions data are the sum of the months. Preliminary data are available two months after the reference year.

Budgetary central government units have to submit final accounts to the Accountant-General within three months of the reference year. Final audited data are available eight months after the reference year.

Local governments must submit final accounts to the Auditor-General within four months of the end of the financial year. Final audited data usually are available eight months after the reference year.

The source data for central government debt are timely with data available within two months of the end of the reference year.

\subsection{Assessment of source data}

\subsubsection{Source data - including censuses, sample surveys and administrative records-are routinely assessed, e.g., for coverage, sample error, response error, and nonsampling error; the results of the assessments are monitored and made available to guide statistical processes}

A number of manual cross-checks and reconciliations are routinely undertaken to check the accuracy of the source data. For expenditure, the Ugandan Computer Services, Treasury and Fiscal Section share the same classifications. If cross-checks by the Fiscal Section reveal an error in classification, the Ugandan Computer Services is contacted and adjustments are requested. For financing, consistency checks are made with banking data. The adjustment line between the overall deficit/surplus and financing is an indicator for compilers of the accuracy of the source data. For the final audited accounts, a comparison is made with resources, commitments and debt numbers and any discrepancies are discussed with the Auditor-General. For local government, contact may be made directly with the relevant units to resolve any discrepancies.

For the debt numbers, the MFPED undertakes a monthly reconciliation with the BOU. Actual payments are checked against scheduled payments and any differences in timing are queried. 


\subsection{Statistical techniques}

\subsubsection{Data compilation employs sound statistical techniques to deal with data sources}

Compilation procedures currently are manual. The introduction of the IFMS will automate many of the procedures. Projected data are replaced with preliminary data and then with final data for each reference period. If errors are identified, data will be corrected in the period in which the error occurred. As data are cash based, annual data are the sum of the monthly data.

Compilation procedures for cash flow estimates and local government finance statistics are documented in respective manuals.

\subsubsection{Other statistical procedures (e.g., data adjustments and transformations, and statistical analysis) employ sound statistical techniques}

Bridge tables have been prepared between the accounting and GFS classifications.

Data adjustments (for the check float and revenue in transit) are made to bring the overall deficit/surplus and financing into closer alignment. The basis for estimation of the split between project grants and loans for donor funds has been confirmed from examination of commitments data for several years.

\subsection{Assessment and validation of intermediate data and statistical outputs}

\subsubsection{Intermediate results are validated against other information where applicable}

The MFPED undertakes a range of checks against other information. Final accounts are audited. Total cash flows for the year are checked against audited data. Revenue receipted and deposited can be reconciled. Expenditure data are captured at three levels and reconciled. Actual debt payments are reconciled with scheduled debt payments.

\subsubsection{Statistical discrepancies in intermediate data are assessed and investigated}

The authorities involved in the compilation of the GFS are well aware of the discrepancies in data on government finance. Several committees, including a committee for "Government Finance Statistics Reconciliation," have been established to examine reconciliations and identify ways to improve the data. The replacement of manual procedures with the automated IFMS should minimize errors in the compilation.

A reconciliation of debt stocks and payments is undertaken. Data on revaluations are not captured. 


\subsubsection{Statistical discrepancies and other potential indicators of problems in statistical outputs are investigated}

Compilers check statistical outputs horizontally and vertically to reduce discrepancies. Values that are not within the expected ranges are identified and investigated.

Reconciliations are prepared and work has been undertaken by the authorities to identify the sources of the discrepancies. IMF-GFS technical assistance missions also have worked with the authorities on this issue.

\subsection{Revision studies}

\subsubsection{Studies and analyses of revisions are carried out routinely and used internally to inform statistical processes (see also 4.3.3)}

Revision studies are undertaken as part of the revisions process. However, an error identified in a subsequent year is corrected, using an adjustment line, in the annual data for the year in which the cash flows actually occurred. As the monthly cash flows are not revised, the revision is not carried through to the subannual data.

Revisions to budgetary central government data are documented by way of footnotes to compilation spreadsheets. Electronic and hard copies for each period are archived. For debt, revisions are documented on a paper file and summary files are archived.

\section{Serviceability}

\subsection{Periodicity and timeliness}

\subsubsection{Periodicity follows dissemination standards}

Cash flow statistics (broad aggregates only, which do not meet GDDS requirements) for budgetary central government operations are disseminated monthly in the BOU's Monthly Economic and Financial Indicators. Detailed monthly cash flow statistics on a GFSM 1986 basis are available on request. Aggregate GFS data on central government budgetary operations are released quarterly in the BOU's Quarterly Economic Report. Monthly data are summed to provide quarterly, half yearly, and annual data. The GDDS requirement for the release of statistics on central government budgetary operations quarterly is met.

Statistics for domestic central government debt are compiled monthly by the MFPED and disseminated quarterly in the BOU's Quarterly Economic Report. Statistics on external central government debt are disseminated annually in the MFPED's Background to the Budget. The GDDS requirement for the release of central government debt statistics annually is met. 


\subsubsection{Timeliness follows dissemination standards}

Monthly cash flow statistics (broad aggregates only, which do not meet GDDS requirements) for budgetary central government operations are disseminated approximately five weeks after the reference month. Despite timely compilation of GFS data, delays occur in the dissemination of the data. Quarterly budgetary operations data on a GFS basis are released in the BOU's Quarterly Economic Report. The latest issue available on the BOU's website is for June quarter 2004 and it includes data for March quarter 2004. The GDDS requirement for release within one quarter of the reference quarter is not being met.

Quarterly statistics for central government domestic and external debt are disseminated in the BOU's Quarterly Economic Report, with the latest quarter available being for March quarter 2004. Annual statistics for central government external debt are disseminated in the Background to the Budget 11 months after the reference year. This is not in accordance with the GDDS requirements because annual data for central government debt are required to be released within two quarters of the reference year.

\subsection{Consistency}

\subsubsection{Statistics are consistent within the dataset}

Major aggregates on budgetary central government operations such as revenue, grants, recurrent expenditure and development expenditure equal the sum of their respective components. The net result of revenue and grants minus expenditure (recurrent and development) and net lending equals the overall deficit/surplus. However, an adjustment line is added to financing to match the overall deficit/surplus. The discrepancy is due to a number of factors:

- differences in the time of recording. Transfers to local governments are recorded above-the-line on the basis of releases made, while the below-the-line data show the actual changes in bank balances;

- $\quad$ recording of externally financed development expenditure. No actual data are available on a monthly basis for externally financed development expenditure and actual annual data are only available about six months after the fiscal year end. As a result, the MFPED estimates the monthly expenditure. The below-the-line counterpart entries are the actual changes in the BOU and commercial account balances; and

- different foreign currency conversion rates are used for some above-the-line transactions compared to the below-the-line counterparts, for example, donor financing.

The MFPED makes adjustments to account for the difference in the timing of recording of expenditure data (the check float) and for revenue in transit. 
Monthly meetings of key stakeholders are held to discuss the budgetary central government monthly cash flow data and the implications for policy analysis (see 0.1.2).

Ugandan Computer Services (MFPED), which is responsible for the issuance of checks, and the BOU, which is responsible for the monetary survey, regularly meet to discuss the discrepancy.

Summation of the months is used to compile quarterly, half yearly and annual statistics, as the data are cash based. In the event that an error is discovered, a correction is made to the annual data for the year in which the cash flows actually occurred. The monthly cash flows are not revised. The revision is recorded in an adjustment line

The relationship between debt flows and stocks is monitored.

\subsubsection{Statistics are consistent or reconcilable over a reasonable period of time}

Consistent time series are available for:

- $\quad$ budgetary central government operations monthly cash flow series from 1997-98 and annual series for longer; and

- $\quad$ central government debt monthly for the last five years and annually for longer.

When changes are made to methodologies, the historical time series is reconstructed as far back as reasonably possible.

Detailed methodological notes are not prepared for changes to budgetary central government operations data. However, changes are footnoted in the compilation spreadsheets and in published tables. For central government debt, the changes are documented on paper files and footnoted in published tables.

Unusual changes in economic trends are explained in the commentary on fiscal statistics in relevant publications.

\subsubsection{Statistics are consistent or reconcilable with those obtained through other data sources and/or statistical frameworks}

The MFPED examines the consistency of GFS with banking sector transactions and debt flows and stocks. See the discussion in 4.2.1 above on the statistical discrepancy arising between revenue and expenditure and financing data.

Monthly reconciliations are made with BOU debt data. The MFPED has a schedule of debt repayments and checks this against actual payments. Discrepancies are investigated with the BOU. 
The Trade and External Debt Section (BOU) is responsible for the reconciliation of external debt data in the GFS and the BOP. Reconciliations are regularly prepared and discussed with the MFPED.

The dataset on budgetary central government operations is an input into the national accounts. These data are supplemented with data for extrabudgetary central government and local government obtained from various other sources. Statistics in the national accounts are therefore not reconcilable with those presented in the budgetary central government operations table.

A new committee recently has been established to undertake the reconciliation of the GFS with national accounts general government sector, to improve the accuracy of data, and monitor international standards. The committee members are from the MFPED, UBOS, the BOU, and the Auditor-General's Office. In particular, the committee is considering the rationalization of collection of data from local government.

\subsection{Revision policy and practice}

\subsubsection{Revisions follow a regular and transparent schedule}

There is no written policy on revisions. Revisions during the year are performed routinely and are incorporated in the disseminated data, with explanations provided in footnotes. The revisions policy and practices are not made public.

\subsubsection{Preliminary and/or revised data are clearly identified}

Projected, preliminary, final and revised data are clearly identified in publications tables.

\subsubsection{Studies and analyses of revisions are made public (see also 3.5.1)}

Studies and analyses of revisions are not disseminated to the public. Reasons for revisions are investigated and the revisions are footnoted on the relevant publication tables.

\section{Accessibility}

\subsection{Data accessibility}

\subsubsection{Statistics are presented in a way that facilitates proper interpretation and meaningful} comparisons (layout and clarity of text, tables, and charts)

There is no statutory requirement for the MFPED to publish data on either budgetary central government operations or central government debt.

The MFPED compiles GFS on the basis of GFSM 1986 and shares the data with the BOU and UBOS. A summary table, broadly in line with the GFSM 1986 Summary Table of Major 
Components, is disseminated by the MFPED, the BOU and UBOS. Detailed monthly cash flow GFS series are available on request from the MFPED. However, a current and capital split of revenue and expenditure classified according to the functional classification recommended in the GFSM 1986 are not available.

UBOS compiles and disseminates, in its annual Statistical Abstract, a range of detailed tables on revenue and expenditure of selected subsectors of the general government sector. The latest issue is for 2003.

The government and government-guaranteed foreign debt data are disseminated in the in MFPED publication the Background to the Budget and the Annual Report of the BOU. The data include external debt repayments, by principal and interest. A forward schedule of projected repayments is not published.

In the MFPED, the BOU and UBOS publications, time series (up to four years) are presented along with commentary, charts and graphs on government operations and debt.

\subsubsection{Dissemination media and format are adequate}

Data for budgetary central government operations are disseminated in electronic files and, in some instances, in hard copy. The electronic releases are available on the websites of the MFPED, the BOU, and UBOS. Some users have experienced problems assessing the files on the MFPED website. More detailed statistics are available on request in Excel spreadsheets. Analysis is provided in publications. No explanatory notes are provided with disseminated data.

The MFPED does not publish data for local government, but the data are available on request. Data for local government have been published by the IMF in the Government Finance Statistics Yearbook 2004.

\subsubsection{Statistics are released on a preannounced schedule}

The MFPED does not have a schedule announcing in advance the release dates for fiscal statistics. No press release is issued when publications are released or data are put up on the MFPED website. However, the budget process is available on the MFPED website and it identifies the months in which the Background to the Budget and budget outturn information are to be released.

The publications of UBOS and the BOU, which include the GFS, are not released to a preannounced schedule. 


\subsubsection{Statistics are made available to all users at the same time}

The statistics are not made available to all interested users simultaneously. The MFPED shares the data with the BOU and UBOS prior to release in order to reconcile the data with other datasets and to ensure accurate data are released to the public.

The press is not briefed in advance of releases.

\subsubsection{Statistics not routinely disseminated are made available upon request}

Detailed fiscal statistics are made available on request. Customized tabulations may be provided to meet specific requests. If publications are provided on request a fee may be charged. Otherwise, no fees are charged for fiscal statistics.

The availability of additional statistics and the procedures for obtaining them are not publicized. However, Ugandan government agencies are aware of the availability of additional data and the need to submit a formal request to the Permanent Secretary

(MFPED). The MFPED address is provided on the MFPED website to assist users wishing to contact the MFPED for additional statistics.

\subsection{Metadata accessibility}

5.2.1 Documentation on concepts, scope, classifications, basis of recording, data sources, and statistical techniques is available, and differences from internationally accepted standards, guidelines, or good practices are annotated

The GDDS metadata are limited as they contain only brief descriptions of concepts and classifications in use, and broadly describes departures from international standards. The GDDS metadata on GFS are reviewed and updated periodically. The metadata are available on the IMF's DSBB website.

The new chart of accounts, available on the MFPED website, provides a list of budgetary central government and local government units and detailed descriptors for each code for revenue, expense, assets and liabilities.

Manuals provide detailed metadata on cash flow and local government finance statistics for internal use.

\subsubsection{Levels of detail are adapted to the needs of the intended audience}

No general use or more specialized information on the GFS other than that disseminated on the DSBB is available to the public. 


\subsection{Assistance to users}

\subsubsection{Contact points for each subject field are publicized}

Prompt and knowledgeable service and support are available to users of the GFS.

No contact points are identified on statistical releases. However, the agency responsible for the compilation of the data is noted under each table released by the MFPED, the BOU and UBOS, and the address is provided for the agency releasing the publication.

5.3.2 Catalogs of publications, documents, and other services, including information on any charges, are widely available

A list of the MFPED publications is available on the MFPED website. There is no catalog of publications. 
- 54 -

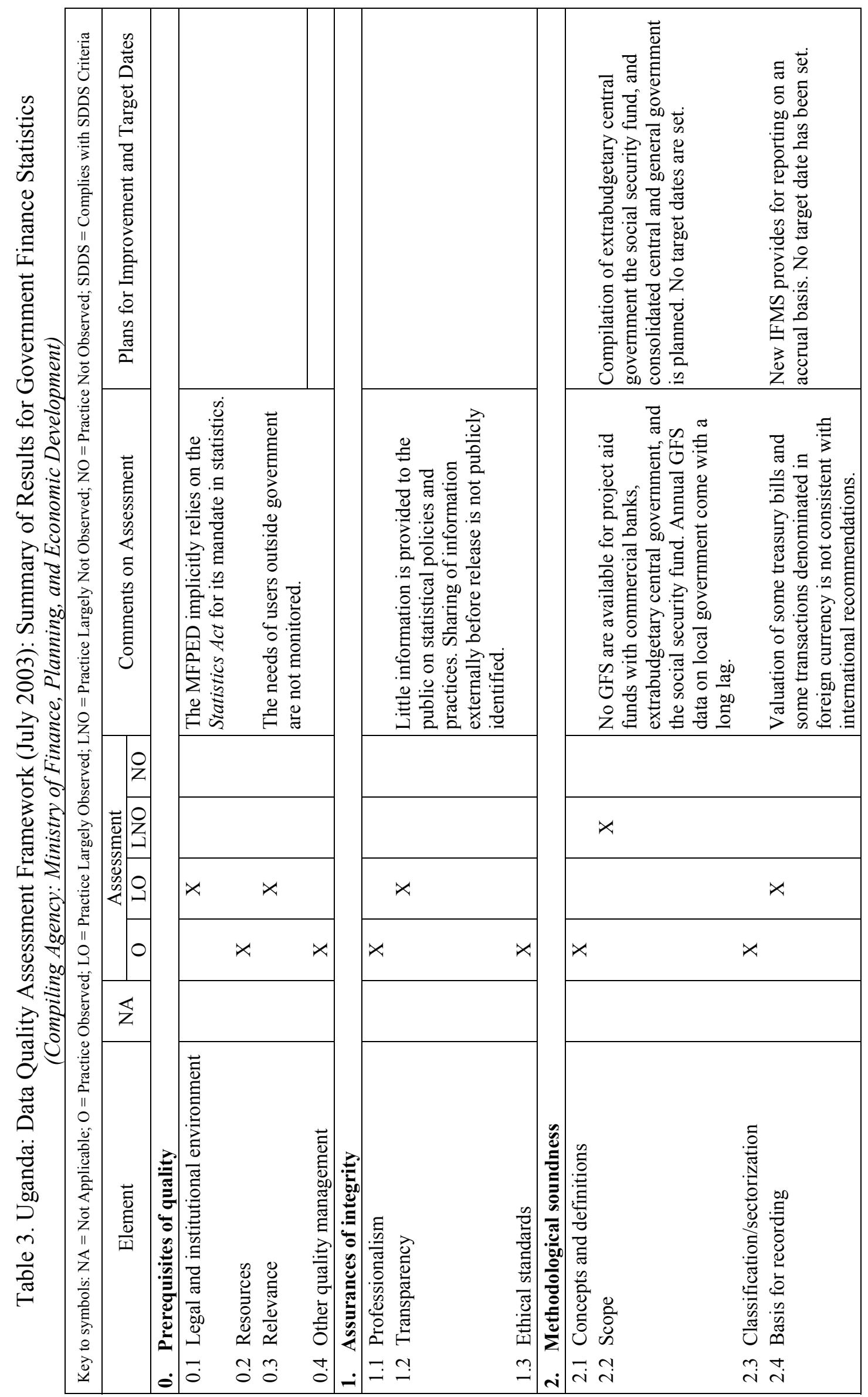


- 55 -

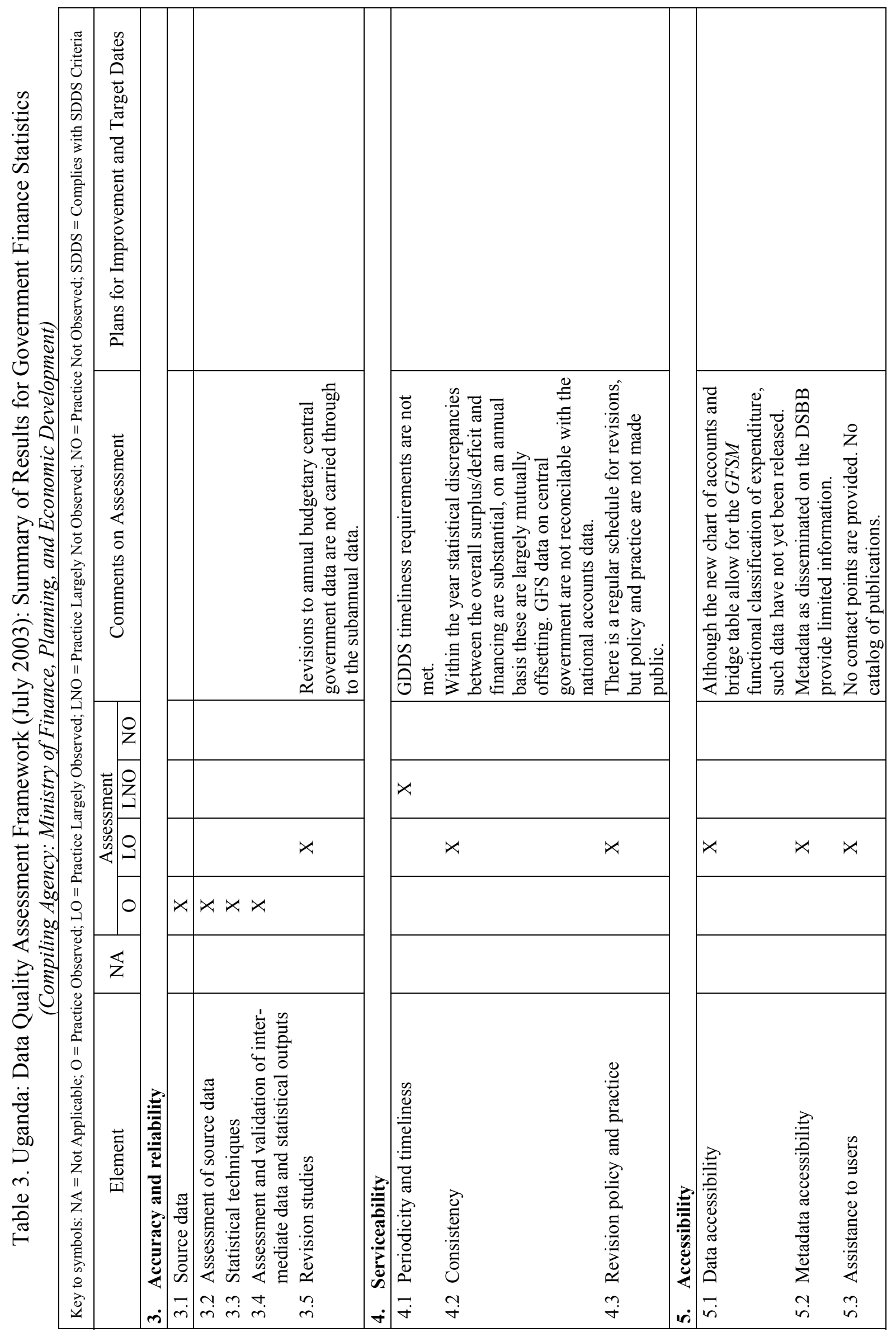




\section{Balance of Payments Statistics}

\section{Prerequisites of quality}

\section{$0.1 \quad$ Legal and institutional environment}

\subsubsection{The responsibility for collecting, processing, and disseminating the statistics is clearly specified}

No legal documents explicitly mention the responsibility of the Bank of Uganda (BOU) to compile and disseminate the balance of payments (BOP) statistics. The Bank of Uganda Statute, 1993 does not include collection and dissemination of statistics among its functions.

As empowered by the Uganda Bureau of Statistics Act, 1998 (Fourth Schedule), the Uganda Bureau of Statistics (UBOS) is responsible for collecting, compiling, analyzing, and disseminating the BOP statistics. Section 21 of the Statistics Act states UBOS can delegate authority to institutions to compile and disseminate specified statistical data. There is a memorandum of understanding signed between UBOS, the BOU, and the Uganda Revenue Authority (URA), in which UBOS delegated to the BOU the power to collect, compile, and disseminate monetary and external sector statistics.

According to Article 11(1) of the Foreign Exchange Act, 2004 the BOU may request any person in Uganda to furnish any information the BOU may require for the purpose of securing compliance with the provision of the Act. While the Foreign Exchange Act strengthened the BOU's ability to collect information, it does not provide for comprehensive collection of information for BOP statistics. Article 4 of the Act refers to foreign exchange transactions only; the Act apparently does not cover the need to collect information on the resident nonresident transactions in national currency.

Data dissemination functions are granted to the BOU by Article 41 (2) of the Bank of Uganda Statute, 1993 that states that the BOU may publish in whole or in part information furnished to it under subsection 1 as the Board may determine.

The BOU collects data for the BOP estimates from various data-producing agencies, including the Uganda Revenue Authority (URA), UBOS, the Ministry of Finance, Planning and Economic Development (MFPED), the Ministry of Trade, Tourism and Industry (MTTI), the Uganda Investment Authorities (UIA), the Uganda Coffee Development Authorities (UCDA), the Cotton Development Organization (CDO), the Civil Aviation Authority (CAA), the Uganda Electricity Distribution Company Ltd., the Kasese Cobalt Company Ltd., the Uganda Tea Authority (UTA), the Ministry of Agriculture, Animal Industry and Fisheries (MAAIF), and from the British-American Tobacco Company.

Within the BOU, the Balance of Payments Section (BOPS) of the Research Department compiles and disseminates the BOP statistics. The BOPS has relevant working arrangements with the Trade and External Debt Department (TEDD) and the External Operations 
Department (EOD) of the BOU, where many of the source data are received, processed, and aggregated.

\subsubsection{Data sharing and coordination among data-producing agencies are adequate}

The system of data sharing among the compiling agencies is generally adequate. Article 4 (1) of the Statistics Act stipulates that UBOS is responsible for coordinating, monitoring, and supervising the National Statistical System. UBOS should promote standardization in the collection, analysis, and publication of statistics to ensure uniformity in quality, coverage, and reliability of statistics information, and promote cooperation and rationalization among users and providers of statistics to avoid duplication of efforts and ensure optimal utilization of scarce resources.

No formal agreement on interagency cooperation provides for an efficient data sharing process between BOU and data-producing agencies other than UBOS and the URA. Article 1(Ivb) of the Memorandum of Understanding between the BOU, UBOS and the UIA contains a general statement, but it does not fully cover the total scheme of the BOP compilation. However, the coordination is enhanced through the following interagency groups that promote consistency of methods and results:

- the International Trade Statistics Committee (ITSC) that comprises the BOU, UBOS, the UCDA, the CDO, the UIA, the URA, the MFPED, and the MTTI, with terms of reference to ensure that the trade statistics remain a priority for the agencies that participate in the Committee, that they remain actively involved in identification of the sources for the international trade statistics, and to ensure adherence to international standards. Among issues recently being discussed by the ITSC are the results of the ad hoc review of the comprehensiveness and completeness of trade data at the Custom points of the eastern borders of Uganda and statistical treatment of the new arrangements within the East African Community (EAC);

- $\quad$ the Task Force on Trade Statistics (TFTS), established in March 2002 and accountable to the ITSC on the objective to improve coverage and accuracy of data on international trade in goods. One of the tasks of the TFTS is to establish and undertake a survey of informal cross-border trade (the TFTS conducts monthly meetings);

- the Committee on Tourism Statistics (CTS) consists of the BOU, the MTTI, UBOS, the CAA, Immigration Department, Uganda Tourism Board, Uganda Tourism Association, Uganda Wildlife Authority, Uganda Police, and the Office of the President. The main objective of the CTS is to design and undertake the tourism expenditure survey (ad hoc meetings are held when the biannual survey is conducted);

- $\quad$ the Working Group on Private Capital Flows (WGPCF) comprises the BOU, UBOS, the URA, Private Sector Foundation, Uganda Manufacturing Association, Economic 
Policy Research Centre, and the Uganda Bankers Association. The WGPCF consists of several technical subgroups and handles administrative and methodological work for the Private Capital Flow Survey (PCFS), including designing software and providing training (meeting of the technical subgroups are conducted monthly, meetings of the WGPCF - ad hoc);

- $\quad$ the Committee on External Debt comprises the BOU and the MFPED and handles issues related to the external debt statistics, such as the reconciliation exercise, the Heavily Indebted Poor Country Initiative (HIPC) receipt treatment, and technical arrears (meets every month); and

- $\quad$ the Prayer Breakfast Group (the BOU and the MFPED) during its weekly meetings handles BOP, national accounts, monetary, and fiscal issues.

\subsubsection{Individual reporters' data are to be kept confidential and used for statistical purposes only}

Confidentiality is assured to reporters by Article 41 (3) of the Bank of Uganda Statute, 1993, which states that the BOU shall not publish or disclose any information regarding the affairs of a financial institution or of a customer of financial institution, unless the consent of the institution or the customer is obtained. Article 46 of the Statute requires officers and employees of the BOU to make a declaration of secrecy with regard to any information obtained in the performance of their functions and prescribes substantial penalties for contravention of the declaration of secrecy.

The Mission Statement of the BOU, published on the BOU website, states that the BOU maintains appropriate confidentiality in all its transactions. The BOU has established confidentiality rules to prevent the residual disclosure of information.

The BOU Terms and Conditions of Services and Staff Regulations stipulates that strictest secrecy shall be observed by all employees in regard to information acquired in the course of their duties. An employee shall not allow any person to have access to the books or other documents belonging to the BOU, nor give information of any kind without obtaining the permission of the Governor (Chapter on Staff Regulations (9)). All employees shall be required to take an oath of secrecy before they become legally recognized as employees of the BOU (the BOU Administration Manual, Chapter 3(3.2)).

However, the International Transactions Reporting System (ITRS) forms are not used for statistics purposes only, as they are disclosed to the Supervision Department of the BOU. Copies of all ITRS reports are submitted to supervision on a regular basis. In addition, all changes to the ITRS forms should be made through (approved by) supervision. The BOU Financial Information Sharing Committee (FISC) monitors the reporting to the BOU. The FISC comprises the Commercial Banking Department (that undertakes a supervision function), the Non-Bank Financial Institutions Department, the TEDD, the Domestic Financial Market Department, and the Research Department. 


\subsubsection{Statistical reporting is ensured through legal mandate and/or measures to encourage response}

With regard to data compilation from financial institutions, Article 41, subsection 1 of the Bank of Uganda Statute, 1993 requires that every financial institution shall furnish to the $\mathrm{BOU}$, in a manner prescribed by statutory instrument, all information that may be required by the BOU for the proper discharge of its functions. Article 27 (1) of the Financial Institution Statute, 1993 (FIS) stipulates that financial institutions shall furnish to the BOU all information and data of its operations in Uganda at the time and in the form prescribed by the BOU. Article 52 of the FIS states that the BOU may, in consultation with the Minister of Finance, make regulations providing for reporting requirements by financial institutions to the BOU.

According to Article 27 (5) of the FIS, a financial institution that fails to provide information to the BOU is liable to a fine of 0.5 percent of the total deposit liabilities of the financial institution for each month of default. Article 53 (3) states that a manager of financial institution that gives any information which is false in answer to any request under the FIS is liable on conviction, to a fine of not less than one million shillings, or to imprisonment for a term not exceeding two years, or both.

With regard to data compilation from nonfinancial institutions, the BOU does not always receive the full cooperation of corporations in submitting accurate and timely reports. Compilers have experienced delays in submitting the reports, high nonresponse rates, and inaccurate reporting - situations that reflect a culture of nonreporting. The Foreign Exchange $A c t, 2004$ identifies a number of enforcement procedures for use in cases where there is a violation of the Act on the provision of information (Article 11(3)). There are sizeable penalties for violations of the Act (Article 17(1)). However, regulations for its implementation are yet to be issued (it is expected to be completed by the end of 2005).

The BOU carefully considers the response burden by adjusting the report forms to the applied accounting standards. BOPS staff assist to respondents via shared BOPS e-mail box and visit to all commercial banks (15 banks) once a year. At the time that new report forms were introduced, there was one training session with the banks and foreign exchange bureaus. All planned seminars and workshops for commercial banks were put on hold in anticipation of enhanced authority of the BOU to collect information that will be stipulated by the regulations of the Foreign Exchange Act.

\section{$0.2 \quad$ Resources}

\subsubsection{Staff, facilities, computing resources, and financing are commensurate with statistical programs}

Despite the fact that the BOPS has expanded in recent years, the current number of staff is not entirely adequate to meet the operational needs for compilation of the BOP statistics. At present, there are four permanent staff in the BOPS, as one person is temporarily reassigned 
to other duties. All BOPS staff are university-trained professionals. An additional 23 staff in the TEDD provide BOPS with source data. Only one staff member has five years' experience in BOP compilation and was trained at the IMF's BOP courses in Washington. The remaining three staff members have less than two years of experience and did not receive any formal training in BOP methodology and compilation. There is a problem of high staff turnover at the BOU.

Computing resources are adequate and are well utilized in achieving efficient data collection and compilation procedures. All staff members of the BOPS have personal computers that are connected to the local area network and to the Internet. However, there is a need for a software to analyze the time series, as currently analysis is carried out primarily in Excel.

It appears that currently some budgetary constraints impede data collection, compilation, and dissemination of BOP statistics (delays in BOP publication were caused by lack of financing for the specific financial year). The financial resources to conduct surveys are available, providing they were secured through the one-year planning mechanism. The collection program can be adjusted to emerging needs.

\subsubsection{Measures to ensure efficient use of resources are implemented}

The BOU put in place an effective mechanism to enhance staff performance and productivity. The core of this process is the staff performance appraisal system with the list of competencies to be used in appraising staff performance, determining suitability for promotion, and identifying training and development needs. The BOU Competence Dictionary contains the description of required competencies, such as motivation, analytical thinking, commitment to work, knowledge, time management, leadership, and team work.

To improve the efficiency, consistency is promoted of concepts and methodologies across the different departments within the BOU. The future work plan of the Research Department is included in the annual Strategic Plan of the BOU, which allows for the prioritization of work plans and the development of annual work programs to be accommodated within existing budget allocations. The Research Department carries out a quarterly evaluation of the tasks and work actions against the Strategic Plan, and takes actions as needed.

\subsection{Relevance}

\subsubsection{The relevance and practical utility of existing statistics in meeting users' needs are monitored}

The Mission Statement of the BOU, published on the website, stipulates that the BOU is committed to fulfilling the need of the public and takes pride in offering the best services to customers.

The Prayer Breakfast Group is performing the role of advisory committee for BOP compilation and outlines new data requirements. Users feedback is actively sought via the 
monthly forum of executives of the commercial banks organized by the Uganda Banks Associations, with participation of the BOU. The BOU Research Department and Public Relations Department meet weekly with media, seeking users' views.

To identify emerging data requirements, the Financial Market Operation Committee (FMOC) that comprises External Sector Policies Division and Investment Division in External Operation Department, monitors market developments, has daily discussions, and shares the findings with BOPS staff. The Executive Director of the Research Function participates in the annual meetings of the IMF Committee on Balance of Payments Statistics. Data users are informed on the periodicity and timeliness of the BOP data through the GDDS website, which is linked to the national website.

\subsection{Other quality management}

\subsubsection{Processes are in place to focus on quality}

The Governor of the BOU emphasizes the need of accurate and reliable statistics for informing the policymaking process during his meeting with the public. The management of the BOU recognizes the trade-off between timeliness and accuracy and reliability in the development of its work plans, and the quality of BOP data as a function of coverage and timeliness of source data. As a result, there are preliminary reports subject to revisions, but annual reports can be delayed to the time of arrival of more reliable data sources. Annual internal training seminars are emphasizing quality.

\subsubsection{Processes are in place to monitor the quality of the statistical program}

Although no documentation exists that would facilitate consistent quality review procedures at the various stages of collecting, processing, and disseminating data, reviews are undertaken to identify problems at some stages of data collection. In addition, one of the core functions of the Prayer Breakfast Group is to review the numbers and monitor data, especially in preparation to the IMF Article IV consultations. The BOU also provides quarterly reports to the IMF on the implementation of its work plan to indicate what has been achieved and what problems have been encountered in meeting the deadlines.

\subsubsection{Processes are in place to deal with quality considerations in planning the statistical program}

The BOPS contributes to the BOU annual Strategic Plan, based on the action plan from the IMF technical assistance mission report that outlines the required quality standards and emerging data requirements. 


\section{Assurances of integrity}

\subsection{Professionalism}

\subsubsection{Statistics are produced on an impartial basis}

The Mission Statement of the BOU, published on the BOU website, states that the BOU rigorously upholds integrity in all its activities.

The activities of the Bank of Uganda are governed by the Bank of Uganda Statute, 1993 that states in Article 8 that the governing body of the BOU is a Board of Directors. A person may be appointed a director if he/she has recognized qualification in economic, financial, business, or banking experience (Article 9). A governor shall be a person of recognized financial or banking experience and shall be appointed by the President on the advice of the Cabinet (Article 28).

Chapter 3 (3.1) of the BOU Administration Manual states that the BOU shall attract, motivate and retain the right people, with the right knowledge, skills, attitude, and behavioral characteristics. The BOU employs rigorous selection mechanisms with the established minimum qualification requirements for each category of employees, written and practical tests, interviews by the interview panel, and a probationary period of not less than 6 months.

BOU staff are encouraged to undertake research and analysis and produce relevant publications. The following are recent publications related to the BOP compilation issues: Compiling Trade in Services in Fully Liberalized Developing Country: the Case of Uganda; Foreign Direct Investment Flows in Sub-Saharan Africa; The HIPC Initiative in East Africa: Implication to Debt Sustainability and Poverty Reduction (some of these publications are available on the BOU website).

\subsubsection{Choices of sources and statistical techniques as well as decisions about dissemination are informed solely by statistical considerations}

The choice of source data and statistical techniques for the BOP is made by the BOPS staff and is based on statistical considerations only. The BOP staff work closely with their colleagues in TEDD. Moreover, the interagency groups can also advise in the choice of sources and the introduction of new methodological changes. The selection and design of surveys are based solely on statistical considerations, taking into account international recommendations. The advice can be made in conjunction with other institutions represented in the relevant interagency group, as has been the case with the PCFS.

\subsubsection{The appropriate statistical entity is entitled to comment on erroneous interpretation and misuse of statistics}

When there is an erroneous interpretation, the BOPS, through the BOU Public Relation Department, provides comments and clarifications to the media. 


\subsection{Transparency}

\subsubsection{The terms and conditions under which statistics are collected, processed, and disseminated are available to the public}

The BOP methodology and compilation methods, as well as the BOU legislative documents, are available on the BOU website http://www.bou.go.ug. In addition, the terms and conditions under which the BOP statistics are compiled are shown in the GDDS metadata on the DSBB.

\subsubsection{Internal governmental access to statistics prior to their release is publicly identified}

There is no internal governmental or other public access to the BOP statistics prior to their release. This fact is made available to the public via the IMF's DSBB website which is available on the national website.

\subsubsection{Products of statistical agencies/units are clearly identified as such}

The BOU Quarterly Economic Report, and BOU Annual Report, in which BOP statistics are published, are clearly identified as a product of the BOU by name and by logo. The BOP data published in UBOS Statistics Abstract are attributed to the BOU. However, in the BOU's statistical publications, there is no request to provide the source reference when statistics compiled by the BOU are used or reproduced.

\subsubsection{Advance notice is given of major changes in methodology, source data, and statistical techniques}

Revisions are indicated in the BOU's publications. The BOU has not yet developed the standard procedure of giving advance notice of major changes in methodology or informing the public of new statistical collections in its statistical series, but is considering providing such notice in the future in its publications and on its website.

\subsection{Ethical standards}

\subsubsection{Guidelines for staff behavior are in place and are well known to the staff}

The BOU Terms and Conditions of Services and Staff Regulations states that employees are required to perform their duties with diligence and loyalty to obey implicitly the directions of their superiors, and to treat public and their colleagues with civility and courtesy. The employees are required to have a detailed knowledge of these staff regulations, as ignorance of their content will not be accepted as an excuse for noncompliance (Chapter on Staff Regulations (1)). It is required that periodic reports be submitted on the work and conduct of all employees. An employee whose work or conduct falls short of the required standards after suitable warnings renders himself liable to dismissal. All employees whose conduct appears 
to require investigation may be suspended from the service, and salary may be wholly or partly withheld during such suspension (Chapter on Terms and Conditions of Services $(8,9)$ ).

The BOU Administration Manual (on the BOU Intranet website), Chapter I, General Rules and Regulations maintains clear ethical guidelines. Memoranda from the Human Resources Department are sent regularly to the staff to remind them of the ethical standards.

\section{Methodological soundness}

\subsection{Concepts and definitions}

\subsubsection{The overall structure in terms of concepts and definitions follows internationally accepted standards, guidelines, or good practices}

Since 1997, Uganda has been gradually adopting the conceptual framework and classification structure recommended in the fifth edition of the Balance of Payments Manual (BPM5). The BOP current and financial accounts clearly distinguish between the income component and the goods and services components, separately record transactions in assets and transactions in liabilities, and apply a directional principle of recording the foreign direct investment (FDI) component.

However, in the BOP statement the capital account is not clearly defined. As a result, the HIPC debt forgiveness is shown as a below-the-line financing item in the analytical presentation, but not recorded in the capital account. In addition, the content of the net errors and omissions is unclear, as no explicit statistical discrepancy has been reported in the balance of payment statement (except for government sector transactions). The net errors and omissions component is indistinguishably included in the other investment assets, currency and deposits of other sectors component.

The definitions, for example, the definition of residency given in the Foreign Exchange Act, 2004 (Part I(3)) and a definition of FDI given in the Survey on Foreign Private Capital, 2004 (Part D(14)), broadly conform with the BPM5. However, while the application of the ITRS is limited, it is built on reports of foreign exchange transactions, where the BOP transactions represent only the foreign exchange transactions between residents and nonresidents, while transactions between residents and nonresidents in shillings are not included.

It is presumed that all construction projects are long-term. Therefore, data on expenditures for construction activity are recorded under the foreign direct investment component that may include both projects (i) completed within one year, which would generally be classified as services, and (ii) projects that require more than one year to complete.

In addition, the Bank of Uganda Statute, 1993, Article 32(Ib(i)) states that the time deposits of the central bank are regarded as part of the country's gross international reserves, which 
may not necessarily meet the availability for use (the immediate usability) criteria of the BPM5 definition of the reserve assets component.

\subsection{Scope}

\subsubsection{The scope is broadly consistent with internationally accepted standards, guidelines, or good practices}

Geographic Coverage: The economic territory is defined as consisting of the geographic territory administrated by government of Uganda. It includes islands that belong to Uganda, airspace, and waters. The BOP data cover the whole territory of Uganda and its embassies abroad.

Unit Coverage: Basically, all resident institutional units engaged in transactions with nonresidents are covered.

Transaction Coverage: Besides the limitations of the ITRS described above, in principle, all transactions with nonresidents are covered. However, coverage of the data is incomplete for the following components:

Services: Export of freight and import of passenger transportation are not covered in the data. The travel debit component, while assumed to be small, is not covered.

Income: No interest credits estimates are recorded for general government. However, interest is earned on some privatizations to nonresidents when there is a balance outstanding. This information is available from the Privatization Unit of MFPED. No interest credits estimates are made for other sectors. Compensation of employees credit is not covered.

There is information about at least two companies with investments abroad; however, no estimates of direct investment abroad and no estimates for direct investment income credits are recorded.

Currently, there are no estimates of the portfolio investment, assets component, and there are no estimates of financial derivatives flows, either debits or credits. However, it appears that the commercial banks are undertaking forward contracts with nonresidents. This information should be obtained from the banks and, if significant, classified to financial derivatives: assets or liabilities.

From time to time, the BOU holds some amounts of Kenyan and Tanzanian shillings, in the form of currency notes. When these are returned to the central banks of Kenya and Tanzania, the currencies are converted into U.S. dollars and included in reserve assets. However, there are no estimates for other investment assets, currency and deposits of monetary authorities component. 


\subsection{Classification/sectorization}

\subsubsection{Classification/sectorization systems used are broadly consistent with internationally accepted standards, guidelines, or good practices}

The current account records transactions in goods (exports and imports of goods), services (transportation, travel, and other business services), income (direct, portfolio, and other investment income, compensation of employees), and current transfers (with a breakdown by general government and private sector). About 30 percent of unidentified outflows debits (from private sector cash flows estimates) are added to other services. The adjustment may add as much as 33 percent to the original estimate for identified services debits. Transfers (specifically grants and debt forgiveness) are not disaggregated into current and capital transfers. No proper split is available for the compensation of employees and workers' remittances components.

The financial account is compiled with a breakdown by direct investment, portfolio investment, and other investment components. Other investment is disaggregated by trade credits, loans, currency and deposits, and other. Transactions of the BOU in foreign currencies are recorded under reserves, which has provisions for a breakdown by monetary gold, SDRs, and foreign exchange.

Four sectors are distinguished in the BOP statistics: monetary authorities, general government, banks, and other sectors. Loans guaranteed by the government are not classified to other sectors, as required. To the extent the guarantee is called, the debt would then be that of the government.

\subsection{Basis for recording}

\subsubsection{Market prices are used to value flows and stocks}

The BOP data are compiled in millions of U.S. dollars. Transactions denominated in other currencies are converted into U.S. dollars using the mid-rate weighted average exchange rate for the month, calculated from the current official exchange rate quotations.

In general, transactions are valued at market prices. Services are valued at the price paid for the services provided. The book value is used for recording the foreign direct investment transactions. Market price is used for portfolio investment transactions for seven companies listed on the Stock Exchange (such as Uganda Clays and Bank of Baroda), and a cost value (issue price with the capitalized interest) is used for recording transactions in securities issued at a price that is at a discount to the redemption price, and which also make annual interest payments. 


\subsubsection{Recording is done on an accrual basis}

Most of the BOP is prepared on a cash, not an accrual, basis. For the transactions collected through the ITRS, it is designed in a way that does not allow capture of the transactions following the change of ownership principle. For instance, receipts for service exports are recorded when the exporter sells the foreign exchange to the commercial bank. Accrual of interest costs on a straight-line basis is applied for recording income on debt securities. The other investment income for loans of general government is recorded on a due-for-payments basis.

In principle, goods are valued f.o.b. but, in practice, a mix of valuations of ex-factory, free on rail and truck, as well as f.o.b. is used for recording export of goods component.

\subsubsection{Grossing/netting procedures are broadly consistent with internationally accepted standards, guidelines, or good practices}

Following recommendations of the BPM5, the current and capital account transactions are recorded gross while financial account transactions are recorded net, separately for the individual asset and liability components. However, in the BOP statement dividends are recorded net (rather than gross) of taxes withheld. The issue will be addressed in the design of new survey questionnaire.

\section{Accuracy and reliability}

\subsection{Source data}

\subsubsection{Source data are obtained from comprehensive data collection programs that take into account country-specific conditions}

The data collection program to compile the BOP statistics is evolving. The BOU employs a collection program that is comprised of several surveys, such as the PCFS, surveys of the enterprises engaged in international trade in services, and the ITRS. Data from these sources are supplemented with information from the Customs Department of the URA on the international merchandise trade statistics, administrative data from the ministries and other government institutions responsible for exports, data on the government's external liabilities, and information on the government's external transactions from the MFPED and the BOU data for monetary and financial statistics.

Data sources are not entirely adequate for most parts of the BOP. There are some conflicting data sources, and for some series the data are projected forward from a data source that is several years' out-of-date. The BOP survey framework is developing. The surveys are based on the business register, and most of the survey forms are thoughtfully designed. However, some of them are cumbersome, attempting to accommodate several tasks in one survey questionnaire. As a result, the response rate for some crucial surveys (such as PCFS) is low, and many surveys fail to meet the timeliness and periodicity for the proper BOP compilation. 
The ITRS, based on the foreign exchange records, needs substantial improvements and redesign. The banks report only some transactions between residents and nonresidents in foreign exchange. The accuracy of data is low. There is substantial underreporting as well as misreporting, because the commercial banks often do not know the precise purpose of a transaction but are nevertheless required to categorize them in the monthly return. No data are compiled from the enterprises on the transactions through their accounts with banks abroad.

Data obtained from customs is not entirely accurate owing to (i) under-declaration of the value of imports by some importers, (ii) smuggling, and (iii) omission of classified imports (mainly military hardware and equipment).

The data sources for the specific BOP components are listed below.

Goods: Trade statistics are derived mainly from customs documents for exports and imports (from the single bill of entry - the SBE) obtained from URA and processed by both UBOS and the BOU. These data are supplemented by a variety of other data sources for exports, mostly from administrative sources. For exports, data are supplied by (i) individual exporters associations (for tobacco, electricity, and cobalt); (ii) industry organizations (such as the UCDA, UTA, and CDO); and (iii) government institutions (for fish from the MAAIF, and the CAA for gold, flowers, and sundry perishables). Import source data are augmented by the records from the authorized foreign exchange dealers (commercial banks and foreign exchange bureaus). Data on the oil import are collected by the URA from the oil companies.

Transportation: Passenger services (credits) estimates are based on data derived from an outdated survey done in 1993-94 from which extrapolations have been made using assumed annual growth rates of the transport sector based on projected developments in the sector. There no estimates made for freight credits. Debit entries estimates are based on the f.o.b. adjustments. However, a survey for passenger transportation (both credits and debits) was carried out between November 2004 and January 2005 for resident bus companies (2), resident airlines (3), nonresident airlines (9), and nonresident bus companies (3). The outcome is not yet incorporated into the BOP statement.

Travel: Credit entries are based on the results of the MTTI survey on the average length of stay and average expenditure per visitor to Uganda that is conducted biannually, together with information on the numbers of visitors received from the Department of Immigration, Ministry of Internal Affairs. The BOU and MTTI have agreed on the definition of residency for the survey questionnaire. The problem remains computing the average expenditure per traveler (BOP compilers assessment is too high because the sample taken concentrated on the ports of exit for people leaving through airports, which is the highest expenditure group.) The BOU makes an adjustments to the survey results. There is also a survey of education institutions, the results of which were processed; the second one is planned for JuneSeptember 2005. 
For debit entries, a the new questionnaire is designed for arrivals of resident from abroad (through airports and by roads). There are currently no travel debits, but there are plans to undertake yearly survey and to consider seasonality.

Communications: Communication services data are based on a quarterly survey of communications providers (three telephone companies, twelve postal companies, and seven internet service providers. The response rate has been adequate (seven out of eight main companies have provided data).

Insurance services: Credit entries are based on the surveys of the insurance companies. Freight insurance debits are obtained by adjusting imports from c.i.f. values to f.o.b.

Financial services: The ITRS is used as a main source for this component.

Other business services: Other services (debits) are a combination of results from the ITRS and estimates based on the returns from the commercial banks and foreign exchange bureaus. These include all unidentified services, which is a percentage of the total unidentified uses of sales of foreign exchange.

Government, n.i.e.: Debit entries on government services not included elsewhere are provided by the BOU Operations Department and the MFPED. For credit entries, a survey of the embassies in Kampala is conducted. The response rate to this survey is very low.

Compensation of employees: Debit entries are estimated based on data on technical assistance attributed to government projects and obtained from the MFPED. Compensation of employees debit as well as workers remittances outflow are yet to be captured. Registration with the Immigration Department of the Ministry of Internal Affairs is planned to be used as a starting point for estimates.

Direct investment income: There are no estimates for credits entries. Debit entries are estimated based on the results of the PCFS.

Portfolio investment income: There are no credit estimates for portfolio investment income. Debit estimates for portfolio investment income are obtained from the Central Depository System of the BOU for interest earned on money market instruments and government bonds.

Other investment income: Estimates are based on the BOU accounting data augmented by data of commercial banks' profit and loss statements and balance sheets, which are submitted to the BOU quarterly.

Current transfers: Estimates are based on administrative data from the MFPED on budget and project grants and loans. For private transfers credits, the estimates based on unidentified balance of foreign exchange credit transactions is used. 
Direct investment: The results of PCFS 2003 (for 2001 data) are used adjusted with nominal GDP growth for the relevant periods. The composition of direct investment has been changed, in line with the results of the PCFS 2003. Previously, all inflows of direct investment were assumed to be equity. The PCFS indicated that about 60 percent of inflows are debt. In addition, in light of the results of the PCFS, reinvested earnings have been adjusted upwards because the previously derived figure had been held constant (at a very low level) since 1997.The results of the Private Sector Investment Survey (2004) for the 2001-03 data are yet to be finalized. In addition, information from the UIA on planned foreign direct investment in Uganda is used to update a survey list.

Portfolio investment: Estimates for debt securities are obtained from the Central Depository System at the BOU.

Other investment: Trade credits inflows are estimated for the other sectors of the economy (excluding general government and the monetary authority); information on other investment for general government is obtained from the MFPED and the TEDD. These include disbursements of new loans both budget and project support and repayments of principal. Information on monetary authority (other investment) is available at the BOU. This comprises the use of Fund credit and loans from the Fund.

Reserve assets: Data are derived from balance sheets of the BOU.

\subsubsection{Source data reasonably approximate the definitions, scope, classifications, valuation, and time of recording required}

The following specific procedures have been developed to adjust data from various sources:

Custom data are adjusted to include (i) informal trade (including those transported by ferry across Lake Victoria); (ii) imports or exports of small values (below $\$ 1,000$ ) that are not captured by URA; (iii) goods imported in small installments, for which an average rate for container that contains a composition of different goods is provided by URA; and (iv) for custom documents that has not been processed for technical reasons.

The PCFS survey questionnaire design has been recently modified to align with the BPM5 classification.

\subsubsection{Source data are timely}

The timeliness of source data is not always adequate. The customs authority (URA) provides the TEDD, monthly, with information on imports, with an approximate lag of 15 days after the reference month. The data from ministries are coming every month within two weeks. Daily and monthly reports by commercial banks and monthly returns by foreign exchange bureaus are timely. Administrative data are timely. However, most survey data are not timely. MTTI's survey of expenditures by visitors to Uganda is submitted with the lag of six 
months, the quarterly survey of communications providers has a three-month lag, and the PCFS comes with a one-year lag.

\subsection{Assessment of source data}

3.2.1 Source data - including censuses, sample surveys and administrative records-are routinely assessed, e.g., for coverage, sample error, response error, and nonsampling error; the results of the assessments are monitored and made available to guide statistical processes

Monthly data on imports are reviewed by the TEDD to place them on a BOP basis, as well as to check them for accuracy. There are major underreporting problems in URA statistics. As a result, adjustments are made to both imports and exports by the BOU. For consistency checks of data from the Customs Department, several other data sources for some export items are used. In case of differences in the export figures, compilers use the data from development authorities and associations for the major export crops, major industrial producers and miners, line ministries, and civil aviation authority, which are considered to be superior to those obtained from the Customs Department

The ITRS electronic data verification and processing are yet to be completed. Monthly aggregates are checked through daily returns, and large transactions are verified. BOPS produces monthly reports on the editing and checking procedure results.

An assessment of survey results is made. Some imputations are done with data on enterprises' income statements and published balance sheets.

\subsection{Statistical techniques}

\subsubsection{Data compilation employs sound statistical techniques to deal with data sources}

The data compilation procedures used by the BOU to compile the BOP statistics are reasonably sound.

The survey data are processed by the BOU using a customized MS-Access application. Data at all stages of the survey exercise are verified against a set of control indicators. Both external and internal checks are employed in the source data validations including on-site and off-site editing carried out by enumerators. The editing procedures include checks on the internal inconsistencies in data, missing data (gaps), exchange rate conversion, and completeness in recording entries. The data editing procedures are followed by source data analysis at the various levels of data categorization.

The ITRS data compilation procedures incorporate a continuous process of assessment of the accuracy and reliability of reported ITRS data. After verifying the response rate, the initial editing procedures are based on the results of assessment of the reliability of incoming data, manual or computerized checks of the logical consistency, including consistency with data 
from the previous month, and completeness of the reports. In addition, limited ITRS data time series analysis is conducted at the moment, with decomposition analysis applied to the large data fluctuations. Such fluctuations are then further investigated. Measures are incorporated for correcting errors after contacting respondents. The results of the verification and validation procedures are communicated to the managers on a regular basis. Authorized BOPS staff has a right to undertake an on-site inspection of the accuracy of the ITRS data.

\subsubsection{Other statistical procedures (e.g., data adjustments and transformations, and statistical analysis) employ sound statistical techniques}

The BOU prepares estimates for the c.i.f./f.o.b. adjustment. The adjustment is 15 percent for transportation and 1 1/2 percent for insurance of the c.i.f. value. These adjustments are based on data from a preshipment inspection company report (since discontinued); thus the basis for the adjustment is not sufficiently robust. There is room for refinement of the approach, given that a significant amount (about 25 percent) of Uganda's imports come from contiguous countries (Kenya and Tanzania), which means that the c.i.f. and the f.o.b. values are the same. Consequently, no adjustment should be made for imports from these countries. Some SBEs indicate freight and insurance charges but these data are not processed at present by URA. In addition, the proportion of imports that is carried or insured with resident carriers and insurance companies is unknown.

Agreed estimates are developed by the BOU and UBOS for undercoverage of imports for those ports not included in $A S Y C U D A$ (the system for processing imports at the major imports) and for informal cross border trade for exports. ${ }^{4}$ To test the data, UBOS has applied a blow-up factor from duties paid (on the imports as they leave customs warehouses). The BOU adjusts customs data on imports based on the reconciliation between commodity flow and ITRS data. It is assumed that total sales of foreign exchange adjusted for interbank, bank/bureau and interbureau transactions by the commercial banks and the foreign exchange bureau less sales of foreign exchange for domestic transactions, result in outflows of foreign exchange to settle transactions between residents and nonresidents. The estimates are expected to be further revised based on the results of the Joint BOU/UBOS Survey of Informal Cross Border Trade. The first survey was conducted in 2003. Currently UBOS and the BOU are at the stage of carrying out the second round, to be completed by June 2005 . The results of the 2003 Survey are not yet incorporated in the BOP, as the seasonal fluctuations intrinsic to the informal trade trends are not considered within the survey frame; therefore the results of the survey are considered to overestimate the informal trade data. The BOPS has provided UBOS with comments on the methodology of this survey.

UBOS has developed a method for deriving estimates for military imports, gold, goods (which are not for personal use) brought in by returning Ugandans. In addition, there are

\footnotetext{
${ }^{4}$ The current estimate for informal cross border trade is based on studies done by ADC/IDEA a USAID funded project.
} 
estimates for changes in inventories in warehouses. The BOU, however, uses data for such imports from the receipts and payments reports of government forex transactions generated by the External Operations Department of the BOU. In addition, export data are adjusted based on estimates provided by the Uganda's Investment in Developing Export Agriculture (IDEA), a project funded by the United States Agency for Internal Development (USAID).

Compensation of employees (debits) captures technical assistance attributed to government projects financed by inflows of project aid. The estimates on project aid inflows are obtained from MFPED. It is assumed that about 90 percent of the budgeted amount for technical assistance in the Public Investment Plan (PIP) in any fiscal year is spent and of that amount, 90 percent is spent on expatriates on short-term assignments. Expatriates on long-term assignments are considered residents. Plans are under way to obtain details on project aid expenditures including compensation of employees directly from MFPED as soon as all project accounts have been transferred to BOU. This is scheduled to be finalized by June 2006.

Trade credit inflows of buyers credit and repayments are estimated to grow in line with exports while inflows of suppliers credit and repayments are based on the private sector investment survey of 2001 and increase in line with imports there after. These are estimated for the other sectors of the economy (excluding general government and the monetary authority). In general, grossing up procedures are used for surveys that are not updated.

The estimates for international reserves that are based on the changes in the reported holdings from the BOU balance sheet are yet to properly include the valuation changes.

\subsection{Assessment and validation of intermediate data and statistical outputs}

\subsubsection{Intermediate results are validated against other information where applicable}

There is an on-going reconciliation exercise between UBOS and the BOU for the merchandise trade data. Data on imports for selected commodities for a given period are compared with the average consumption per period. For instance, this is done for monthly fuel consumption.

Information reported in the financial press is used to verify the BOP transactions. To date no data on withholding taxes on income payments received from the URA are used to assess the accuracy of reported information on income transactions.

\subsubsection{Statistical discrepancies in intermediate data are assessed and investigated}

The MFPED and the BOU undertake monthly reconciliation of the external debt data. Data on the reserve position in the IMF are verified through the published IMF accounting data. The reported financial flow data are routinely reconciled with changes in the corresponding stock data collected for all components of the international investment position. The 
discrepancies between merchandise trade and the associated financial flows from the ITRS are routinely reviewed.

\subsubsection{Statistical discrepancies and other potential indicators of problems in statistical outputs are investigated}

The BOU monitors merchandise trade data for major trade partners, and investigates fluctuations in the merchandise trade data. However, bilateral data reconciliation is yet to be conducted. Also, the BOP data are not checked with the information available on from the Joint Debt Table, the BIS banking statistics, and Coordinated Portfolio Investment Survey.

\subsection{Revision studies}

\subsubsection{Studies and analyses of revisions are carried out routinely and used internally to inform statistical processes (see also 4.3.3)}

No studies and analyses of revisions are carried out for most of the series. However, for revisions due to methodological changes, analyses on the impact of such revisions to the BOP are done for internal discussion. Such studies are not made available to the public. The main reasons for revision are (i) incorporating the results of reconciliation exercise with UBOS on international trade statistics; (ii) arrival of new survey data, such as PCFS data; and (iii) the reconciliation exercise with the MFPED. The documentation on revisions is maintained internally. While the causes for revisions are well known, it is not used to refine data collection programs for the subsequent periods.

\section{Serviceability}

\subsection{Periodicity and timeliness}

\subsubsection{Periodicity follows dissemination standards}

The BOU disseminates quarterly BOP data in the BOU Quarterly Economic Report and annual BOP statistics in the BOU Annual Report. Data are published on both a calendar year and a fiscal year basis. The periodicity exceeds the annual periodicity recommended by the GDDS.

\subsubsection{Timeliness follows dissemination standards}

Quarterly BOP statistics are disseminated on the BOU website within nine months following the reference period, which is not consistent with the GDDS recommendations. Moreover, editing and processing of the hard copy of the BOU Quarterly Economic Report cause a much greater delay (up to two years). Annual BOP statistics data are disseminated by the BOU in its Annual Report within 16 months after the end of the reference period. Thus, timeliness is not consistent with GDDS recommendations on timeliness of six-nine months. 


\subsection{Consistency}

\subsubsection{Statistics are consistent within the dataset}

In general, quarterly and annual BOP statistics are consistent with each other. However, an important indicator of consistency - net errors and omissions - is not properly distinguished. There are discrepancies between some financial account transactions and changes in stocks in the international investment position. Results of the reconciliation between the two datasets (e.g., transactions, exchange rate, price, and other changes) are not disseminated.

\subsubsection{Statistics are consistent or reconcilable over a reasonable period of time}

Annual BOP statistics dating from 1993 and quarterly data for six preceding periods are available in time-series format. The time series broadly utilize the BPM5 classifications. Major changes in methodology and unusual changes in economic trends are explained in internal documents, but not made public. No methodological notes identify or explain the main breaks and discontinuities in the BOP statistics component time series. For instance, in the BOU Annual Report 2002/2003, there is a break in the annual time series in 1998 for the capital account component, apparently due to the changes in the treatment of the HIPC transactions. This discontinuity in the BOP component time series is not indicated and not explained in the BOU publication.

\subsubsection{Statistics are consistent or reconcilable with those obtained through other data sources and/or statistical frameworks}

There is consistency with monetary and financial statistics, as the relevant BOP components are derived from changes in stocks of foreign financial assets and liabilities. The merchandise trade statistics and government external debt data are used as a data source. The current account statistics are broadly consistent with the data on the rest of the world account in the national accounts. The reconciliation exercises also benefit from regular consultation between the MFPED, the BOU, and UBOS.

\subsection{Revision policy and practice}

\subsubsection{Revisions follow a regular and transparent schedule}

There is no written policy on revisions. Revisions to BOP statistics do not have an established schedule, but they are made whenever new source data become available for the relevant BOP component. In addition, the BOP follows as a rule of thumb the revision of statistics for time series not exceeding three years from the current period. However, when major methodological changes that may lead to a break in the series are introduced, the revisions may be done for time series exceeding three years from the current period. 


\subsubsection{Preliminary and/or revised data are clearly identified}

In the BOU publications, the revised time series are identified and the provisional status of the data is indicated in the explanatory notes to the BOP statement.

\subsubsection{Studies and analyses of revisions are made public (see also 3.5.1)}

External users are not informed of the causes of the revisions. The nature of the revisions is not investigated to inform statistical processes. However, documentation for revisions made and the impact of the revisions on the BOP statements are prepared for internal use. A case in point is the revision to the BOP on account of adopting the recommended treatment for HIPC in the BOP.

\section{Accessibility}

\subsection{Data accessibility}

5.1.1 Statistics are presented in a way that facilitates proper interpretation and meaningful comparisons (layout and clarity of text, tables, and charts)

The Annual Report of the BOU includes summary BOP statistics, enriched by detailed tables on BOP statistics components and an analysis. Current-period developments are compared with the relevant period of the previous year. Charts and tables are disseminated with the data to facilitate analysis. A summary quarterly BOP statistics presentation is included in the $B O U$ Quarterly Economic Report.

For other investment and portfolio investment components, data are published on a net basis (liabilities net of assets), and the directional principle is not applied in publishing data for foreign direct investment component. However, drafts publications of the quarterly and annual BOP statements contain a new presentation that shows the liabilities and assets separately in the financial account and foreign direct investment is on a directional basis.

The government and government-guaranteed foreign debt data are reproduced in the Annual Report of the BOU in the MFPED publication the Background to the Budget. The data include external debt repayments, by principal and interest. A forward schedule of projected repayments is not published.

The data on the gross official international reserves in millions of U.S. dollars and in terms of months of imports of goods together with the analysis of trends in reserves and in the structure of international foreign exchange reserves are published annually in the Annual Report of the BOU. 


\subsubsection{Dissemination media and format are adequate}

The dissemination media and format are not entirely adequate. No separate BOP statistical publications have been prepared, and hard-copy publications of the BOU Quarterly Economic Report are prone to long delays. In addition to hard-copy publications, the BOP data are also available at the BOU's website (http://www.bou.go.ug).

Longer time series are provided upon request, but there is no information in the BOP hardcopy publication indicating where to find the detailed data. The longer time series data on quarterly BOP statistics could also be disseminated by the same means.

All publications are currently free of charge.

\subsubsection{Statistics are released on a preannounced schedule}

BOP data are not released according to a preannounced schedule. There is no specific date and/or time when BOP statistics are released to the public.

\subsubsection{Statistics are made available to all users at the same time}

The data are released simultaneously to all interested parties through the publication on the website and of the hard-copy edition. The policy on data release is not made public.

\subsubsection{Statistics not routinely disseminated are made available upon request}

In addition to the BOP data included in the BOU's publications and disseminated on the website, a number of nonpublished but nonconfidential BOP subcomponents are made available upon demand. Requests from users for special tabulations based on unpublished (but nonconfidential) data are usually accommodated, especially from data providers (e.g., PCFS participants) and students carrying out research.

No specific reference is made in BOP statistics publications on the availability of nonpublished subcomponents and the terms and conditions on which they are made available.

\subsection{Metadata accessibility}

5.2.1 Documentation on concepts, scope, classifications, basis of recording, data sources, and statistical techniques is available, and differences from internationally accepted standards, guidelines, or good practices are annotated

A detailed description of the BOP concepts, sources, and methods is posted on the BOU website. It contains (i) the conceptual framework, (ii) the classifications, (iii) the data sources, and (iv) the compilation practices. While departures from internationally accepted compilation standards are documented in the general description of the methodology, no 
explicit reference is made toward what the best practice should be and the reasons for the deviations. In addition, documentation of the methods used for compiling the BOP statistics is published in the IMF Balance of Payments Statistics Yearbook and in the GDDS metadata posted on the DSBB.

\subsubsection{Levels of detail are adapted to the needs of the intended audience}

General-use information, as well as more specialized information about the BOP and other external sector statistics, are available on the BOU website. However, the absence of the separate publication of the BOP statistics limits the level of detail that can be adapted to users needs.

\subsection{Assistance to users}

\subsubsection{Contact points for each subject field are publicized}

A contact person is identified on the DSBB. Arrangements have been established within the BOU to ensure that any queries received by that contact are directed to the relevant person in the BOPS.

\subsubsection{Catalogs of publications, documents, and other services, including information on any charges, are widely available}

Hard-copy catalogs of publications and other services are not produced by the BOU, but information on published documents is available on the BOU website. 
- 79 -

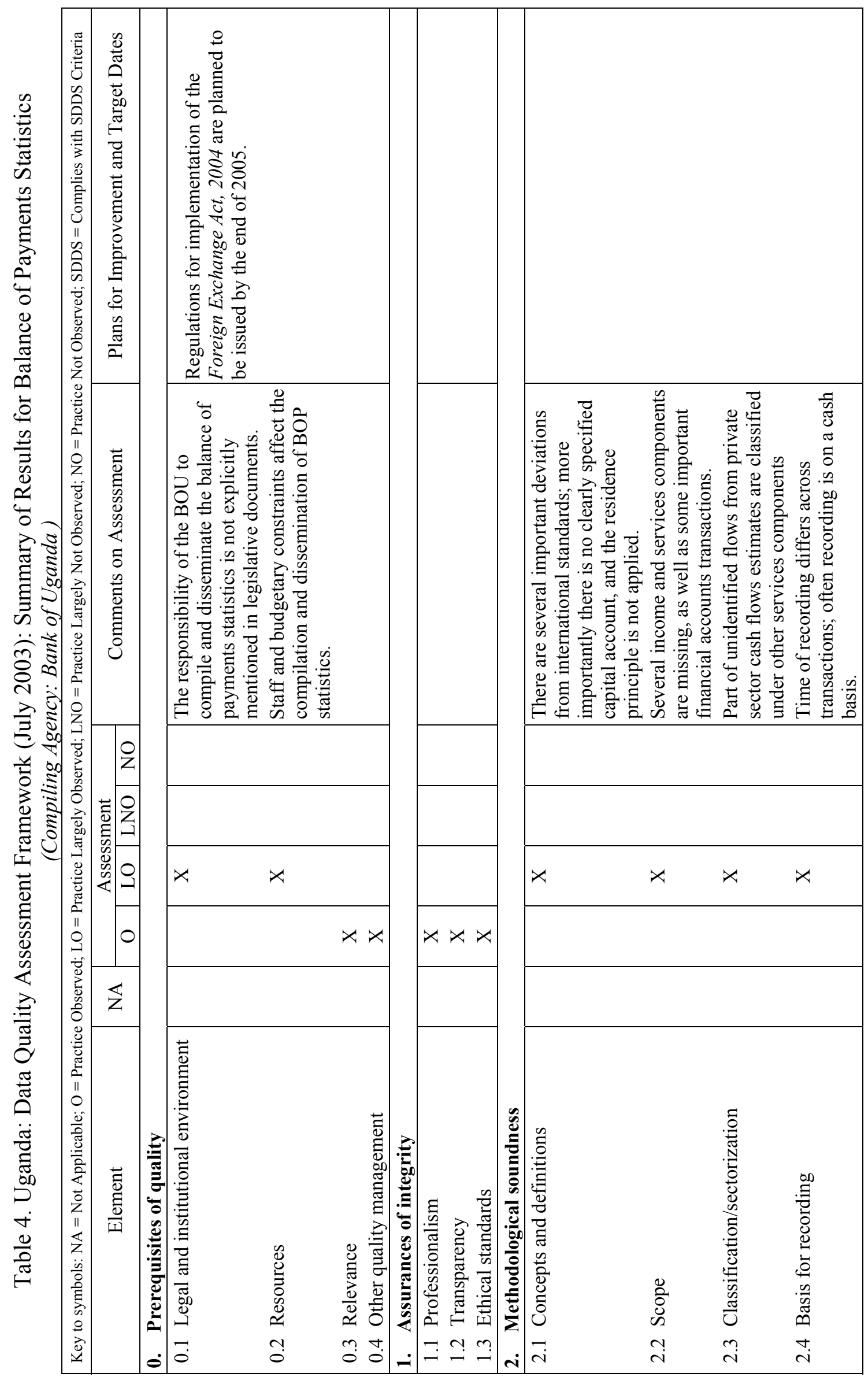


- 80 -

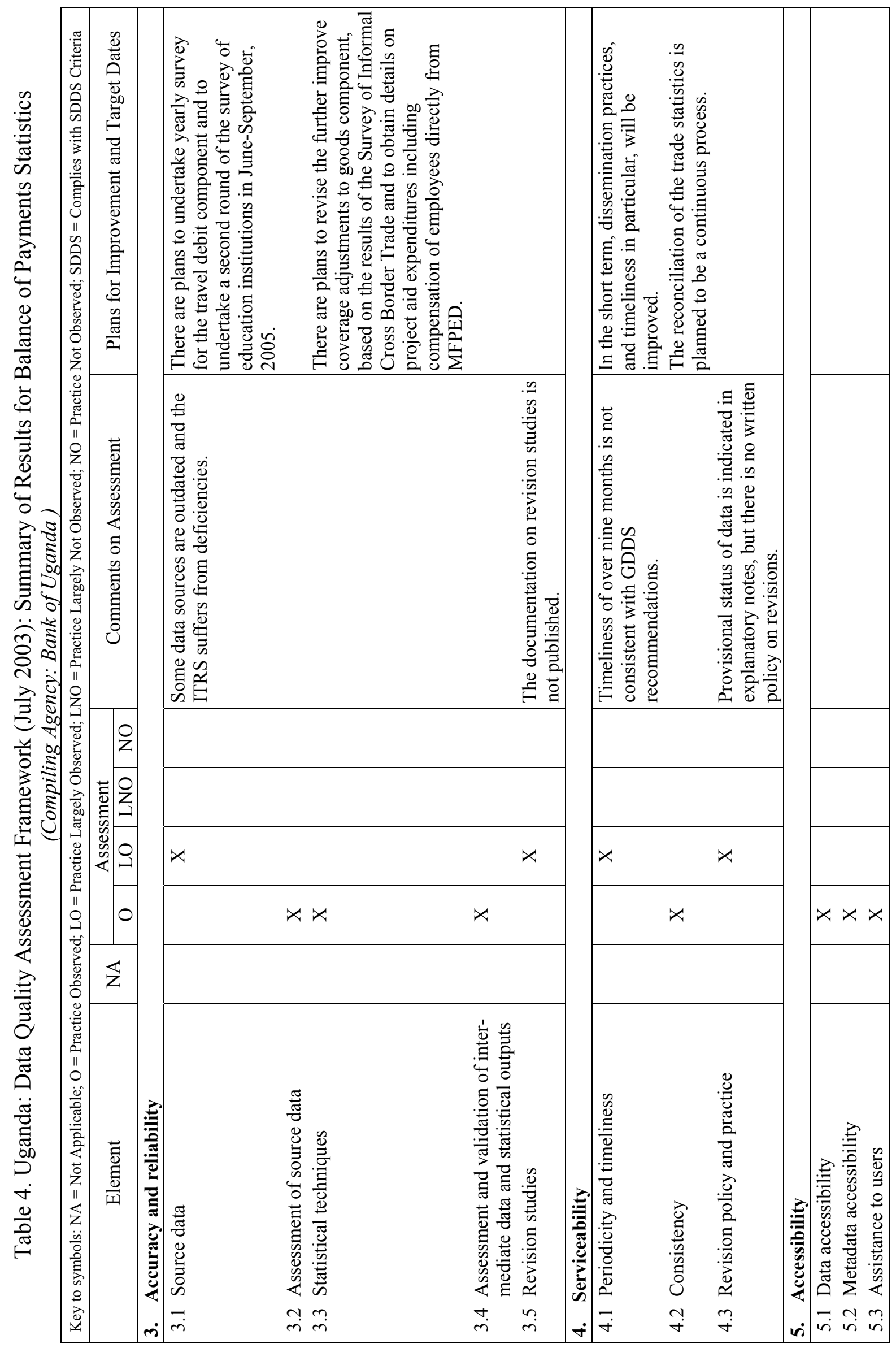




\section{Summary of the General Data Dissemination System (GDDS)}

\section{Data coverage, periodicity, and timeliness}

Dissemination of reliable, comprehensive, and timely economic, financial, and sociodemographic data is essential to the transparency of macroeconomic performance and policy. The GDDS contains specific recommendations concerning coverage, periodicity, and timeliness for comprehensive frameworks as well as for data categories and indicators.

\section{Quality}

Data quality must have a high priority. Data users must be provided with information to assess quality and quality improvements. The GDDS recommends:

- dissemination of documentation on methodology and sources used in preparing statistics; and

- $\quad$ dissemination of component detail, reconciliations with related data, and statistical frameworks that support statistical cross-checks and provide assurance of reasonableness.

\section{Integrity}

To fulfill the purpose of providing the public with information, official statistics must have the confidence of their users. In turn, confidence in the statistics ultimately becomes a matter of confidence in the objectivity and professionalism of the agency producing the statistics. Transparency of practices and procedures is a key factor in creating this confidence. The GDDS, therefore, recommends:

- dissemination of the terms and conditions under which official statistics are produced, including those relating to the confidentiality of individually identifiable information;

- $\quad$ identification of internal government access to data before release;

- $\quad$ identification of ministerial commentary on the occasion of statistical releases; and

- $\quad$ provision of information about revision and advance notice of major changes in methodology.

\section{Access to the public}

Dissemination of official statistics is an essential feature of statistics as a public good. Ready and equal access by the public are principal requirements. The GDDS recommends:

- $\quad$ dissemination of advance release calendars; and 
- $\quad$ simultaneous release to all interested parties.

\section{Plans for improvement}

The GDDS recommends that plans for improvement be developed for all areas in which shortcomings exist and that these plans be disseminated.

The GDDS also recommends that any needs for assistance be identified in the metadata. This may also be helpful for donors and technical assistance providers to prioritize their activities.

For each participating member country, the GDDS metadata provide descriptions of the dimensions listed above, together with plans for improvement and needs for assistance. This information is posted on the DSBB; participating countries are encouraged to also post the metadata on their national websites.

Source: Guide to the GDDS, March 2002: http://dsbb.imf.org 


\section{Data QuAlity ASSESSMENT FraMeWORK-GENERIC FRAMEWORK (JULY 2003 FRAMEWORK)}

\begin{tabular}{|c|c|c|}
\hline Quality Dimensions & Elements & Indicators \\
\hline \multirow[t]{4}{*}{$\begin{array}{l}\text { 0. Prerequisites of } \\
\text { quality }\end{array}$} & $\begin{array}{l}\text { 0.1 Legal and institutional } \\
\text { environment-The environment } \\
\text { is supportive of statistics }\end{array}$ & $\begin{array}{l}\text { 0.1.1 The responsibility for collecting, processing, } \\
\text { and disseminating the statistics is clearly specified. } \\
\text { 0.1.2 Data sharing and coordination among data- } \\
\text { producing agencies are adequate. } \\
\text { 0.1.3 Individual reporters' data are to be kept } \\
\text { confidential and used for statistical purposes only. } \\
\text { 0.1.4 Statistical reporting is ensured through legal } \\
\text { mandate and/or measures to encourage response. }\end{array}$ \\
\hline & $\begin{array}{l}\text { 0.2 Resources-Resources are } \\
\text { commensurate with needs of } \\
\text { statistical programs. }\end{array}$ & $\begin{array}{l}0.2 .1 \text { Staff, facilities, computing resources, and } \\
\text { financing are commensurate with statistical } \\
\text { programs. } \\
0.2 .2 \text { Measures to ensure efficient use of resources } \\
\text { are implemented. }\end{array}$ \\
\hline & $\begin{array}{l}\mathbf{0 . 3} \text { Relevance-Statistics cover } \\
\text { relevant information on the } \\
\text { subject field. }\end{array}$ & $\begin{array}{l}\text { 0.3.1 The relevance and practical utility of existing } \\
\text { statistics in meeting users' needs are monitored. }\end{array}$ \\
\hline & $\begin{array}{l}\text { 0.4 Other quality } \\
\text { management-Quality is a } \\
\text { cornerstone of statistical work. }\end{array}$ & $\begin{array}{l}\text { 0.4.1 Processes are in place to focus on quality. } \\
0.4 .2 \text { Processes are in place to monitor the quality of } \\
\text { the statistical program. } \\
0.4 .3 \text { Processes are in place to deal with quality } \\
\text { considerations in planning the statistical program. }\end{array}$ \\
\hline \multirow{3}{*}{$\begin{array}{l}\text { 1. Assurances of } \\
\text { integrity } \\
\text { The principle of } \\
\text { objectivity in the } \\
\text { collection, } \\
\text { processing, and } \\
\text { dissemination of } \\
\text { statistics is firmly } \\
\text { adhered to. }\end{array}$} & $\begin{array}{l}\text { 1.1 Professionalism-Statistical } \\
\text { policies and practices are } \\
\text { guided by professional } \\
\text { principles. }\end{array}$ & $\begin{array}{l}\text { 1.1.1 Statistics are produced on an impartial basis. } \\
\text { 1.1.2 Choices of sources and statistical techniques } \\
\text { as well as decisions about dissemination are } \\
\text { informed solely by statistical considerations. } \\
\text { 1.1.3 The appropriate statistical entity is entitled to } \\
\text { comment on erroneous interpretation and misuse of } \\
\text { statistics. }\end{array}$ \\
\hline & $\begin{array}{l}\text { 1.2 Transparency-Statistical } \\
\text { policies and practices are } \\
\text { transparent. }\end{array}$ & $\begin{array}{l}\text { 1.2.1 The terms and conditions under which } \\
\text { statistics are collected, processed, and disseminated } \\
\text { are available to the public. } \\
\text { 1.2.2 Internal governmental access to statistics prior } \\
\text { to their release is publicly identified. } \\
\text { 1.2.3 Products of statistical agencies/units are } \\
\text { clearly identified as such. } \\
\text { 1.2.4 Advance notice is given of major changes in } \\
\text { methodology, source data, and statistical techniques. }\end{array}$ \\
\hline & $\begin{array}{l}1.3 \text { Ethical standards-Policies } \\
\text { and practices are guided by } \\
\text { ethical standards. }\end{array}$ & $\begin{array}{l}\text { 1.3.1 Guidelines for staff behavior are in place and } \\
\text { are well known to the staff. }\end{array}$ \\
\hline
\end{tabular}




\begin{tabular}{|c|c|c|}
\hline Quality Dimensions & Elements & Indicators \\
\hline $\begin{array}{l}\text { 2. Methodological } \\
\text { soundness } \\
\text { The methodological } \\
\text { basis for the } \\
\text { statistics follows } \\
\text { internationally } \\
\text { accepted standards, } \\
\text { guidelines, or good } \\
\text { practices. }\end{array}$ & $\begin{array}{l}\text { 2.1 Concepts and definitions- } \\
\text { Concepts and definitions used } \\
\text { are in accord with } \\
\text { internationally accepted } \\
\text { statistical frameworks. } \\
2.2 \text { Scope-The scope is in } \\
\text { accord with internationally } \\
\text { accepted standards, guidelines, } \\
\text { or good practices. } \\
2.3 \text { Classification/ } \\
\text { sectorization-Classification } \\
\text { and sectorization systems are in } \\
\text { accord with internationally } \\
\text { accepted standards, guidelines, } \\
\text { or good practices. } \\
\text { 2.4 Basis for recording-Flows } \\
\text { and stocks are valued and } \\
\text { recorded according to } \\
\text { internationally accepted } \\
\text { standards, guidelines, or good } \\
\text { practices }\end{array}$ & $\begin{array}{l}\text { 2.1.1 The overall structure in terms of concepts and } \\
\text { definitions follows internationally accepted } \\
\text { standards, guidelines, or good practices. } \\
\text { 2.2.1 The scope is broadly consistent with } \\
\text { internationally accepted standards, guidelines, or } \\
\text { good practices. } \\
\text { 2.3.1 Classification/sectorization systems used are } \\
\text { broadly consistent with internationally accepted } \\
\text { standards, guidelines, or good practices. }\end{array}$ \\
\hline $\begin{array}{l}\text { 3. Accuracy and } \\
\text { reliability } \\
\text { Source data and } \\
\text { statistical techniques } \\
\text { are sound and } \\
\text { statistical outputs } \\
\text { sufficiently portray } \\
\text { reality }\end{array}$ & $\begin{array}{l}\text { 3.3 Statistical techniques- } \\
\text { Statistical techniques employed } \\
\text { conform to sound statistical } \\
\text { procedures } \\
\text { 3.4 Assessment and validation } \\
\text { of intermediate data and } \\
\text { statistical outputs- } \\
\text { Intermediate results and } \\
\text { statistical outputs are regularly } \\
\text { assessed and validated. } \\
\text { 3.5 Revision studies- } \\
\text { Revisions, as a gauge of } \\
\text { reliability, are tracked and } \\
\text { mined for the information they } \\
\text { may provide. }\end{array}$ & $\begin{array}{l}\text { 3.1.1 Source data are obtained from comprehensive } \\
\text { data collection programs that take into account } \\
\text { country-specific conditions. } \\
\text { 3.1.2 Source data reasonably approximate the } \\
\text { definitions, scope, classifications, valuation, and } \\
\text { time of recording required. } \\
\text { 3.1.3 Source data are timely. } \\
\text { 3.2.1 Source data-including censuses, sample } \\
\text { surveys, and administrative records-are routinely } \\
\text { assessed, e.g., for coverage, sample error, response } \\
\text { error, and nonsampling error; the results of the } \\
\text { assessments are monitored and made available to } \\
\text { guide statistical processes. } \\
\text { 3.3.1 Data compilation employs sound statistical } \\
\text { techniques to deal with data sources. } \\
\text { 3.3.2 Other statistical procedures (e.g., data } \\
\text { adjustments and transformations, and statistical } \\
\text { analysis) employ sound statistical techniques. } \\
\text { 3.4.1 Intermediate results are validated against other } \\
\text { information where applicable. } \\
\text { 3.4.2 Statistical discrepancies in intermediate data } \\
\text { are assessed and investigated. } \\
\text { 3.4.3 Statistical discrepancies and other potential } \\
\text { indicators or problems in statistical outputs are } \\
\text { investigated. } \\
\text { 3.5.1 Studies and analyses of revisions are carried } \\
\text { out routinely and used internally to inform statistical } \\
\text { processes (see also } 4.3 .3 \text { ). }\end{array}$ \\
\hline
\end{tabular}




\begin{tabular}{|c|c|c|}
\hline Quality Dimensions & Elements & Indicators \\
\hline $\begin{array}{l}\text { 4. Serviceability } \\
\text { Statistics, with } \\
\text { adequate periodicity } \\
\text { and timeliness, are } \\
\text { consistent and } \\
\text { follow a predictable } \\
\text { revisions policy. }\end{array}$ & $\begin{array}{l}\text { 4.1 Periodicity and } \\
\text { timeliness-Periodicity and } \\
\text { timeliness follow internationally } \\
\text { accepted dissemination } \\
\text { standards. } \\
\text { 4.2 Consistency - Statistics are } \\
\text { consistent within the dataset, } \\
\text { over time, and with major } \\
\text { datasets. } \\
\text { 4.3 Revision policy and } \\
\text { practice-Data revisions follow } \\
\text { a regular and publicized } \\
\text { procedure. }\end{array}$ & $\begin{array}{l}\text { 4.2.1 Statistics are consistent within the dataset. } \\
\text { 4.2.2 Statistics are consistent or reconcilable over a } \\
\text { reasonable period of time. } \\
\text { 4.2.3 Statistics are consistent or reconcilable with } \\
\text { those obtained through other data sources and/or } \\
\text { statistical frameworks. } \\
\text { 4.3.1 Revisions follow a regular and transparent } \\
\text { schedule. } \\
\text { 4.3.2 Preliminary and/or revised data are clearly } \\
\text { identified. } \\
\text { 4.3.3 Studies and analyses of revisions are made } \\
\text { public (see also 3.5.1). }\end{array}$ \\
\hline $\begin{array}{l}\text { 5. Accessibility } \\
\text { Data and metadata } \\
\text { are easily available } \\
\text { and assistance to } \\
\text { users is adequate. }\end{array}$ & $\begin{array}{l}\text { 5.1 Data accessibility- } \\
\text { Statistics are presented in a } \\
\text { clear and understandable } \\
\text { manner, forms of dissemination } \\
\text { are adequate, and statistics are } \\
\text { made available on an impartial } \\
\text { basis. } \\
\text { 5.2 Metadata accessibility- } \\
\text { Up-to-date and pertinent } \\
\text { metadata are made available. } \\
\text { Prompt and knowledgeable } \\
\text { support service is available. }\end{array}$ & $\begin{array}{l}\text { 5.1.1 Statistics are presented in a way that facilitates } \\
\text { proper interpretation and meaningful comparisons } \\
\text { (layout and clarity of text, tables, and charts). } \\
\text { 5.1.2 Dissemination media and format are adequate. } \\
\text { 5.1.3 Statistics are released on a preannounced } \\
\text { schedule. } \\
\text { 5.1.4 Statistics are made available to all users at the } \\
\text { same time. } \\
\text { 5.1.5 Statistics not routinely disseminated are made } \\
\text { available upon request. } \\
\text { 5.2.1 Documentation on concepts, scope, } \\
\text { classifications, basis of recording, data sources, and } \\
\text { statistical techniques is available, and differences } \\
\text { from internationally accepted standards, guidelines, } \\
\text { or good practices are annotated. } \\
\text { 5.2.2 Levels of detail are adapted to the needs of the } \\
\text { intended audience. } \\
\text { 5.3.1 Contact points for each subject field are } \\
\text { publicized. } \\
\text { 5.3.2 Catalogs of publications, documents, and other } \\
\text { services, including information on any charges, are } \\
\text { widely available. }\end{array}$ \\
\hline
\end{tabular}




\section{Users' Survey}

With the assistance of the IMF Resident Representative a survey of the principal users of official macroeconomic statistics of Uganda was conducted during January-February 2005. The questionnaire was sent to users among the academic and research community, banks and businesses, government agencies, the international community, media and other entities, and in total 23 responses were received. While in Kampala, the mission held discussions with a selection of users.

Users' views on the overall quality of Uganda's macroeconomic statistics were reasonably consistent. On a scale of 1 to 5, with 5 being "excellent" and 1 being "poor", all sectors were judged to be within the 3 to 4 range, with monetary and balance of payments being situated towards the higher end, and national accounts and government statistics towards the lower end. In most areas, the users considered the quality of Uganda's statistics to be similar to that of other countries in the region, but better for national accounts.

Key points among the users' views on Uganda's statistics emerging from both the survey and discussions held are as follows:

- Coverage could be improved, particularly in the geographical coverage of the consumer price index, government finance (coverage of operations of local government entities), and balance of payment statistics (better coverage of foreign trade).

- Timeliness of the dissemination of statistics was generally viewed as satisfactory, with some concern about the national accounts and balance of payments, and there was some dissatisfaction about the periodicity of the national accounts with a number of respondents expressing a desire for quarterly accounts.

- There is clearly a strong need for the dissemination of calendars of publication for all sectors, and even though one is published for the CPI this was not widely known. There was dissatisfaction with the revision policies for all statistics, so more information and explanation regarding revisions would be of benefit to users.

- Views on data and metadata accessibility were mixed. Generally, access to official statistics was considered satisfactory by around 80 percent of the users but only around half considered that the methodological descriptions were adequate for analytical purposes, with all areas showing a need for improvement in this regard.

- Underlying methodology and accuracy of statistics was viewed as satisfactory for the consumer price index and the balance of payments statistics while the other areas could be improved, particularly the national accounts.

Several users indicated that they used data from the IMF, rather than obtaining them directly from Government sources. 